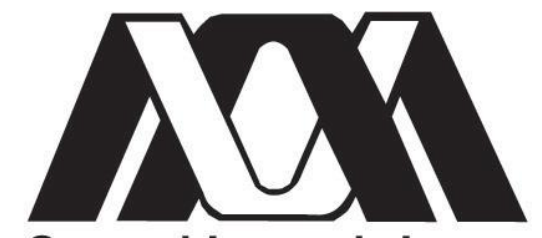

Casa abierta al tiempo

UNIVERSIDAD AUTÓNOMA METROPOLITANA
UNIVERSIDAD AUTÓNOMA

METROPOLITANA UNIDAD

IZTAPALAPA

DIVISIÓN DE CIENCIAS BÁSICAS E INGENIERÍA

\title{
"MODELAMIENTO HIDROGEOQUÍMICO Y PROPUESTA DE POSIBLE REMEDIACIÓN DE ARSENICO EN AGUA EN LA ZONA DE MATEHUALA, SAN LUIS POTOSI'”
}

\author{
TESIS \\ Que para obtener el grado de \\ MAESTRA EN CIENCIAS \\ (ENERGÍA Y MEDIO AMBIENTE) \\ Presenta: \\ Eunice Angélica Ranchero Cerón
}

Codirectoras:

Dra. Judith Cardoso Martínez

Dra. Nadia Valentina Martínez Villegas

Iztapalapa, Ciudad de México, Junio 2021 


\section{Agradecimientos}

Agradezco a la Universidad Autónoma Metropolitana por permitirme cursar estudios de posgrado, así como al Consejo Nacional de Ciencia y Tecnología (CONACYT) por el apoyo de beca con No. CVU815199.

A la Comisión Académica del Posgrado en Energía y Medio Ambiente (CAPEMA) por el apoyo recibido durante la duración del posgrado. A la Dra. Judith Cardoso Martínez, la Dra. Nadia Valentina Martínez Villegas y el Dr. Jorge Vázquez Arenas, por aceptarme en su grupo de investigación y brindarme los recursos necesarios para la realización de este proyecto. AI M.C. Francisco Javier Almazán Ruiz, por su paciencia, apoyo y enseñanzas; así como al proyecto SECTEI-CDMX-MÉXICO (proyecto 8994c19/SECTEI/2019) por su apoyo económico.

A mis sinodales, Dra. Nadia Martínez Villegas, Dr. Israel Razo Soto y Dra. Mónica Meraz Rodríguez, por su tiempo para la revisión de esta tesis y sus valiosos comentarios que ayudaron a mejorarla. 


\section{Agradecimientos personales}

A mi familia, mis padres y mi hermanito por el apoyo incondicional que siempre me han dado.

A la Dra. Nadia por la paciencia, el apoyo, el tiempo brindado y la hospitalidad que siempre me demostró en San Luis Potosí; a la Dra. Judith, por confiar en mí, por sus enseñanzas y su paciencia; las experiencias y aprendizaje que obtuve de ambas, son para toda la vida.

A Natalia, oso, gracias por estar siempre, porque la distancia nunca ha sido un impedimento; gracias por confiar en mí.

A Mario, gracias por tu cariño, la confianza y la motivación. 


\section{Resumen}

En el acuífero somero de Matehuala se han reportado concentraciones de arsénico (As) que rebasan los límites máximos permisibles establecidos en las normas oficiales mexicanas: $0.2 \mathrm{mg} / \mathrm{L}$ en agua para riego (NOM-001-SEMARNATH-1996) y $0.025 \mathrm{mg} / \mathrm{L}$ de As en agua para uso y consumo humano (NOM-127-SSA-). Debido a que la contaminación en la zona se debe a la disolución de arseniatos de una antigua fundición que se encuentra dentro de la ciudad de Matehuala, dicha contaminación es extremadamente alta (hasta 158 mg/L). En 2013, MartínezVillegas y colaboradores, determinaron las fuentes de contaminación y los mecanismos de movilidad del As, sin embargo, no se estimó la especiación química. Por ello, en el presente trabajo, utilizando los datos experimentales obtenidos por Martínez-Villegas, se plantean los siguientes objetivos: 1) Establecer la especiación química de arsénico en Matehuala mediante modelación hidrogeoquímica directa;

2) determinar el carácter hidrogeoquímico del agua; 3) analizar la eficiencia de remoción de arsénico en agua por electrodesionización. Para cumplir los objetivos, en la elaboración del modelo hidrogeoquímico (elaborado con el software PHREEQC), se utilizaron datos de química del agua recolectados en la literatura correspondientes a un año de muestreo. Para el último objetivo, se construyó una celda de electrodesionización de tres compartimentos; se utilizaron resinas de tipo comercial: Amberlite IRA-900 (resina aniónica) y Amberlite IRA-120 (resina catiónica). Se trabajó con soluciones sintéticas de $\mathrm{Na}_{2} \mathrm{HAsO}_{4} \cdot 7 \mathrm{H}_{2} \mathrm{O}$, utilizando para ello lecho de resinas aniónico y mixto. Las primeras pruebas se realizaron a $15 \mathrm{mg} / \mathrm{L}$ sobre lecho de resinas aniónico y mixto. En Matehuala, debido a las condiciones óxicas del medio, el arsénico se encuentra principalmente como $\mathrm{As}(\mathrm{V})$, siendo las especies más abundantes: $\mathrm{HAsO}_{4}{ }^{2-}(41.3 \%), \mathrm{H}_{2} \mathrm{AsO}_{4}{ }^{-}$(31.2\%), $\mathrm{CaHAsO}_{4}(32.4 \%)$ y $\mathrm{CaAsO}_{4}(88.5 \%)$. El tipo de agua en la que se encuentra la contaminación se identificó como un agua de tipo sulfatada cálcica. Las pruebas en lecho aniónico 
mostraron una mayor eficiencia en tiempo de remoción: en 280 minutos y con una corriente de $40 \mathrm{~mA}$. Para dichas condiciones se logró remover por completo los iones arseniato, por lo que, bajo estas condiciones, se realizaron más pruebas a $50 \mathrm{mg} / \mathrm{L}$ de As. En las pruebas de electrodesionización a $50 \mathrm{mg} / \mathrm{L}$, bajo las condiciones mencionadas, se llega a valores normados en un tiempo de 690 minutos; la concentración de $50 \mathrm{mg} / \mathrm{L}$ se reduce hasta $0.01 \mathrm{mg} / \mathrm{L}$, por lo que la remoción de arsénico por electrodesionización podría ser una tecnología viable para remoción de arsénico en Matehuala, lo que aportaría a resolver dicha problemática a nivel nacional.

Palabras clave: arsénico, modelación hidrogeoquímica, Matehuala, electrodesionización. 


\section{Abstract}

In the Matehuala shallow aquifer, in the community of Matehuala, high arsenic concentrations have been reported, these concentrations exceed the maximum permissible limits established in the official Mexican standards: $0.2 \mathrm{mg} / \mathrm{L}$ for natural water (NOM-001-SEMARNAT-1996) and $0.025 \mathrm{mg} / \mathrm{L}$ of As in water for human use and consumption (NOM-127-SSA1-1994). Because pollution in the area is caused by the dissolution of metal arsenates from an inactive smelter located within the Matehuala city, this contamination is extremely high (up to $158 \mathrm{mg} / \mathrm{L}$ of As). $\ln 2013$, Martínez-Villegas and collaborators determined the contamination source of arsenic species and the mechanism of mobilization, however, chemical speciation was not estimated. Therefore, in the present, using the experimental data obtained by Martínez Villegas, the following objectives arises: 1) to establish the chemical speciation of arsenic in water from Matehuala using direct hydrogeochemical modeling; 2) to determine the hydrogeochemical nature of water; 3) to analyze the efficiency of arsenic removal in water by electrodeionization. To this effect, in the elaboration of the hydrogeochemical model, water chemistry data collected from literature, corresponding to one year of sampling, were used. In addition, a three compartment electrodeionization cell was built; commercial resins: Amberlite IRA900 (anionic resin) and Amberlite IRA-120 (cationic resin) were used. Synthetic arsenic solutions were used, a resin bed was packed in the central compartment, using anionic and mixed resin bed. The first tests were performed at $15 \mathrm{mg} / \mathrm{L}$ on anionic and mixed resin beds. In Matehuala, due to the redox conditions prevailing in the environment, arsenic is found mainly as $\mathrm{As}(\mathrm{V})$, being the most abundant species: $\mathrm{HAsO}_{4}{ }^{2-}(41.3 \%), \mathrm{H}_{2} \mathrm{AsO}_{4}^{-}(31.2 \%), \mathrm{CaHAsO}_{4}(32.4 \%)$ y $\mathrm{CaAsO}_{4}(88.5 \%)$. The type of water in which the contamination is found was identified as a sulphate calcium water. The anionic tests showed a greater efficiency in removal time: in 280 minutes and with $40 \mathrm{~mA}$ of current. For these conditions, the arsenate ions were completely removed, therefore, under these conditions, more tests were carried out 
at $50 \mathrm{mg} / \mathrm{L}$ of As. Under the mentioned conditions, in the electrodeionization tests at $50 \mathrm{mg} / \mathrm{L}$, the arsenic concentration decreases to regulated values in a time of 690 minutes; a concentration of $50 \mathrm{mg} / \mathrm{L}$ is decreased to $0.01 \mathrm{mg} / \mathrm{L}$, because of this, arsenic removal by electrodeionization could be a viable technology for the removal of arsenic in Matehuala, which would contribute to solving this problem at the national level.

Keywords: arsenic, hydrogeochemical model, Matehuala, electrodeionization 


\section{Índice general}

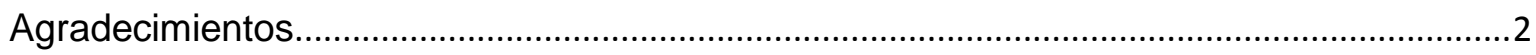

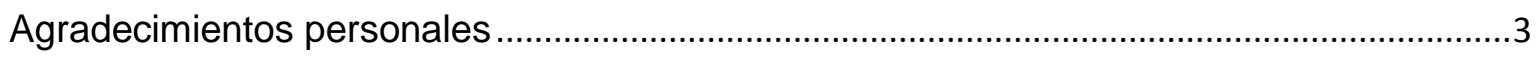

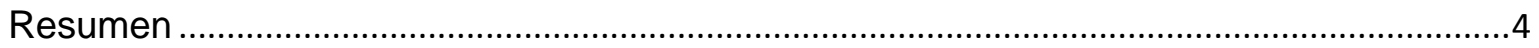

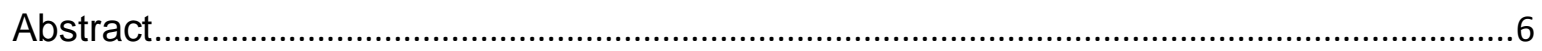

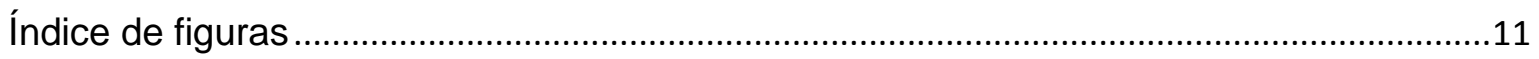

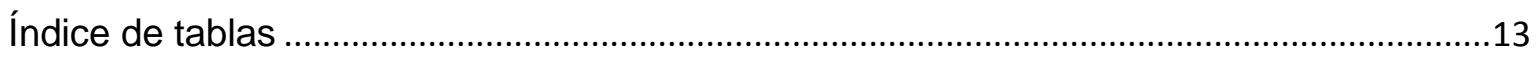

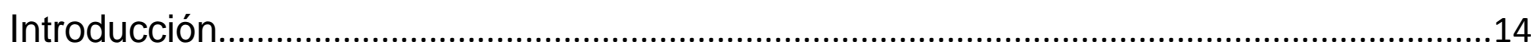

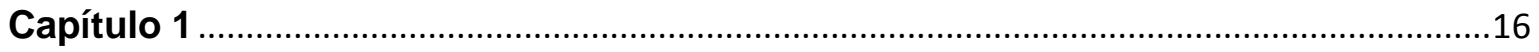

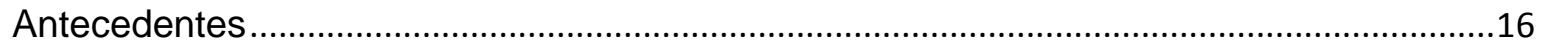

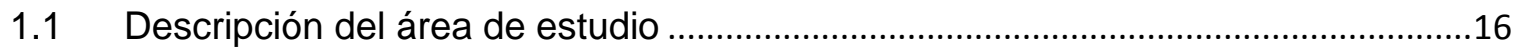

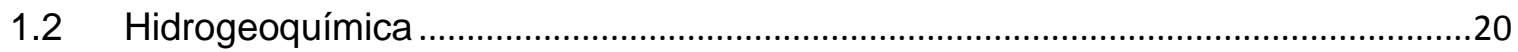

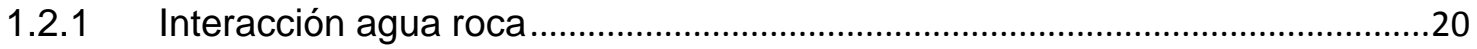

1.2.2 Caracterización hidrogeoquímica del agua.....................................................22

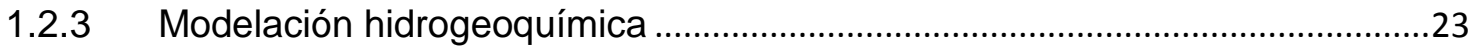

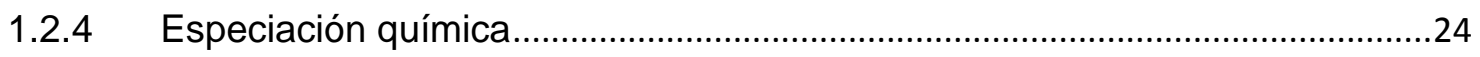

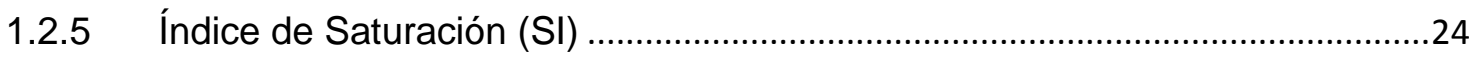

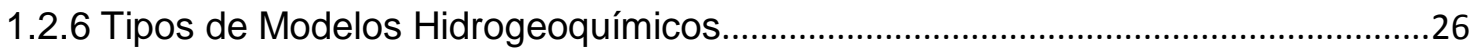

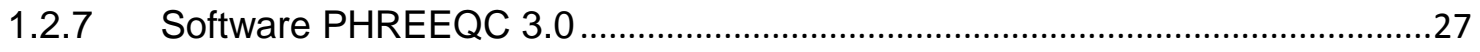

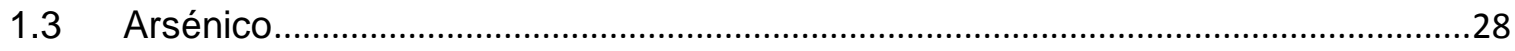

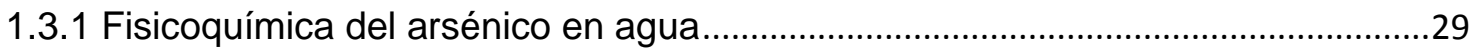

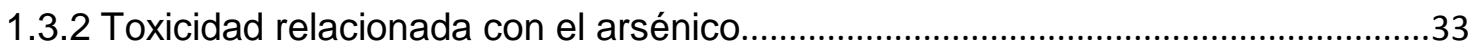

1.3.3 Normas que regulan el contenido de arsénico en agua .....................................35

1.3.4 Casos de estudio de presencia de arsénico .........................................................39

1.3.5 Tecnologías de remoción de arsénico en agua ....................................................43 


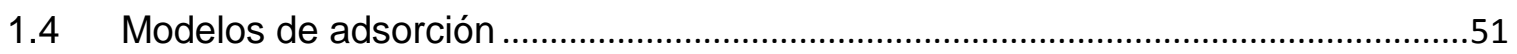

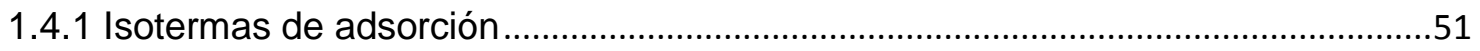

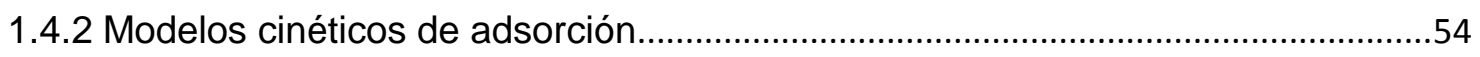

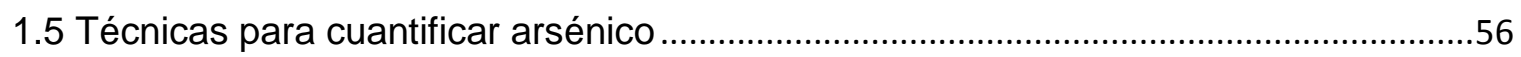

1.5.1 Espectrofotometría de absorción atómica...........................................................56

1.5.2 Técnica de espectroscopia de emisión atómica ....................................................58

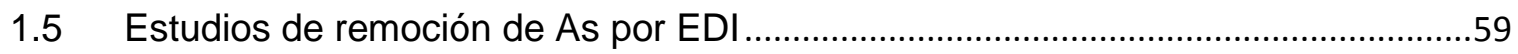

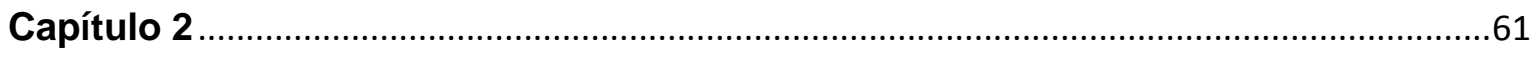

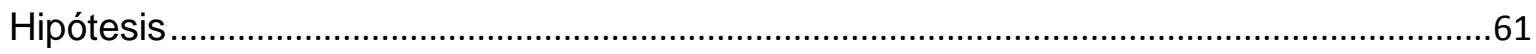

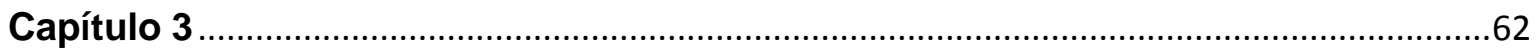

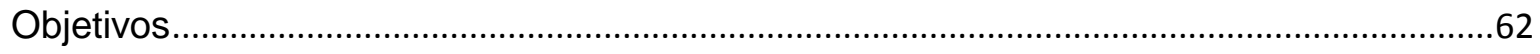

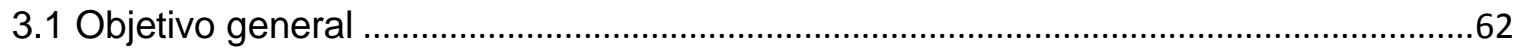

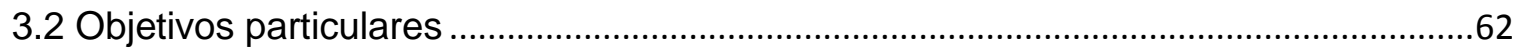

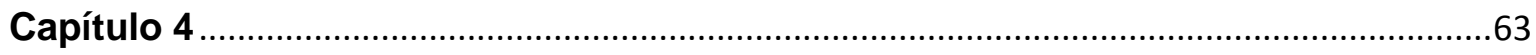

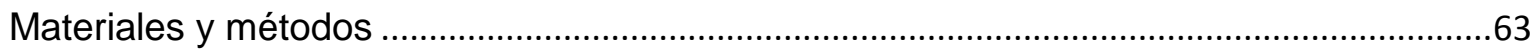

4.1 Base de datos utilizada en modelamiento hidrogeoquìmico...................................63

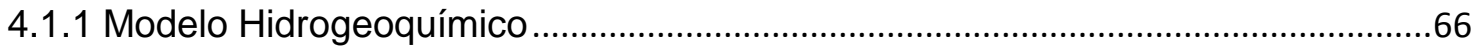

4.2 Tratamiento para la remoción de arsénico ...........................................................67

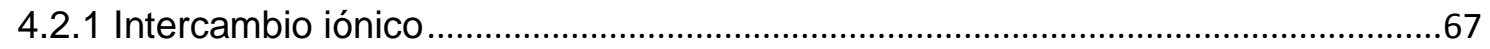

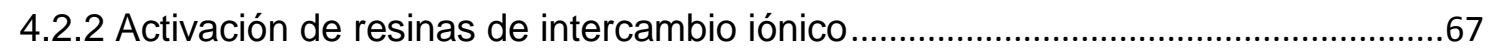

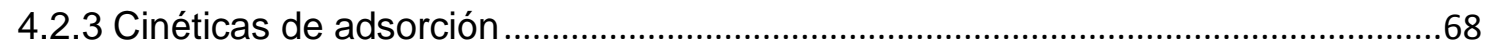

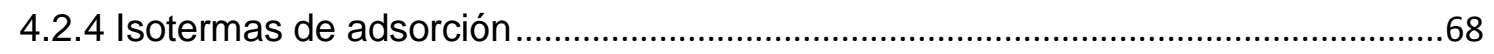

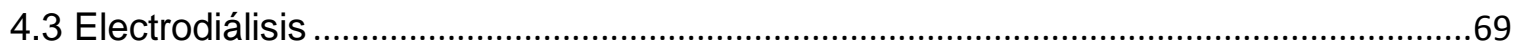

4.3.1 Activación de membranas ...............................................................................69

4.3.2 Síntesis de ánodo dimensionalmente estable (DSA) .........................................69 


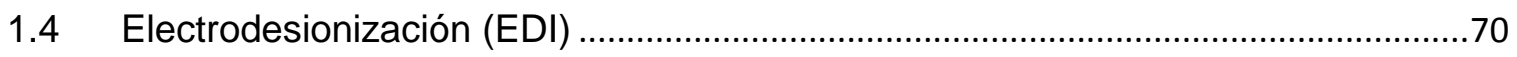

4.4.1 Construcción de celda de electrodesionización .....................................................70

4.4.2 Pruebas de remoción de As en celda de electrodesionización ...............................73

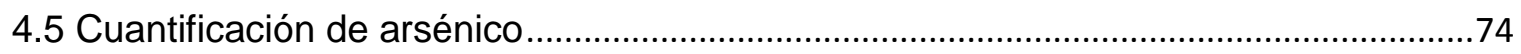

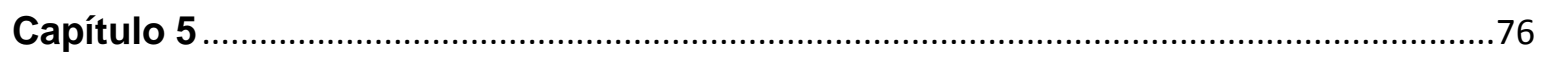

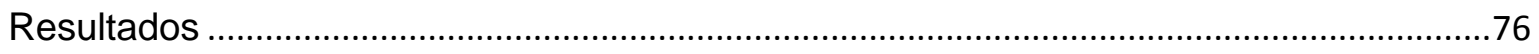

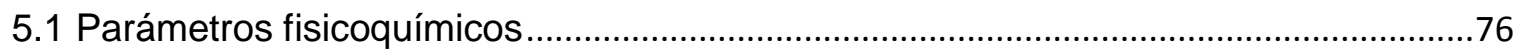

5.2 Clasificación hidrogeoquímica del agua en el sitio de interés......................................81

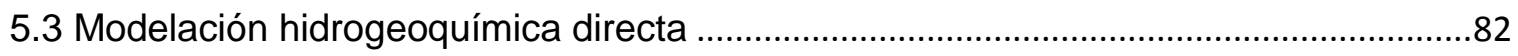

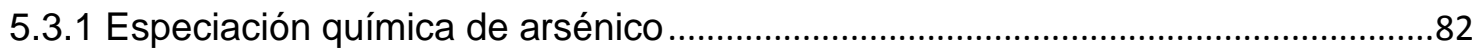

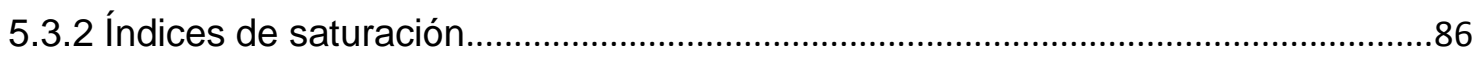

5.4 Resultados de remoción de arsénico en agua sintética por la técnica de electrodesionización (EDI) ..............................................................................................93

5.4.1 Isoterma de adsorción de Amberlite IRA-900...................................................93

5.4.2 Cinética de adsorción de Amberlite IRA-900.......................................................95

5.4.3 Pruebas de electrodesionización .........................................................................97

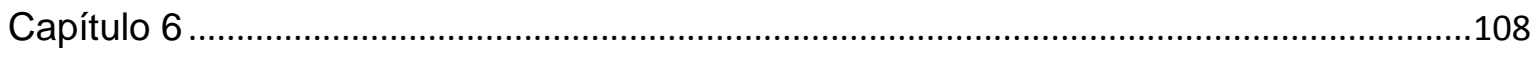

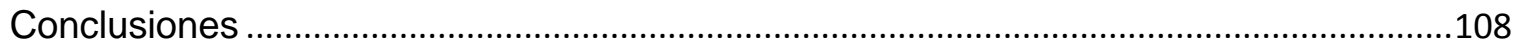

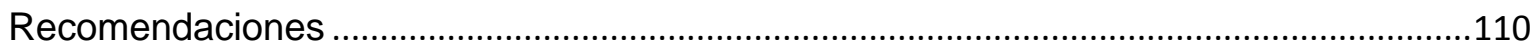

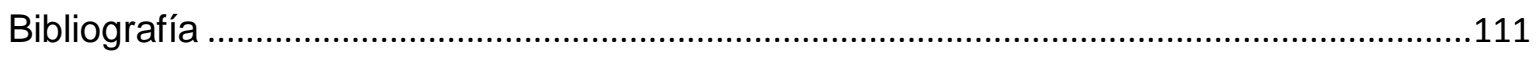

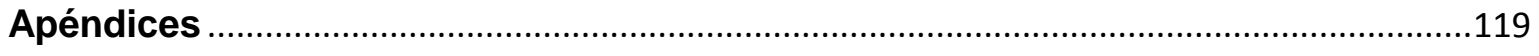

Apéndice I. Datos de entrada y salida en PHREEQC 3.0 ............................................119

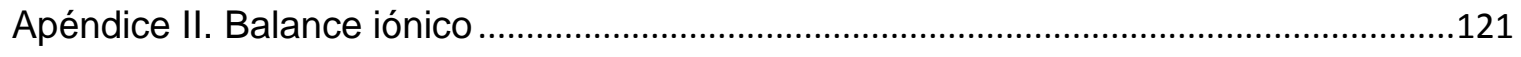




\section{Índice de figuras}

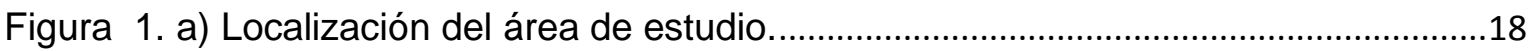

Figura 2. Ejemplo para ilustrar el diagrama de Piper ...........................................................23

Figura 3. Diagrama Eh-pH de especies acuosas de arsénico............................................31

Figura 4. Distribución de especies de arsénico en función del $\mathrm{pH}$.....................................31

Figura 5. Lugares en México con presencia de arsénico en agua para consumo

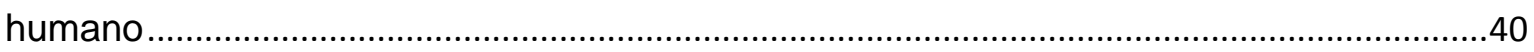

Figura 6. representación del proceso de intercambio iónico ...............................................48

Figura 7. Representación del proceso de electrodiálisis .......................................................49

Figura 8. Representación de una celda de EDI. ...............................................................50

Figura 9. a) Esquema del complejo hidráulico Matehuala-Cerrito Blanco ..........................65

Figura 10. Esquema de la celda de electrodesionización ...................................................71

Figura 11. Esquema del sistema de EDI...........................................................................72

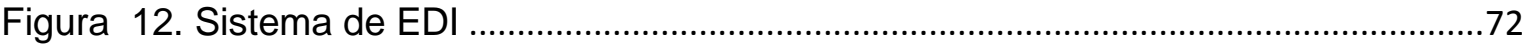

Figura 13. Diagrama de Piper para la zona de estudio (puntos de muestreo CT y TR) ...81

Figura 14. Distribución de especies de arsénico pentavalente en los puntos de muestreo CT y TR (las concentraciones están dadas en $\mathrm{mol} / \mathrm{L}$ y fueron obtenidas mediante

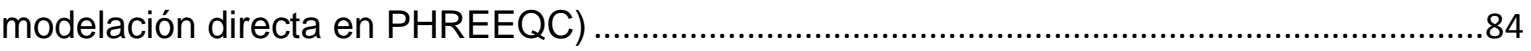

Figura 15. Distribución de especies de arsénico trivalente en el punto de muestreo CT (las concentraciones están dadas en $\mathrm{mol} / \mathrm{L}$ y fueron obtenidas mediante modelación directa en PHREEQ

Figura 16. Datos experimentales y ajuste a modelos no lineales de isotermas de adsorción

Figura 17. Datos experimentales y su ajuste a modelos no lineales de cinética de adsorción .95

Figura 18. comportamiento del pH en los tres compartimentos: Compartimento Anódico (CA), Compartimento del Diluido (CD) y compartimento Catódico (CC) (lecho mixto).......97 Figura 19. Comportamiento del pH en los tres compartimentos: Compartimento Anódico (CA), Compartimento del Diluido (CD) y compartimento Catódico (CC) (lecho aniónico) .99 
Figura 20. Conductividad eléctrica para los tres compartimentos: Compartimento Anódico (CA), Compartimento del Diluido (CD) y compartimento Catódico (CC) (lecho aniónico) 100

Figura 21. Conductividad eléctrica para los tres compartimentos: Compartimento Anódico (CA), Compartimento del Diluido (CD) y compartimento Catódico (CC) (lecho mixto).....101 Figura 22. Potencial REDOX, para los tres compartimentos: Compartimento Anódico (CA), Compartimento del Diluido (CD) y compartimento Catódico (CC) (lecho mixto) 102

Figura 23. Potencial REDOX, para los tres compartimentos: Compartimento Anódico (CA), Compartimento del Diluido (CD) y compartimento Catódico (CC) (lecho aniónico)...........102

Figura 24. Remoción de Arsénico en lecho mixto a 15 ppm de As(V) ..............................105

Figura 25. Remoción de Arsénico en lecho aniónico a 15 ppm de As(V)..........................106

Figura 26. Remoción de As en lecho aniónico a 50 ppm de As(V) ...................................106 Figura 27. Conductividad eléctrica para los tres compartimentos: Compartimento Anódico (CA), Compartimento del Diluido (CD) y compartimento Catódico (CC) (lecho aniónico)

Figura 28. Potencial REDOX, para los tres compartimentos: Compartimento Anódico (CA), Compartimento del Diluido (CD) y compartimento Catódico (CC) (lecho mixto) 122 Figura 29. Potencial REDOX, para los tres compartimentos: Compartimento Anódico (CA), Compartimento del Diluido (CD) y compartimento Catódico (CC) (lecho aniónico)...........122

Figura 30. Remoción de As en lecho aniónico 15 ppm de As(V)iError! Marcador no definido.

Figura 31 Remoción de As en lecho aniónico a 50 ppm de As(V)iError! Marcador no definido. 


\section{Índice de tablas}

Tabla 1. Valores de índices de saturación y su correspondiente proceso.............................25

Tabla 2. Constantes de disociación para arsenato y arsenito ..............................................30

Tabla 3. Tabla de cumplimiento gradual para arsénico .......................................................36

Tabla 4. Límites máximos permisibles para arsénico en descargas de aguas residuales y

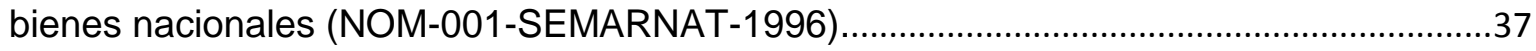

Tabla 5. Límites máximos permisibles de contaminantes en las descargas de aguas residuales a los sistemas de alcantarillado............................................................................38

Tabla 6. Límites máximos permisibles de contaminantes en aguas tratadas .....................38

Tabla 7. Ecuación de Langmuir y sus parámetros .............................................................52

Tabla 8. Ecuación de Freundlich y sus parámetros ............................................................53

Tabla 9. Ecuación de Redlich-Petterson y sus parámetros .................................................53

Tabla 10. Ecuación para cinética de pseudo primer orden y sus parámetros .....................54

Tabla 11. Ecuación para cinética de pseudo segundo orden y sus parámetros .................55

Tabla 12. Ecuación de Elovich y sus parámetros ..................................................................56

Tabla 13. Características de las resinas de intercambio iónico ............................................67

Tabla 14. Parámetros fisicoquímicos medidos en campo por Martínez Villegas., et al 2013, correspondientes al área de interés...............................................................................79

Tabla 15. Parámetros medidos en laboratorio, utilizados en el modelo hidrogeoquímico 80

Tabla 16. Porcentajes relativos de las especies de arsénico más significativas .86

Tabla 17. Índices de saturación de las principales fases minerales presentes en el área de estudio (campaña 2008-2009) .......................................................................................90

Tabla 18. Valores de coeficientes y constantes para cada modelo de isoterma ................94

Tabla 19. Valores de coeficientes y constantes para cada modelo no lineal de cinética...96 Tabla 20. Límites de detección y cuantificación para arsénico ...........................................104

Tabla 21. Concentración de arsénico en el compartimento del diluido ...............................104 


\section{Introducción}

La contaminación de aguas superficiales y subterráneas puede ocurrir por una gran variedad de materiales y sustancias; uno de los contaminantes más importantes es el arsénico (As), debido a su toxicidad y efectos nocivos a la salud humana. El principal mecanismo de transporte de especies de arsénico en el ambiente es a través del agua. El uso de agua potable contaminada representa, hasta el momento, el mayor peligro para la salud humana (Kaltreider et al., 2001).

Un gran número de acuíferos en varias partes del mundo han sido reportados por problemas de contaminación con As, debido a fuentes naturales y antropogénicas. Uno de ellos es el acuífero somero de Matehuala, en San Luis Potosí, en donde se han reportado concentraciones de hasta $158 \mathrm{mg} / \mathrm{L}$ de As (Martínez-Villegas et al., 2013). En este sitio las concentraciones de As rebasan los límites máximos establecidos en las Normas Oficiales Mexicanas (NOM-001-SEMARNAT y NOM127-SSA). La contaminación por As en Matehuala se atribuye a la disolución de sales de arseniatos en una antigua fundición, inactiva desde la década de 1960 (Martínez-Villegas et al., 2013). En dicho acuífero, las concentraciones de arsénico en agua son extremadamente altas debido a la disolución de arseniatos encontrados en residuos de una antigua fundición abandonada en el centro de Matehuala. La comprensión de la especiación del arsénico utilizando un modelo hidrogeoquímico podría proporcionar información que nos permita desarrollar una estrategia de remediación de arsénico en el marco de las condiciones geoquímicas del mismo. Es decir, la caracterización de la especiación de arsénico en el acuífero somero de Matehuala podría impulsar el desarrollo de tecnologías adecuadas que permitan solucionar la contaminación por As en agua en la zona de estudio.

Algunas de las tecnologías más utilizadas para tratamiento de aguas contaminadas son: floculación-coagulación, ósmosis inversa, fitorremediación, adsorción, 
intercambio iónico, electrodiálisis y electrodesionización (EDI). Algunas de estas técnicas presentan desventajas asociadas a generación de residuos y costos (Morató et al., 2006).

En el presente estudio se eligió como tratamiento para la remoción de As en agua, la electrodesionización (EDI) debido a su eficiencia obtenida al combinar las técnicas de electrodiálisis e intercambio iónico, eliminando sus desventajas individuales. En la EDI, la aplicación de corriente eléctrica juega un rol muy importante, debido a que la regeneración de resinas de intercambio iónico se realiza "in situ" por la producción de iones hidrógeno e hidróxido, en la disociación del agua al aplicar corriente eléctrica, evitando así el uso de sustancias químicas adicionales (Nagarale et al., 2006).

Por lo anterior, se plantea la hipótesis y objetivos que contribuirán al conocimiento de las características mencionadas, generando una posible línea de investigación que permita ampliar el conocimiento del área de estudio. 


\section{Capítulo 1}

\section{Antecedentes}

\subsection{Descripción del área de estudio}

El municipio de Matehuala, en el norte del estado de San Luis Potosí, se localiza entre los paralelos $23^{\circ} 38^{\prime} 51^{\prime \prime}$ de latitud norte y $100^{\circ} 39^{\prime} 27^{\prime \prime}$ de longitud oeste, a una altitud entre 1300 y 2500 m sobre el nivel del mar (Figura 1a). El clima de la región es semiárido y tiene una precipitación promedio anual de $515.2 \mathrm{~mm}$ de lluvia (INEGI, 2010). Predominan los suelos carbonatados, con yeso en el horizonte profundo y suelos cementados con carbonato en zonas superficiales. El tipo de suelo predominante en la zona es el Xerosol cálcico y Xerosol háplico, los cuales son de color claro, de origen aluvial en la zona del valle y coluvioaluvial en las laderas. Estos suelos tienen un $\mathrm{pH}$ que varía de neutro a ligeramente alcalino, con altos contenidos de sales y por lo general se encuentran asociados a Regosoles (Figura 1b). La zona urbana está creciendo sobre suelos del Cuaternario, en llanura desértica con lomerío; sobre áreas originalmente ocupadas por suelos denominados Calcisol y Gypsisol (INEGI, 2009).

Existen en la zona yacimientos de plata de origen hidrotermal, producidos por la mineralización e intrusión de cuerpos ígneos en rocas calizas y calizas-arcillosas del Jurásico y Cretácico; así como yacimientos de $\mathrm{Pb}, \mathrm{Cu}$ y $\mathrm{Zn}$ formados por intrusiones de cuerpos de granodiorita, granito y diorita a rocas calcáreas y calcáreo-arcillosas del Jurásico y Cretácico (INEGI, 2002).

El área de interés (Figura 1 a) se localiza cerca del distrito minero Santa María de la Paz, localizado entre los municipios de Villa de la Paz y Matehuala, que tiene una mineralización formada por un conjunto de vetas de origen hidrotermal, 
constituidas por galena (PbS), arsenopirita (FeAsS), pirita $\left(\mathrm{FeS}_{2}\right)$ y sulfosales de cobre (Castro et al., 1997). En la zona se reporta un alto grado de contaminación relacionado a la dispersión pluvial de desechos mineros; y, en menor grado, la contaminación se relaciona a la dispersión eólica de partículas provenientes de la antigua planta de fundición (Razo, et al., 2004). No obstante, también se reporta una alta contaminación del agua subterránea relacionada a la disolución de sales de arseniatos en una antigua fundición en el centro de Matehuala (MartínezVillegas et al., 2013). 


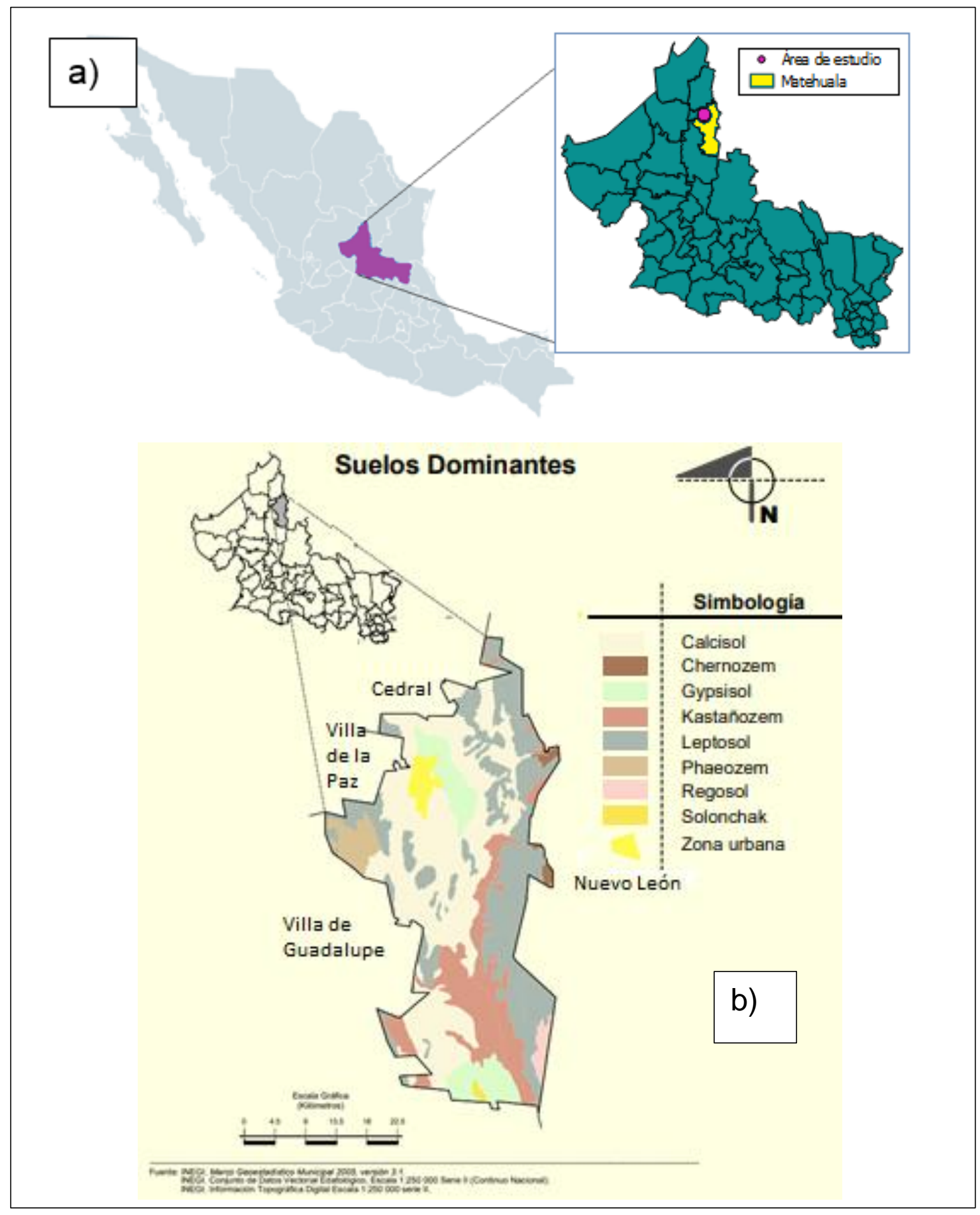

Figura 1. a) Mapa de Matehuala, San Luis Potosí mostrando el área de estudio.

b) Tipos de suelo en Matehuala

Fuente: (INEGI, Prontuario de información geográfica municipal de Matehuala, 2009) 
Para la realización de este estudio, se utilizaron datos experimentales obtenidos por Martínez-Villegas, 2013, en dos puntos de muestreo; en el primero, el agua proviene de una surgencia (que a últimas fechas, de acuerdo a Gómez et al., (2020) se ha identificado como el nivel freático de la zona) ubicada en una propiedad privada conocida como Club de Tiro (CT), mientras que el segundo punto se localiza cerca del Instituto Tecnológico Regional (TR) de Matehuala; ambos puntos, dentro de un complejo hidráulico llamado Matehuala-Cerrito Blanco. Entre los puntos de muestreo, la concentración de arsénico presenta un importante decrecimiento del punto CT al punto TR. A partir del punto TR, la concentración de As se mantiene constante dentro del complejo hidráulico hasta llegar a la laguna. Para comprender la especiación de arsénico, se utilizaron los puntos CT y TR por considerarse representativos del sitio. La distancia entre el punto CT y TR es de 1.3 km (Martínez-Villegas et al., 2013).

El complejo hidráulico Matehuala-Cerrito Blanco tiene una longitud de aproximadamente $6 \mathrm{~km}$ y comprende una galería con 24 pozos, un canal y una laguna, localizada en el interior de un parque, donde el agua es almacenada y utilizada para actividades recreativas y de irrigación. El complejo hidráulico se abastece de un acuífero somero donde el flujo del agua va en dirección oeste a este (Martínez Villegas, et al., 2013). 


\subsection{Hidrogeoquímica}

La hidrogeoquímica, es una ciencia interdisciplinaria que se nutre de los conocimientos de la química del agua y la hidrogeología. Se encarga del estudio de las propiedades químicas del agua superficial y subterránea en relación con la geología (Fagundo \& González, 2005).

\subsubsection{Interacción agua roca}

El término "interacción agua-roca" hace referencia a los intercambios predominantemente químicos y termales (reacciones) que ocurren entre el agua subterránea y las rocas del medio. La composición química e isotópica del agua subterránea refleja la composición mineralógica de las rocas en un acuífero y puede ser usada para localizar áreas de descarga, y para determinar el origen del agua subterránea (meteórica, marina, fósil, magmática o metamórfica) y de los componentes individuales (carbonato, sulfato, nitrato y amonio). La composición del agua también proporciona información sobre los procesos de interacción aguaroca y procesos microbianos presentes en el agua (Litter et al., 2010).

El agua subterránea, en su interacción con el medio ambiente, provoca cambios físicos (lubricación y modificación de presiones intersticiales), químicos (disolución, hidratación, oxido-reducción, precipitación e intercambio iónico) y cinéticos (transporte de agua y calor) (Litter et al., 2010).

En las interacciones entre el agua subterránea y el medio circundante tienen lugar diversos procesos:

\section{Disolución}

Este proceso ocurre en el suelo, en la zona vadosa y saturada; en zonas de acumulación de gas (los poros del suelo, presentan $\mathrm{CO}_{2}$ ), dando origen a aguas ácidas debido a la reacción del $\mathrm{CO}_{2}$ con el agua. El grado de disolución depende 
de la solubilidad del mineral, su concentración en el agua, la presión y la temperatura del sistema (Tóth, 2000).

\section{Intercambio iónico}

Asimismo, los minerales de tipo arcilloso, se caracterizan por presentar tamaño del orden coloidal, originando procesos de intercambio iónico con el agua que circula a través de las mismas (Fagundo \& González, 2005). Las partículas de arcilla presentan una carga residual negativa sobre su superficie, convirtiéndose en intercambiadores catiónicos, a diferencia de los oxihidróxidos de hierro y aluminio que están cargados positivamente, de modo que son intercambiadores aniónicos (Fagundo \&González, 2005).

\section{Reacciones oxido-reducción}

Muchas reacciones químicas que tienen lugar en el medio acuático implican transferencia de electrones entre constituyentes disueltos, gases o sólidos. Como resultado de estas transferencias se producen cambios en los estados de oxidación-reducción de los reactivos y los productos (Appelo \& Postma, 1993). Este proceso representa el equilibrio en el intercambio de electrones entre una especie que los libera y otra que los incorpora. Naturalmente, el agua contiene sustancias oxidantes mientras que el suelo contiene las sustancias reductoras, por lo tanto, la fase acuosa adquiere propiedades reductoras debido a su contacto con la fase sólida (Fagundo \& González, 2005).

\section{Precipitación}

La precipitación de minerales puede ocurrir por: variaciones en presión y temperatura que afectan la solubilidad de algunos componentes y por la oxidación de materia orgánica disuelta, que, en contacto con las condiciones atmosféricas, generan compuestos con menor solubilidad (Tóth, 2000). 
Para dichos procesos, la especiación química de los elementos en la solución es de primordial importancia toda vez que de ésta depende, en gran medida, el tipo de procesos hidrogeoquímicos que sufrirán los elementos en el agua.

\subsubsection{Caracterización hidrogeoquímica del agua}

Para constatar el carácter químico dominante del agua, se utilizan gráficos que permiten obtener una visualización de forma simple y completa de los datos y procesos del agua. Para ello, se han desarrollado una variedad de diagramas; cada uno de ellos con cualidades específicas ante su representación. En el presente estudio, la caracterización hidrogeoquímica del agua se realizó utilizando el diagrama de Piper. El diagrama de Piper ha sido ampliamente utilizado para el estudio de similitudes y diferencias en la composición químicas del agua (Chadha, 1999).

El diagrama de Piper es un diagrama triangular, utilizado como un gráfico efectivo para la representación de muestras de agua en estudios hidrogeológicos. Los porcentajes de las concentraciones de los principales iones son mostrados en el diagrama. En el triángulo inferior izquierdo se muestran las concentraciones de cationes, mientras que, en triángulo derecho, se muestran las concentraciones de aniones. Ambas concentraciones son proyectadas en un rombo central donde se evalúa el punto de intersección de ambos triángulos (Gidahatari, 2018). El rombo central se divide en cuatro rombos pequeños, dependiendo de la posición de las muestras, será la clasificación del agua, pudiendo ser (Milán, 2015):

1. Rombo superior: agua de tipo sulfatada, clorada, cálcica y/o magnésica.

2. Rombo inferior: agua de tipo bicarbonatada sódica.

3. Rombo central izquierdo: agua de tipo bicarbonatada cálcica y/o magnésica.

4. Rombo central derecho: agua de tipo clorurada y/o sulfatada sódica. 


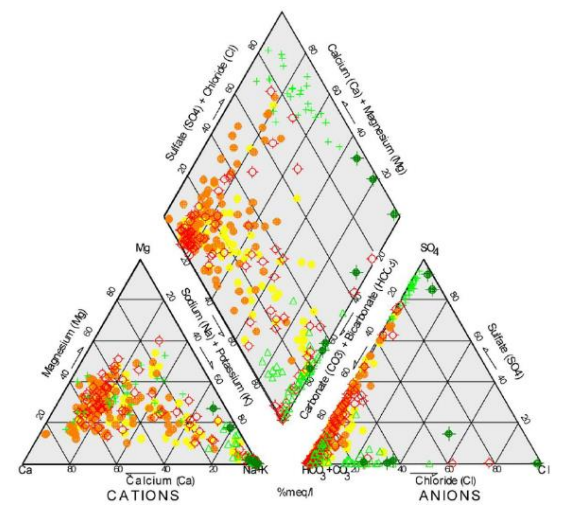

Figura 2. Ejemplo para ilustrar el diagrama de Piper

\subsubsection{Modelación hidrogeoquímica}

La modelación hidrogeoquímica es la aplicación de principios físico-químicos a la interpretación de sistemas hidrogeoquímicos.

El objetivo de la modelación geoquímica es crear o idear modelos teóricos de reacción capaces de explicar lo observado en la interacción agua-roca, es decir, consiste en utilizar los datos disponibles (análisis químicos de la fase acuosa, hidrogeología del sistema, mineralogía, composición de gases, datos isotópicos) para determinar que reacciones químicas han ocurrido, la medida en que han ocurrido y las condiciones en que ocurrieron (Fagundo \& González, 2005). En este sentido, la especiación química es uno de los primeros cálculos de la modelación hidrogeoquímica.

Los modelos hidrogeoquímicos se emplean fundamentalmente para predecir la distribución de las diferentes especies químicas presentes en una disolución acuosa, así como la transferencia de materia que se produce al poner en contacto diferentes fases (Fagundo \& González, 2005). 
Los cálculos geoquímicos que se realizan con los modelos hidrogeoquímicos están basados en el cumplimiento de las ecuaciones de conservación de materia y en los principios que rigen el equilibrio químico. Básicamente, estos códigos trabajan en dos líneas asociadas en serie-paralelo. La primera serie de cálculos está constituida por ciertos algoritmos numéricos capaces de ajustar los datos experimentales a modelos matemáticos capaces de simular el comportamiento de los sistemas, mientras que la segunda línea de trabajo consiste en un método de cálculo capaz de estimar propiedades termodinámicas a partir de una amplia base de datos termodinámica que puede ir ampliándose (Fagundo \& González, 2005). Actualmente existen dos tipos de modelos para describir reacciones hidrogeoquímicas: modelos directos y modelos inversos.

\subsubsection{Especiación química}

La especiación química ha sido definida, en forma general, como el proceso de identificación y cuantificación de las formas químicas de un mismo elemento en una muestra dada. La especiación química, distingue el grado de oxidación de un elemento (HIvay et al., 2004).

\subsection{5 Índice de Saturación (SI)}

El índice de Saturación (SI), es un valor de importancia, ya que es el primer acercamiento a la relación que existe entre las actividades en solución de los iones que forman un determinado mineral y la constante de equilibrio de la reacción de disolución de ese mineral, determinando ambos parámetros a la misma temperatura (la temperatura que se registra en el sitio de estudio) (Martínez et al., 2000). 
Con el SI, es posible pronosticar la evolución de la solución acuosa, debido a procesos de disolución o precipitación en la interacción agua-roca mediante la siguiente ecuación:

\section{$\mathrm{SI}=\log (\mathrm{IAP} / \mathrm{K})$}

En donde:

$\mathrm{IAP}=$ producto de actividad iónica

$\mathrm{K}$ : constante de equilibrio

Dependiendo el valor obtenido de SI, se tendrá el proceso descrito en la tabla 1

Tabla 1. Valores de índices de saturación y su correspondiente proceso

\begin{tabular}{|c|c|}
\hline SI & Proceso \\
\hline $\mathrm{SI}=0$ & el sistema se encuentra en equilibrio de saturación \\
\hline $\mathrm{SI}<0$ & el sistema presenta condiciones de subsaturación (disolución) \\
\hline $\mathrm{SI}>0$ & el sistema presenta condiciones de sobresaturación (precipitación) \\
\hline
\end{tabular}

(Appelo \& Postma, 1993) 


\subsubsection{Tipos de Modelos Hidrogeoquímicos}

\subsubsection{Modelos directos}

Los modelos directos son aquellos en los que se conoce la composición inicial de una solución y se establecen las reacciones hidrogeoquímicas que se considera tienen o tendrán lugar en el sistema. Permite hacer predicciones acerca del funcionamiento de un sistema y son especialmente útiles en el caso de situaciones hipotéticas o con un elevado nivel de incertidumbre respecto a las características reales del medio (Fagundo \& González, 2005).

La evaluación cuantitativa de la interacción química agua-roca, se basa en la utilización de un modelo de especiación y transferencia de masa, que calcula las concentraciones de todas las especies en solución, sus productos de actividades y coeficientes de actividad química debido a que se considera que las soluciones acuosas son reales y no ideales (Fagundo \& González, 2005).

\subsubsection{Modelos inversos}

Los modelos inversos o de balance son aquellos que calculan las reacciones químicas netas que han ocurrido en el medio físico entre dos puntos situados sobre una línea de flujo y en los cuáles se conoce la composición del agua. Se parte de la composición de una solución inicial y una solución final conocidas que tienen lugar en el sistema (Fagundo \& González, 2005). La modelación inversa permite cuantificar las fases de reacción gaseosa y acuosa en cantidades apropiadas a fin de determinar las diferencias entre los productos inicial y final (Parkhust \& Apello, 1999).

Para la aplicación de este tipo de modelo, se supone la existencia de diferencias entre los componentes químicos de ambos puntos; esta diferencia es el delta 
iónico. El modelo cuantifica los procesos y reacciones posibles que pudiesen ocurrir entre los puntos extremos y la fase mineral definida (André et al., 2005).

El software PHREEQC genera múltiples modelos; de acuerdo con Plummer (1991), el cálculo de los índices de saturación ayuda a conocer las posibles fases que se encuentran presentes en el sistema, con ello, es posible saber que minerales presentan procesos de precipitación o disolución. Parkhurst (1991) indica que el grado de incertidumbre del análisis, permite reducir el número de fases y el número de modelos que son necesarios reproducir en las reacciones químicas. La validez de un modelo depende significativamente del conocimiento geológico de sus fases en la selección de éste (Plummer et al., 1991).

En este trabajo de tesis, se utilizó la modelación directa para conocer la especiación del arsénico en los puntos de estudio Club de Tiro (CT) e Instituto Tecnológico Regional de Matehuala (TR).

\subsubsection{Software PHREEQC 3.0}

PHREEQC es un programa diseñado para la realización de una amplia variedad de cálculos geoquímicos. Implementa varios tipos de modelos acuosos:

- Dos modelos acuosos de asociación iónica: el modelo del Laboratorio Nacional de Lawrence Livermore y WATEQ4F.

- Modelo acuoso Pitzer de interacción iónica específica.

- Modelo acuoso SIT (Teoría de interacción lónica Específica).

Utilizando alguno de estos modelos, PHREEQC es capaz de realizar:

1. Cálculos de especiación e índices de saturación

2. Reacción por lotes y transporte unidimensional (1D) con reacciones reversibles e irreversibles 


\section{Modelación inversa}

(Parkhurst \& Appelo, 2013)

PHREEQC simula reacciones químicas y procesos de transporte en el agua con base en cálculos geoquímicos; representa una síntesis de distintos tipos de cálculos tales como: cálculos de especiación-solubilidad, pautas de reacción, transporte reactivo y balance de masas, tanto para aproximaciones de Problema Directo como Inverso. Realiza también cálculos de especiación, reacciones cinéticamente controladas, mezcla de soluciones, cambios de presiones y temperatura (Appelo \& Postma, 1993).

\subsection{Arsénico}

El arsénico (As) es clasificado como uno de los elementos químicos más tóxicos y carcinógenos (Katsoyiannis \& Zouboulis, 2004). Químicamente, es clasificado como un metaloide, presente en el ambiente de forma natural. Tiene la capacidad de formar componentes orgánicos e inorgánicos en el medio ambiente y el cuerpo humano (US, Department of Health and Human Services, 2007).

En el ambiente, cuando el arsénico se encuentra combinado con elementos como oxígeno, cloro y azufre es conocido como arsénico inorgánico, mientras que, combinado con carbón e hidrógeno es arsénico orgánico (Katsoyiannis \& Zouboulis, 2004). En aguas naturales, se encuentra como especies inorgánicas, en dos estados de oxidación: As (III) y $\mathrm{As}(\mathrm{V})$, resultado de la disolución de minerales como el óxido de arsénico y la arsenopirita (US Department of Health and Human Services, 2007).

La presencia de As en el ambiente natural se debe a factores tales como la disolución de minerales como los arseniatos de calcio, la actividad geotérmica, la lixiviación meteórica de desechos mineros, la producción de cenizas de carbón y 
el uso de pesticidas. Las personas expuestas al arsénico pueden desarrollar diversas enfermedades (Lillo, 2008).

El arsénico es considerado un elemento calcófilo, por su tendencia a concentrarse en la fase sulfurada. Se estima que del total de As contenido en los diferentes reservorios naturales (rocas, océanos, suelos), más del 99\% está asociado con rocas y minerales. La concentración varía dependiendo del tipo de roca, generalmente, las rocas sedimentarias contienen niveles de As más elevados que las rocas ígneas. Respecto a los minerales, en los sulfuros se encuentran concentraciones superiores a $105 \mathrm{mg} / \mathrm{kg}$ de As; mientras que en los óxidos de hierro pueden superarse concentraciones de $7.6 \times 10^{4} \mathrm{mg} / \mathrm{kg}$ de As. Los óxidos de hierro, manganeso y aluminio son las fuentes y sumideros de As más importantes en los acuíferos, debido a su amplia presencia, su química y su tendencia a cubrir otras partículas (Litter y otros, 2008).

En el medio ambiente, el arsénico puede unirse o separarse de partículas y cambiar su forma al reaccionar con oxígeno u otras moléculas presentes en el aire, agua o suelo (US Department of Health and Human Services, 2007).

\subsubsection{Fisicoquímica del arsénico en agua}

En agua de mar, la concentración natural de arsénico usualmente es menor que 2 $\mu \mathrm{g} / \mathrm{L}$, mientras que, en aguas superficiales y subterráneas, la concentración varía entre 1 y $10 \mu \mathrm{g} / \mathrm{L}$ (WHO, 2001).

En fase acuosa, el arsénico se encuentra presente en su forma inorgánica, generalmente como especie disuelta, formando oxianiones. En aguas naturales, los estados de oxidación que predominan son As (III) y As $(\mathrm{V})$ y, con menos frecuencia, As(0) y As(-III) (Lillo, 2008). 
El arsénico pentavalente $[\mathrm{As}(\mathrm{V})]$, aparece como arseniato de hidrógeno $\mathrm{H}_{3} \mathrm{AsO}_{4}$ y sus correspondientes productos de disociación:

- Ion arseniato di-ácido $\mathrm{H}_{2} \mathrm{AsO}_{4}$

- Ion arseniato monoácido $\mathrm{HAsO}_{4}{ }^{2-}$

- Ion arseniato $\mathrm{AsO}_{4}{ }^{3-}$

El arsénico trivalente [As (III)] aparece como ácido arsenioso $\left(\mathrm{H}_{3} \mathrm{AsO}_{3}\right)$ y sus correspondientes derivados protolíticos que dependen del $\mathrm{pH}$ :

- Ion arsenito diácido $\mathrm{H}_{2} \mathrm{AsO}_{3}{ }^{-}$

- Ion arsenito monoácido $\mathrm{HAsO}_{3}{ }^{2-}$

- Ion arsenito $\mathrm{AsO}_{3}{ }^{3-}$

La ionización del arsénico está expresada por la constante de disociación $\mathrm{K}_{\mathrm{a}}$, cuyos valores para el arsenato y arsenito son:

Tabla 2. Constantes de disociación para arsenato y arsenito

\begin{tabular}{|c|c|c|c|}
\hline & $\mathrm{K}_{\mathrm{a} 1}$ & $\mathrm{~K}_{\mathrm{a} 2}$ & $\mathrm{~K}_{\mathrm{a} 3}$ \\
\hline $\mathrm{H}_{3} \mathrm{AsO}_{4}$ & 2.2 & 6.94 & 11.5 \\
\hline $\mathrm{H}_{3} \mathrm{AsO}_{3}$ & 9.2 & 14.22 & 19.22 \\
\hline
\end{tabular}

Las constantes de disociación para el arsenato son menores que las del arsenito, por lo que su grado de disociación es más elevado. La capacidad de ionización del As $(V)$ le permite combinarse fácilmente con otros compuestos, lo cual hace que su remoción sea más eficiente (Lillo, 2008).

El estado de oxidación del arsénico y, por lo tanto, su movilidad, están controlados fundamentalmente por el potencial redox (Eh) y el pH (Figura 3). En condiciones oxidantes, el estado pentavalente predomina sobre el trivalente, encontrándose como $\mathrm{H}_{2} \mathrm{AsO}_{4}^{-}$a valores de $\mathrm{pH}$ bajos (inferiores a 6.9), mientras que, en pH más básicos, la especie dominante es $\mathrm{HAsO}_{4}{ }^{2-}$. En condiciones de extrema acidez, la 
especie dominante será $\mathrm{H}_{3} \mathrm{AsO}_{4}{ }^{0}$, mientras que en condiciones de extrema basicidad, la especie dominante será $\mathrm{AsO}_{4}{ }^{3-}$ (Figura 4) (Lillo, 2008).

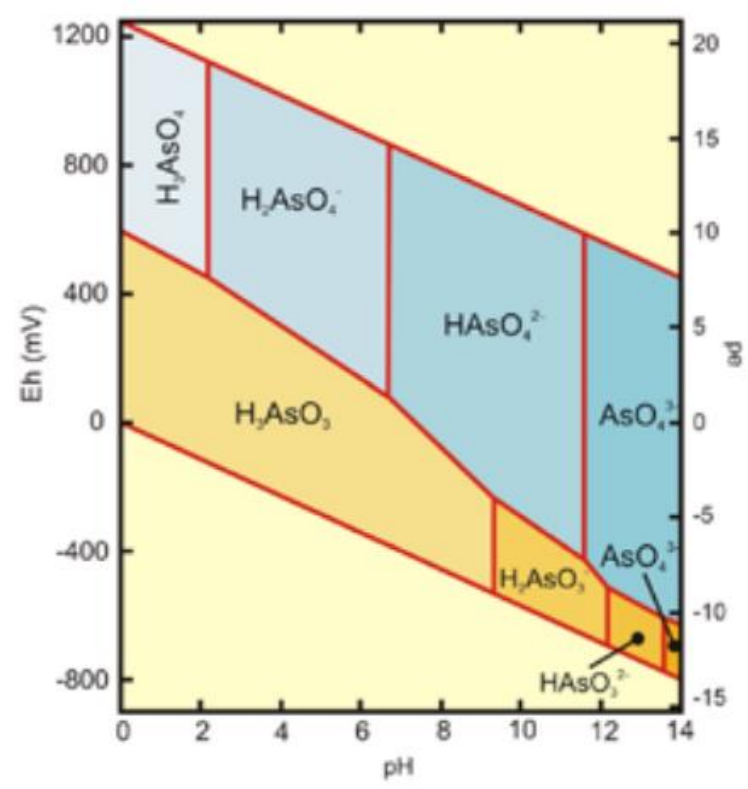

Figura 3. Diagrama Eh-pH de especies acuosas de arsénico

Fuente: (Lillo., 2008)
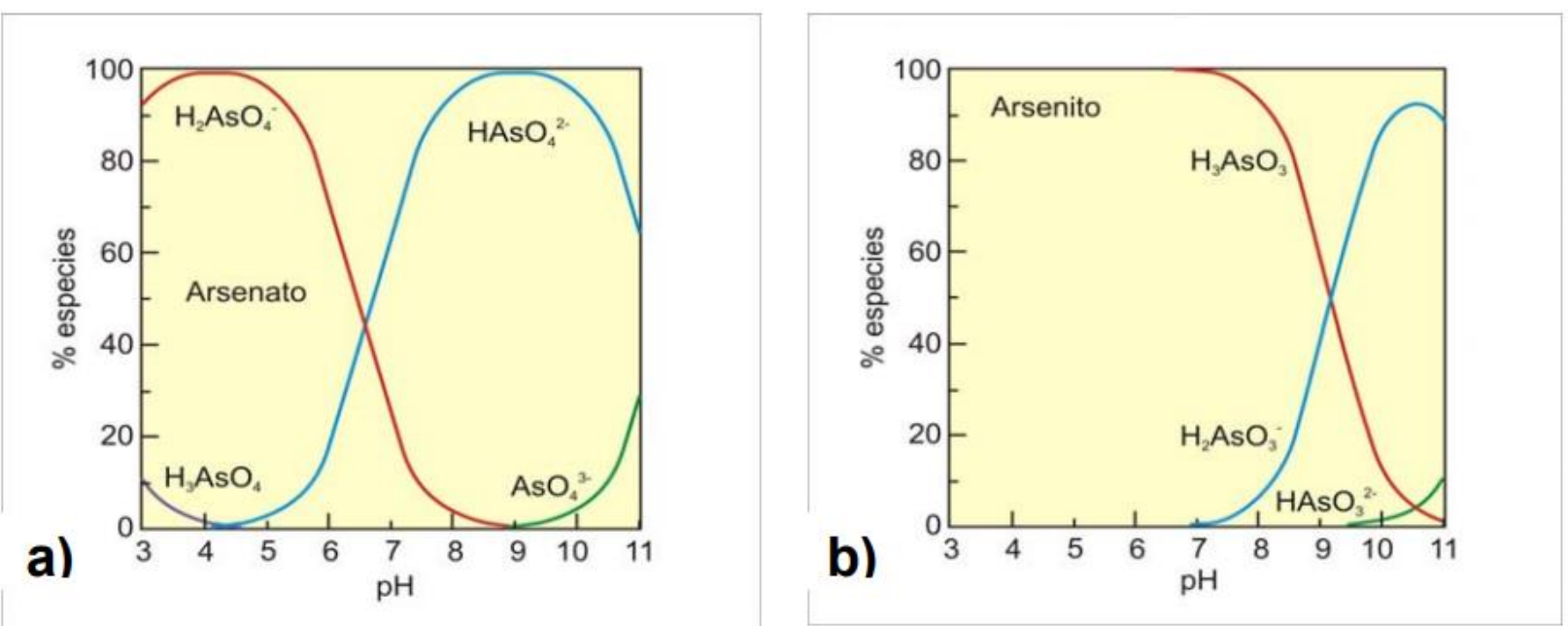

Figura 4. Distribución de especies de arsénico en función del pH

Fuente: (Lillo J., 2008) 
La concentración de determinados elementos también controla la especiación y movilidad del arsénico; en presencia de concentraciones altas de azufre, si se presentan condiciones reductoras y ácidas, precipitarán sulfuros de arsénico como el oropimente $\left(\mathrm{As}_{2} \mathrm{~S}_{3}\right)$ y rejalgar $\left(\mathrm{As}_{4} \mathrm{~S}_{4}\right)$ (Lillo J., 2008).

Los compuestos más comunes del arsénico son los sulfuros en la forma reducida y los arseniatos en forma oxidada. Los numerosos óxidos de arsénico se forman cuando los depósitos de sulfuro y arseniuro quedan expuestos al oxígeno presente en agua. Los arseniatos $\left(\left[\mathrm{AsO}_{4}\right]^{3-}\right)$, son la especie con mayor presencia en condiciones oxidantes y también la especies estables (Robertson, 1989).

En el presente estudio, las condiciones en el medio presentan variaciones que van de moderadamente reductoras a oxidantes con valores de $\mathrm{pH}$ cercanos a la neutralidad y valores ligeramente alcalinos, favoreciendo la presencia de especies de arsénico pentavalentes. De manera general, las técnicas de remoción de As en agua, descritas en la sección 1.3.5, requieren una oxidación previa de As (III) a As (V), al ser la especie oxidada la que prevalece en el sistema, es más estable y fácil de remover. Para la remoción de arseniatos en agua, la electrodesionización (EDI) combina las ventajas de las técnicas de electrodiálisis e intercambio iónico, disminuyendo las desventajas individuales de cada tecnología (polarización por concentración en electrodiálisis y regeneración química de la resina en intercambio iónico) (Alvarado L., 2009). De modo que la EDI es una técnica que ofrece ventajas sobre las tecnologías convencionales, siendo la más importante, la de no generar subproductos residuales. 


\subsubsection{Toxicidad relacionada con el arsénico}

El arsénico se considera altamente tóxico para el organismo humano, no solamente a altas concentraciones donde los resultados por exposición a dicho contaminante pueden ser letales, sino también a concentraciones bajas durante periodos de exposición prolongados (Nava \& Méndez, 2011).

El Departamento de Salud y Servicios Humanos de Estados Unidos (DHHS) y la Agencia de Protección al Ambiente de Estados Unidos (EPA) han determinado que el arsénico en su forma inorgánica es un carcinógeno humano. Este metaloide ocupa el primer lugar en la lista de productos contaminantes de agua de la EPA, por ello, ha sido catalogado en el grupo A en la clasificación de cáncer (Nava \& Méndez, 2011).

La toxicidad de las especies de arsénico varía considerablemente, siendo los compuestos inorgánicos más tóxicos que los compuestos orgánicos. La mayoría de los casos de toxicidad inducida por arsénico en humanos son ocasionados por exposición al arsénico en su forma inorgánica (OMS, 2008).

El arsénico y sus compuestos se introducen al organismo principalmente por los siguientes mecanismos:

- Inhalación: polvo de arsénico en el aire contaminado, el pulmón puede absorber una porción del 50\% del arsénico inhalado en estado gaseoso. Este compuesto se conoce como arsina o hidruro de arsénico.

- Ingestión: arsénico en agua y alimentos contaminados. El sistema gastrointestinal absorbe en promedio el $80 \%$ del arsénico, puede ser como arsenito $\mathrm{o}$ arseniato (dependiendo de las condiciones del medio en que se encuentre), siendo ésta la principal ruta de exposición. 
- Contacto dérmico: la adsorción en la piel de arsenito y arseniato es la ruta de menor exposición (US Department of Health and Human Services, 2007).

Como se ha mencionado, el grado de toxicidad varía según la especie de arsénico. El hidruro de arsénico es el compuesto más tóxico seguido por el arsénico trivalente. El arsénico trivalente es más tóxico que el arsénico pentavalente, ésto debido a que inhibe la reducción de la nocotinamida adenina dinucleótido (NAD) al desactivar los sistemas enzimáticos, se une a grupos sulfhídricos en el ciclo de los ácidos tricarboxílicos (TCA) o del ácido cítrico (Ciclo de Krebs). El arsenito reacciona de manera específica con los receptores hormonales que contienen los grupos tioles, evitando que los esteroides se puedan unir eficientemente a sus receptores; inhibe reacciones enzimáticas provocando una menor producción de energía (OMS, 2008).

Por otra parte, el arsénico pentavalente, al ser más estable, inhibe la fosforilación oxidativa (formación de ATP) reemplazando al fósforo y formando ésteres de arseniato que son hidrolizados. Como consecuencia, los enlaces de alta energía del adenosín trifosfato (ATP) no se conservan por la presencia del arsénico pentavalente, incrementando la producción de radicales libres y ocasionando muerte celular. Este proceso es conocido como arsenólisis (OMS, 2008).

En poblaciones expuestas, las manifestaciones crónicas por exposición a especies de arsénico son las que usualmente se observan. A continuación, se describen las más comunes:

- Lesiones en la piel (usualmente observadas en palmas de manos y plantas de pies): consisten en ulceraciones, hiperqueratosis, hiperpigmentación (manchas en la piel causadas por alteración a la pigmentación) e irritación. Estas lesiones pueden transformarse en carcinomas.

- Ojos: se produce conjuntivitis que puede terminar en necrosis y ulceración de córnea. 
- Fosas nasales: irritación crónica que puede originar la perforación del tabique nasal en su porción cartilaginosa.

- Sistema nervioso: el arsenicismo crónico provoca neuritis periférica que afecta las extremidades inferiores (OMS, 2008).

\subsubsection{Normas que regulan el contenido de arsénico en agua}

Debido a los riesgos ambientales y a la salud humana que representa la presencia de especies de arsénico en agua, organizaciones tanto nacionales como internacionales han establecido normas que permitan controlar la calidad del agua y así, prevenir riesgos.

\subsubsection{Normas internacionales}

Con base en estudios epidemiológicos, la Organización Mundial de la Salud (OMS) recomendó establecer un máximo permisible de $0.01 \mathrm{mg} / \mathrm{L}$ en agua destinada a consumo humano. Desde enero de 2001, este valor se exige como norma tanto en la Unión Europea como en Estados Unidos (OMS, 2008). De igual forma, la Agencia de Protección al Ambiente de los Estados Unidos establece un límite máximo permisible de $0.01 \mathrm{mg} / \mathrm{L}$ de arsénico para agua de riego (EPA, 2010).

En muchos países es deseable reducir la concentración de arsénico en agua; sin embargo, por cuestiones económicas, sociales y políticas, es difícil que países como los de América Latina lleguen a tener límites máximos permisibles de arsénico en agua iguales a los establecidos en las normas internacionales.

\subsubsection{Normas nacionales}

La presencia de altos niveles de arsénico en las aguas subterráneas para uso potable tiene importantes consecuencias para la salud humana. Por tal motivo, 
México disminuyó sus límites máximos permisibles para agua potable de acuerdo con las recomendaciones de la Organización Mundial de la Salud. En el año 2000, la NOM-12-SSA1-1994 tuvo una modificación, estableciendo un límite máximo permisible de $0.025 \mathrm{mg} / \mathrm{L}$ de As en agua para destinada al uso y consumo humano. En 2019, el Proyecto de Norma Oficial Mexicana PROY-NOM-127-SSA1-2017 establece que el límite permisible para arsénico de $0.025 \mathrm{mg} / \mathrm{L}$ deberá ajustarse gradualmente conforme al número de habitantes (tabla 3) (SSA, 2017).

Tabla 3. Tabla de cumplimiento gradual para arsénico

\begin{tabular}{|c|c|c|}
\hline Localidad & Año & $\begin{array}{c}\text { Límite permisible de } \\
\text { arsénico (mg/L) }\end{array}$ \\
\hline$>500,000$ habitantes & 2020 & 0.01 \\
\hline Entre 50,000 y 499,999 habitantes & 2022 & 0.01 \\
\hline$<50,000$ habitantes & 2025 & 0.01 \\
\hline
\end{tabular}

Las normas oficiales mexicanas que se encargan de establecer los límites máximos permisibles de arsénico en aguas (potables o residuales), se describen a continuación:

- NOM-127-SSA1-1994- Salud ambiental, agua para uso y consumo humanoEstablece los límites máximos permisibles de contaminantes, así como los tratamientos a los que debe someterse el agua para su potabilización. Para arsénico se establece un límite de $0.025 \mathrm{mg} / \mathrm{L}$ (SSA, 1994).

- NOM-201-SSA1-2002- Productos y servicios, agua y hielo para consumo humano envasados y a granel- establece las disposiciones $y$ especificaciones sanitarias que deben cumplir el agua y hielo para consumo humano, excepto la que es consumida directamente de los sistemas de abastecimiento. Para arsénico se establece un límite de $0.025 \mathrm{mg} / \mathrm{L}$ (SSA, 2002). 
- NOM-001-SEMARNAT-1996: establece los límites máximos permisibles de contaminantes en las descargas de aguas residuales en aguas y bienes nacionales. Para el arsénico, los valores establecidos se observan en la tabla 4 (SEMARNAT, 1996).

Tabla 4. Límites máximos permisibles para arsénico en descargas de aguas residuales y bienes nacionales (NOM-001-SEMARNAT-1996).

\begin{tabular}{|c|c|c|c|c|c|c|c|c|c|c|c|c|c|c|c|c|c|c|c|c|}
\hline & \multicolumn{6}{|c|}{ Ríos } & \multicolumn{4}{|c|}{$\begin{array}{l}\text { Embalses } \\
\text { naturales y } \\
\text { artificiales }\end{array}$} & \multicolumn{6}{|c|}{ Aguas costeras } & \multicolumn{4}{|c|}{ Suelo } \\
\hline \multirow[t]{2}{*}{ 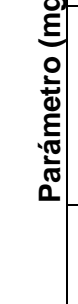 } & \multicolumn{2}{|c|}{ 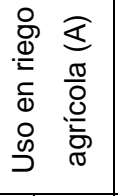 } & \multicolumn{2}{|c|}{ 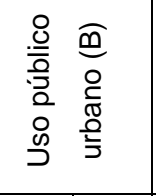 } & \multicolumn{2}{|c|}{ 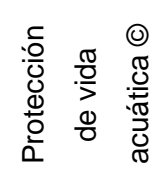 } & \multicolumn{2}{|c|}{ 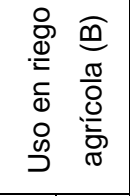 } & \multicolumn{2}{|c|}{ 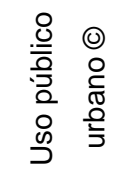 } & \multicolumn{2}{|c|}{ 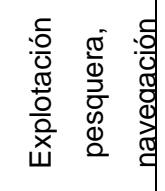 } & \multicolumn{2}{|c|}{ 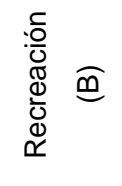 } & \multicolumn{2}{|c|}{ 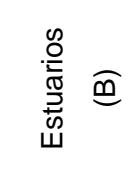 } & \multicolumn{2}{|c|}{ 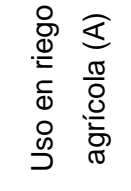 } & \multicolumn{2}{|c|}{ 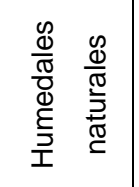 } \\
\hline & 님 & $a$ & $\sum_{0}$ & $a$ & $\sum_{0}$ & a & $\sum_{0}$ & $a$ & $\sum_{0}$ & $a$ & $\sum_{0}$ & a & $\sum_{0}$ & $a$ & $\sum_{0}$ & $a$ & $\sum_{0}$ & $a$ & $\sum_{0}$ & a \\
\hline 岛 & $\stackrel{\sim}{\circ}$ & : & ó & $\stackrel{N}{0}$ & $\dot{0}$ & בֶּ & $\stackrel{N}{0}$ & $\stackrel{\nabla}{\circ}$ & o. & $\stackrel{N}{0}$ & $\overline{0}$ & $\overbrace{}^{2}$ & ִָ. & $\stackrel{+}{0}$ & $\overline{0}^{\circ}$ & $\stackrel{\sim}{\Im}$ & ㅇ. & ț & $\overline{0}$ & בo \\
\hline
\end{tabular}

P.M. = Promedio mensual, P.D.= Promedio diario, (A), (B) y (C) = Tipo de cuerpo receptor según la Ley Federal de Derechos. Extraída de: (N.O.M., 1996)

- NOM-002-SEMARNAT-1996: establece los límites máximos permisibles de contaminantes en las descargas de aguas residuales a los sistemas de alcantarillado urbano o municipal. En la Tabla 5, se muestran la cantidad de arsénico total permisible que van de $0.5 \mathrm{a} 1 \mathrm{mg} / \mathrm{L}$ en el punto de descarga. 
Tabla 5. Límites máximos permisibles de contaminantes en las descargas de aguas residuales a los sistemas de alcantarillado.

\begin{tabular}{|c|c|c|c|}
\hline \multicolumn{2}{|c|}{ Límites Máximos Permisibles } \\
\hline $\begin{array}{c}\text { Parámetro (mg/L } \\
\text { excepto cuando se } \\
\text { especifique otro) }\end{array}$ & Promedio Mensual & Promedio Diario & Instantáneo \\
\hline Grasas y Aceites & 50 & 75 & 100 \\
\hline $\begin{array}{c}\text { Sólidos } \\
\text { sedimentables } \\
\text { (mg/L) }\end{array}$ & 5 & 7.5 & 10 \\
\hline Arsénico total & 0.5 & 0.75 & 1 \\
\hline
\end{tabular}

- NOM-003-SEMARNAT-1996: establece los límites máximos permisibles de contaminantes para las aguas tratadas que se reúsen en servicio al público (tabla 6).

Tabla 6. Límites máximos permisibles de contaminantes en aguas tratadas

\begin{tabular}{|c|c|c|c|}
\hline \multicolumn{2}{|c|}{ Límites Máximos Permisibles } \\
\hline $\begin{array}{c}\text { Parámetro (mg/L } \\
\text { excepto cuando se } \\
\text { especifique otro) }\end{array}$ & Promedio Mensual & Promedio Diario & Instantáneo \\
\hline Grasas y Aceites & 50 & 75 & 100 \\
\hline $\begin{array}{c}\text { Sólidos } \\
\text { sedimentables } \\
\text { (mg/L) }\end{array}$ & 5 & 7.5 & 10 \\
\hline Arsénico total & 0.5 & 0.75 & 1 \\
\hline
\end{tabular}




\subsubsection{Casos de estudio de presencia de arsénico}

A nivel mundial se han identificado acuíferos que presentan concentraciones de arsénico por encima de $0.05 \mathrm{mg} / \mathrm{L}$. Las ocurrencias más notables son en partes de Argentina, Bangladesh, Chile, China, Hungría, India (al oeste de Bengala), México, Rumanía, Taiwán, Vietnam y diversas partes de Estados Unidos (Cortés et al., 2010).

Las concentraciones más altas de arsénico han sido detectadas en aguas subterráneas como resultado de la fuerte interacción agua-roca y las condiciones físicas y geoquímicas que favorecen la movilización y acumulación de As (Smedley \& Kinniburgh, 2002).

En México, el agua subterránea representa la única fuente permanente de abastecimiento para la mayoría de las zonas áridas y semiáridas. En algunos de los acuíferos de estos sitios, se han detectado contaminantes de origen natural como fluoruros, hierro, manganeso y arsénico, especialmente en el norte y centro del país, donde predomina el clima semiárido (Smedley \& Kinniburgh, 2002). En la parte norte y centro del país, principalmente, se han registrado altas concentraciones de arsénico debido a características geológicas, zonas hidrotermales o yacimientos mineros (figura 5) (Leal \& Gelover, 2003). 


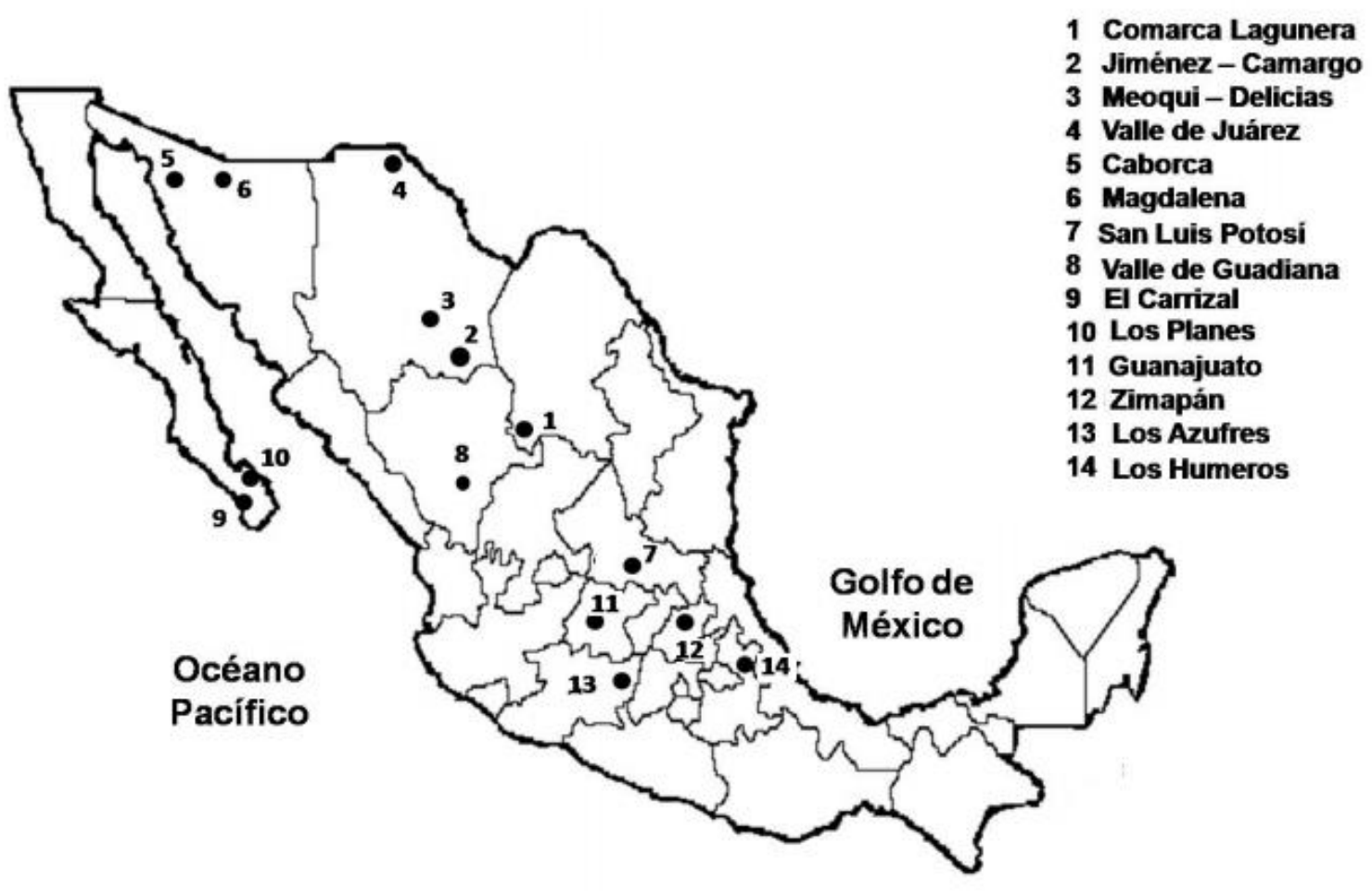

Figura 5. Lugares en México con presencia de arsénico en agua para consumo humano

Fuente: Cortés et al., 2010

Se han identificado tres ambientes hidrogeológicos donde las concentraciones de arsénico superan los $0.025 \mathrm{mg} / \mathrm{L}$ :

- Acuíferos aluviales del norte y centro de México

- Áreas mineras, distribuidas en distintas partes del país.

- Aguas geotérmicas asociadas a rocas volcánicas en el centro del país.

En las planicies aluviales del norte y centro de México, se tiene presencia de As en ambientes áridos oxidantes. Las áreas afectadas incluyen porciones de los estados de Coahuila y Durango (Comarca Lagunera), así como los de Chihuahua, Sonora y San Luis Potosí (Leal \& Gelover, 2003). 
En la región de la Comarca Lagunera, localizada en los estados de Coahuila y Durango, las condiciones del agua subterránea que abastece a la población, son predominantemente oxidantes. Del Razo (1990) reporta valores de pH entre 6.3 y 8.9 y concentraciones de arsénico en el intervalo de $0.008-0.624 \mathrm{mg} / \mathrm{L}$. Sus estudios revelan que la zona presenta un caso de arsenicismo crónico.

Entre las áreas mineras con problemas por contaminación de As, se encuentran los estados de Baja California Sur, Hidalgo, Guanajuato y San Luis Potosí.

El Valle de Zimapán, en el estado de Hidalgo, que ha sido un distrito minero desde el siglo XVII, se han reportado concentraciones de arsénico de hasta $0.437 \mathrm{mg} / \mathrm{L}$, en algunas norias ha sido relacionada a la contaminación por jales presentes en la superficie (Armienta et al., 2001). Mientras que, en el sureste de Baja California Sur, se localizan los distritos mineros de San Antonio-El Triunfo, explotados desde finales del siglo XVIII. En las aguas subterráneas de las zonas de Carrizal y Los Planes, cercanas a los distritos mineros, se han reportado altas concentraciones de As, identificando como fuentes de contaminación los depósitos de mena que contienen arsenopirita y minerales secundarios que contienen As (Castro de Esparza, 2006).

En las regiones geotérmicas, asociadas a la Franja Volcánica Transmexicana (FVTM), se tienen principalmente dos campos geotérmicos con contaminación de As: Los Azufres, en el estado de Michoacán con concentraciones reportadas de hasta $0.8 \mathrm{mg} / \mathrm{L}$ (Birkle \& Merkel, 2000) y los Humeros, en el estado de Puebla con concentraciones de $0.736 \mathrm{mg} / \mathrm{L}$ (González Partida et al., 2001).

En Matehuala, San Luis Potosí, la contaminación por As ha sido ampliamente estudiada. Se reporta un alto grado de contaminación por As en suelo, relacionado 
a la dispersión de desechos mineros a través de flujos de agua; $y$, en menor grado, la contaminación se relaciona a la dispersión eólica de partículas provenientes de una antigua planta de fundición (Razo et al., 2004). También se han reportado concentraciones de arsénico, en aguas superficiales y subterráneas, de hasta 158 $\mathrm{mg} / \mathrm{L}$ de As cuya movilidad se atribuye a la disolución de arseniatos de calcio; la concentración más alta se registra en un punto de muestreo conocido como Club de Tiro (CT) (Martínez Villegas, et al., 2013). En esta zona, la fuente de contaminación por As está relacionada con residuos metalúrgicos de una antigua planta de fundición.

A partir del punto Club de Tiro, a una distancia de $1.3 \mathrm{~km}$, el flujo de agua entra al Complejo hidráulico Matehuala-Cerrito Blanco, llegando así al siguiente punto de muestreo, TR (Instituto Tecnológico Regional de Matehuala), donde se observa un importante decrecimiento en la concentración de As, atribuido a una atenuación natural. El agua del complejo hidráulico Matehuala-Cerrito Blanco es utilizada para irrigación de campos agrícolas y con fines recreativos (canotaje) en una laguna localizada dentro de un parque (Martínez Villegas, et al., 2013). A pesar de que esta agua no es para consumo, si lo es para uso humano, estando en contacto a través de actividades como la agricultura y la recreación por lo que podría llegar a generar problemas de salud; por ello, es importante establecer un método que ayude a solucionar los problemas de contaminación por As en agua de la zona.

Finalmente, con el objetivo de determinar el grado de exposición de la población de Matehuala al As, en 2015, del Río \& de Jesús determinan la concentración de As en el cabello de la población expuesta y utilizarlo como biomarcador de exposición para determinar si la población presenta acumulación de As que supere $1 \mathrm{mg} / \mathrm{kg}$, de acuerdo al valor guía de la Agencia para Sustancias Tóxicas y Registro de Enfermedades (ATSDR). Los resultados mostraron presencia de As en el cabello de la población analizada, debido a exposición por inhalación y contacto dérmico (del Río, L. \& de Jesús, A. 2015; Gómez et al., 2020). 
A continuación, se describen las tecnologías más utilizadas para la remoción de As en agua.

\subsubsection{Tecnologías de remoción de arsénico en agua}

Las características fisicoquímicas y microbiológicas del agua y los materiales disponibles en la región de estudio son un factor importante para elegir el método de remoción más apropiado. La selección del método dependerá de la especiación del arsénico, la composición química del agua, los volúmenes a ser tratados y el grado de sofisticación que pueda ser aplicado (Litter et al., 2008).

La remoción de arsénico depende de sus formas presentes en el agua y del grado de oxidación del mismo. La remoción de los arseniatos $[\mathrm{As}(\mathrm{V})]$, es mayor en comparación con la de arsenitos [As (III)], independientemente de la técnica utilizada. Lo anterior implica la necesidad de oxidación preliminar del agua antes de su tratamiento para mejorar la eficiencia de remoción (Armienta et al., 2001).

\subsubsection{Tecnologías emergentes}

Cuando los métodos convencionales de remoción de arsénico no son viables económicamente es posible optar por tecnologías nuevas que buscan minimizar los costos de inversión, operación y mantenimiento. Las tecnologías convencionales (coagulación-coprecipitación, adsorción, ósmosis inversa, etc.) pueden ser aplicadas a escala media o grande. Sin embargo, para el tratamiento en pequeñas comunidades se pueden aplicar métodos más económicos (Petkova Simeonova V., 1999).

En el trabajo de Litter et al., (2010), se presentan todas las técnicas aplicables al tratamiento de agua, haciendo especial énfasis en métodos económicos como lo son el uso de adsorbentes naturales, tecnologías basadas en luz solar o tratamientos biológicos como una manera de remediar la contaminación de arsénico 
en agua. Algunas de estas tecnologías son la adaptación de métodos convencionales como coagulación y filtración, o adsorción con el uso de materiales económicos.

Sabbatini et al., (2009-2010), detalla la síntesis de materiales novedosos y económicos, que consisten en nanopartículas de óxido de hierro depositadas en tubos de alúmina porosos, constituyendo así membranas cerámicas para la remoción de arsénico en agua.

Cuando los métodos convencionales resultan inadecuados para alcanzar el grado de pureza en agua requerido por la normativa vigente, países industrializados recurren al uso de los llamados Procesos Avanzados de Oxidación (PAOs). Los métodos pueden usarse solos o combinados entre ellos o con métodos convencionales. Los PAOs se basan en procesos fisicoquímicos capaces de producir cambios profundos en la estructura química de los contaminantes. Estos procesos no generan subproductos tóxicos (Doménech et al., 2001).

\subsubsection{Tecnologías convencionales}

Las tecnologías más usadas incluyen:

\section{Oxidación:}

Por medio de la oxidación no es posible remover arsénico en agua debido a que es solamente un pre tratamiento requerido en algunas tecnologías. La eficiencia de remoción de As (V) comparada con la de As (III) justifica la oxidación previa al tratamiento. La oxidación de As (III) a As(V) se produce de acuerdo a las siguientes reacciones:

$$
\begin{aligned}
& \mathrm{H}_{3} \mathrm{AsO}_{3}+\mathrm{H}_{2} \mathrm{O}+\left[\mathrm{O}_{x}\right] \leftrightarrow \mathrm{H}_{2} \mathrm{AsO}_{4}^{-}+3 \mathrm{H}^{+} \\
& \mathrm{H}_{3} \mathrm{ASO}_{3}+\mathrm{H}_{2} \mathrm{O}+\left[\mathrm{O}_{x}\right] \leftrightarrow \mathrm{HAsO}_{4}^{-2}+4 \mathrm{H}^{+}
\end{aligned}
$$


Por ello, es conveniente oxidar los componentes arsenicales presentes en solución, previo a cualquier tratamiento de remoción. El arsénico trivalente puede oxidarse por medio de agentes químicos como: cloro gaseoso, hipoclorito, ozono, permanganato, peróxido de hidrógeno, óxidos de manganeso y el reactivo de Fenton $\left(\mathrm{H}_{2} \mathrm{O}_{2} / \mathrm{Fe}^{2+}\right)$ (Litter \& Igallinella, 2010).

\section{Coagulación, floculación, precipitación y filtrado:}

Las especies de arsénico presentes en solución, al ser electronegativas, se adsorben a partículas insolubles de tamaño coloidal (arcillas activadas o naturales) formando una suspensión coloidal (Litter \& Igallinella, 2010).

La primera etapa del proceso es la coagulación que se efectúa agregando coagulantes que cambian las propiedades de las cargas superficiales permitiendo que las partículas se aglomeren formando flóculos. En esta segunda etapa de floculación, los flóculos por el aumento de masa pueden precipitar, siendo así removido el As en la etapa de sedimentación (Litter \& Igallinella, 2010).

Los coagulantes más comunes son:

- Sales metálicas: sulfato de aluminio, hidróxido de aluminio o de cobre

- Sales de hierro: cloruro férrico, sulfato férrico, hidróxido férrico.

- Cal o cal hidratada. Opera en un intervalo de pH mayor a 10.5. Este proceso se conoce como ablandamiento con cal y depende fuertemente del valor de $\mathrm{pH}$.

\section{Adsorción en alúmina activada:}

La alúmina activada $\left(\mathrm{Al}_{2} \mathrm{O}_{3} / \mathrm{Al}(\mathrm{OH})_{3}\right)$, es un material constituido principalmente por óxido de aluminio. Es un compuesto anfótero que se regenera mediante soluciones de $\mathrm{NaOH}$ que se hacen pasar sobre la superficie del adsorbente para 
posteriormente hacer pasar una solución de $\mathrm{H}_{2} \mathrm{SO}_{4}$ que se encargará de protonar dicha superficie. Este material remueve entre 80 y $50 \%$ de las especies de arsénico. Este método puede aplicarse al tratamiento de grandes volúmenes de lechos de agua antes de que sea necesaria la regeneración (Litter \& Igallinella, 2010).

\section{4. Ósmosis inversa:}

La ósmosis inversa se produce cuando se ejerce presión para invertir el flujo osmótico normal. Este proceso constituye la base para tratar el agua cruda con presencia de arsénico. Así, aplicando presión el agua es forzada a pasar a través de una membrana semipermeable desde el lado más concentrado (agua cruda), hacia el lado menos concentrado (agua tratada), quedando retenidos en la membrana por su tamaño los iones del arsénico (Litter \& Igallinella, 2010).

\section{Procesos biológicos y de fitorremediación:}

En un proceso biológico se emplean microorganismos capaces de remover contaminantes mediante actividades metabólicas como la biometilación, coprecipitación y procesos de óxido-reducción en la biomasa o mediante el uso de biofiltros. Se han reportado algunos casos de remoción de As mediante procesos biológicos:

- En 2007, Choong reporta un $80 \%$ de remoción de As mediante el uso de bacterias sulfato reductoras

- En 2010, Wolf-Simon y colaboradores reportaron presencia de bacterias de la familia halomonadaceas, en un lago en California. Estas bacterias incorporan el As en su ADN, sustituyendo el fósforo, metabolizando así el As.

Por otro lado, la fitorremediación es un proceso que tiene por objeto descontaminar suelos o agua mediante el uso de especies vegetales encargadas de extraer, 
metabolizar y acumular los contaminantes presentes en el ambiente. Se han realizado diversos estudios en plantas capaces de hiperacumular metales y metaloides (Nriagu, 1994).

Se ha estudiado la eficiencia de remoción de As en algunas especies de helechos: Pteris vittata, Pteris cretica y Fastuca orthophylla, obteniendo un porcentaje de remoción de 90\% (Litter \& Igallinella, 2010).

\section{Intercambio iónico:}

El intercambio iónico es un proceso basado en la transferencia de materia fluidosólido (Nevárez, 2009). Durante el proceso, ocurre una reacción química en la que los iones móviles hidratados de un sólido son intercambiados por iones de igual carga provenientes de un fluido (Figura 7) (Choi et al., 2002).

Los primeros productos empleados como intercambiadores iónicos en la industria, fueron las zeolitas inorgánicas de origen natural; después se introdujeron los intercambiadores iónicos orgánicos hechos a base de productos naturales sulfonados como el carbón y la lignita. En la actualidad, se utilizan resinas sintéticas, en su mayoría de poliestireno-divinilbenceno, conocidas como resinas de intercambio iónico (Pérez-Moreno et al., 2006).

Las resinas de intercambio iónico son sustancias granuladas o esféricas insolubles en agua, compuestas por grupos polares, ácidos o básicos; estos grupos son incorporados a una matriz polimérica reticulada por la acción de un agente entrecruzante. Pueden reaccionar como ácidos o bases, con la peculiaridad de tener cationes o aniones que, por su capacidad de migración, toman parte de la reacción química (Nevárez, 2009). 
La concentración de grupos polares en la resina es un número finito, por lo tanto, éstas tienen una capacidad de intercambio definida. Una ventaja importante que poseen las resinas de intercambio iónico es su capacidad para regenerarse; esto mediante el tratamiento con una solución (ácido o base, según el tipo de resina y su uso) que desplace los iones retenidos por la resina, reemplazándolos por los iones que originalmente estaban presentes en la resina (Nevárez, 2009).

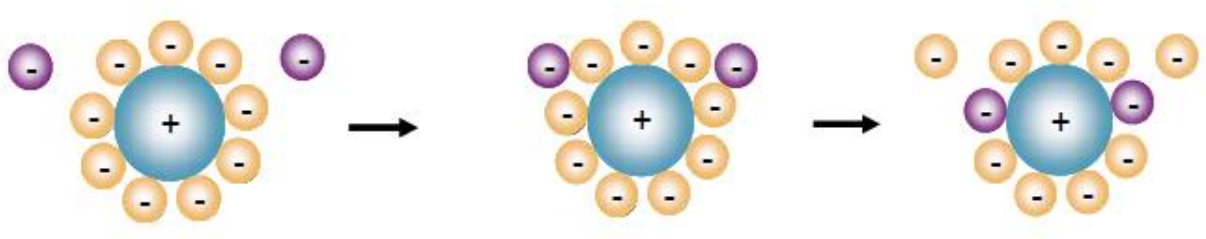

Figura 6. representación del proceso de intercambio iónico

\section{Electrodiálisis}

La electrodiálisis se caracteriza por el uso de membranas selectivas de iones y un campo eléctrico, ortogonal a las membranas. Esta técnica permite separar iones en solución. Normalmente, una unidad de electrodiálisis contiene membranas selectivas de aniones y cationes dispuestas alternadamente en paralelo; seguidas en los extremos, por dos electrodos, un ánodo y un cátodo que son los responsables de generar la diferencia de potencial eléctrico (Dermentzis, 2010).

Como consecuencia de la fuerza impulsora creada por el campo eléctrico y la selectividad de las membranas, los aniones en solución, migran hacia el ánodo, pasando a través de la membrana aniónica mientras que los cationes migran hacia el cátodo (Figura 8), como resultado, se tiene la concentración (compartimento concentrado) y dilución (compartimento del diluido) de la solución de alimentación en los compartimentos contiguos. Para establecer el campo eléctrico en el sistema, se recircula un electrolito en la zona de electrodos (Alvarado L., 2009). 


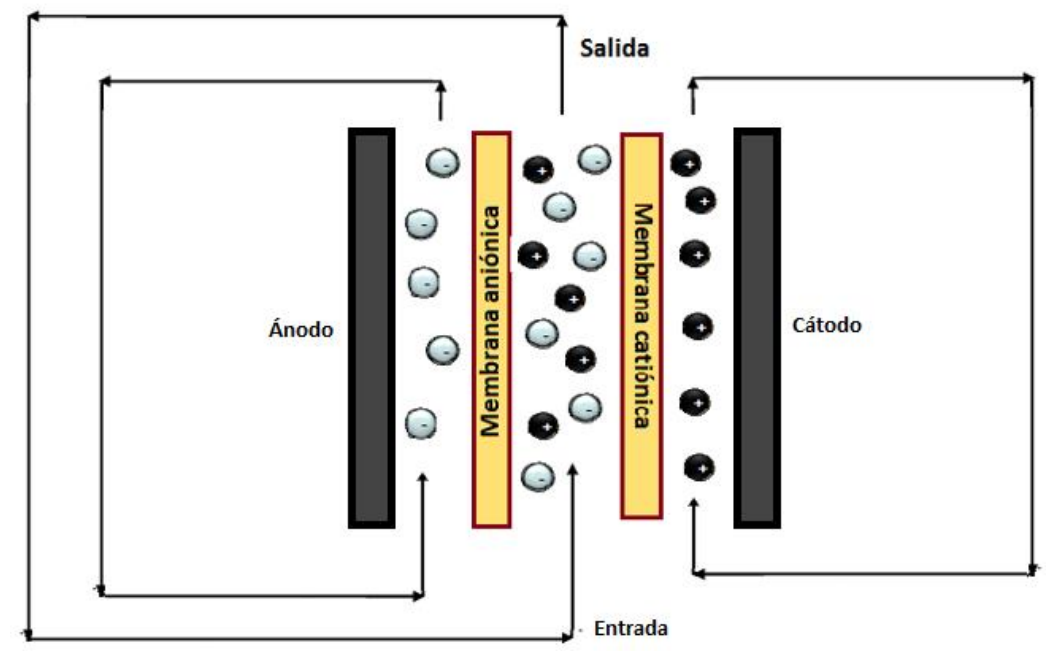

Figura 7. Representación del proceso de electrodiálisis

\section{Electrodesionización}

La electrodesionización (EDI) es una tecnología que combina las técnicas de electrodiálisis e intercambio iónico. Consiste en la eliminación de iones y especies ionizables de agua o líquidos orgánicos. Utiliza medios eléctricamente activos y un potencial eléctrico para favorecer el transporte de iones en solución (Alvarado et al., 2009).

Una celda de EDI está constituida de membranas, colocadas entre los electrodos, generando los compartimentos de diluido y concentrado (Figura 9). El compartimento central es el compartimento del diluido, en éste se empaca el lecho de resinas de intercambio iónico; las resinas proveen un medio activo, de modo que, al aplicar corriente eléctrica, comienza el transporte iónico. El lecho de resinas adsorbe e intercambia las especies iónicas; los iones adsorbidos, posteriormente serán desorbidos por la corriente eléctrica aplicada, migrando así hacia los electrodos. De esta manera se realiza el transporte de masa a través de las membranas y resinas de intercambio iónico. Al mismo tiempo, ocurre la disociación 
del agua en el interior de la celda, generando protones e hidroxilos que favorecen la regeneración "in situ” del lecho de resinas (Alvarado L., 2009).

En el presente estudio, para tratamiento de aguas contaminadas con Arsénico, se eligió la técnica de EDI como un tratamiento terciario eficiente. Esta técnica combina las técnicas de electrodiálisis e intercambio iónico, disminuyendo las desventajas individuales de cada una: polarización por concentración en electrodiálisis, que se refiere al retraso de una reacción electroquímica debido a la baja concentración de especies activas y, regeneración química de las resinas de intercambio iónico; en este proceso se producen residuos tóxicos por el uso de ácidos y bases fuertes (Alvarado L., 2009).

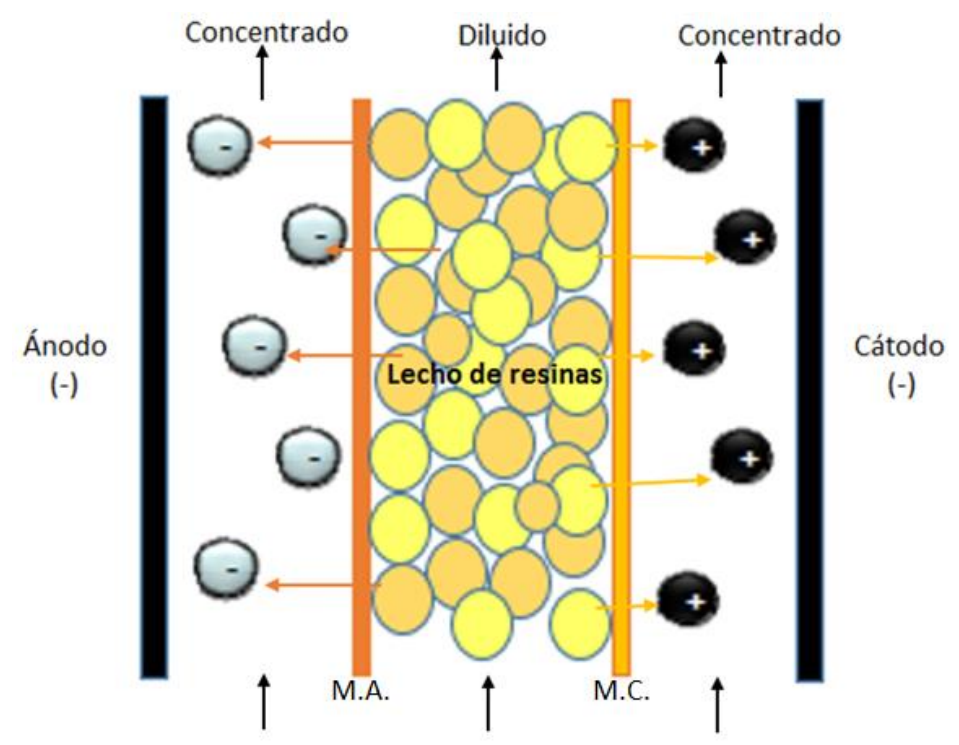

Figura 8. Representación de una celda de EDI.

M.A.: membrana aniónica; M.C.: membrana catiónica 


\subsection{Modelos de adsorción}

La adsorción es un método utilizado para el tratamiento de contaminantes disueltos. Para el escalado de este proceso se requieren modelos cinéticos y de equilibrio que describan la tendencia experimental para cada pareja adsorbatoadsorbente (Figueroa et al., 2015).

Los modelos de adsorción reproducen el comportamiento de un proceso; esto con el objetivo de calcular la velocidad de adsorción en una cinética o para el cálculo de la capacidad máxima de adsorción en una isoterma. Para ello, existen diversos modelos, algunos de los cuales se describen a continuación (Figueroa et al., 2015).

\subsubsection{Isotermas de adsorción}

Las isotermas de adsorción son modelos que relacionan la concentración en equilibrio de las especies adsorbidas en un material con la concentración en equilibrio en la solución, a una temperatura constante. Mediante el uso de esta técnica es posible conocer la capacidad de adsorción del adsorbente, estimar el grado de afinidad, un acercamiento al posible mecanismo de adsorción, algunas propiedades de la superficie, así como hacer una optimización del diseño y proceso de adsorción con el material empleado (Foo \& Hameed, 2010).

Las isotermas de adsorción son modelos que describen el comportamiento de la interacción entre adsorbato-adsorbente y proveen información sobre la capacidad del adsorbente estudiado. Entre los modelos más empleados, se encuentran: Langmuir, Freundlich y Redlich-Peterson. 


\subsubsection{Langmuir}

La isoterma de adsorción de Langmuir, originalmente desarrollada para describir la adsorción de gas en fase sólida sobre carbón activado, se ha utilizado tradicionalmente para cuantificar y contrastar el rendimiento de diferentes biosorbentes (Langmuir I. , 1916). Este modelo asume que existe un número fijo de sitios activos accesibles disponibles en la superficie del adsorbente, dichos sitios poseen la misma energía; la adsorción es por afinidad y es reversible (Vijayaraghavan et al., 2006). La ecuación para este modelo se define en la tabla 7:

Tabla 7. Ecuación de Langmuir y sus parámetros

\begin{tabular}{|l|l|}
\hline Ecuación & \multicolumn{1}{c|}{ Parámetros } \\
\hline$q_{e=\frac{a b C_{e}}{1+b C_{e}}}$ & $\begin{array}{l}\mathrm{q}_{\mathrm{e}}=\text { cantidad adsorbida por peso unitario } \\
\text { de adsorbente }(\mathrm{mg} / \mathrm{g}) \\
\mathrm{a}, \mathrm{b}=\text { constantes empíricas; siendo } \mathrm{b} \text { la } \\
\text { capacidad máxima de adsorción }(\mathrm{mg} / \mathrm{g}) \\
\mathrm{C}_{\mathrm{e}=\text { concentración de equilibrio de }} \\
\text { adsorbato en solución después de la } \\
\text { adsorción }(\mathrm{mg} / \mathrm{L})\end{array}$ \\
\hline
\end{tabular}

(Foo \& Hameed, 2010)

\subsubsection{Freundlich}

Este modelo empírico puede ser aplicado a una adsorción en multicapas con interacciones entre las moléculas adsorbidas, haciendo referencia a procesos de quimisorción (Freundlich, 1907). Se asume que el proceso de adsorción se produce por intercambio iónico (Adamson \& Gast, 1997). La ecuación para este modelo se define en la tabla 8: 
Tabla 8. Ecuación de Freundlich y sus parámetros

\begin{tabular}{|c|l|}
\hline Ecuación & \multicolumn{1}{c|}{ Parámetros } \\
\hline$q_{e}=K_{f} C e^{1 / n}$ & $q_{\mathrm{e}}=$ cantidad adsorbida por peso unitario de \\
& adsorbente $(\mathrm{mg} / \mathrm{g})$ \\
& $\mathrm{C}_{\mathrm{e}}=$ concentración de equilibrio de adsorbato \\
& en solución después de la adsorción (mg/L) \\
& $\mathrm{K}_{\mathrm{f}}, \mathrm{n}=$ constantes empíricas \\
\hline
\end{tabular}

\subsubsection{Redlich-Peterson}

Este modelo, debido a su versatilidad, permite representar un sistema de adsorción en el equilibrio para un amplio intervalo de concentraciones combinando las isotermas de Freundlich y Langmuir y consta de tres parámetros dentro de una ecuación empírica. A altas concentraciones de adsorbato en la fase líquida, se reduce a la ecuación de Freundlich; con la posibilidad de reducirse a la ecuación de Langmuir cuando $\beta=1$ (Foo \& Hameed, 2010).

La ecuación para este modelo se define en la tabla 9:

Tabla 9. Ecuación de Redlich-Petterson y sus parámetros

\begin{tabular}{|c|c|}
\hline Ecuación & Parámetros \\
\hline \multirow[t]{4}{*}{$q_{e}=\frac{A C_{e}}{1+B C_{e}^{\beta}}$} & $\begin{array}{l}\mathrm{q}_{\mathrm{e}}=\text { cantidad adsorbida por peso unitario } \\
\text { de adsorbente }(\mathrm{mg} / \mathrm{g})\end{array}$ \\
\hline & $\begin{array}{l}\mathrm{A}, \mathrm{B}=\text { constantes empíricas de Redlich- } \\
\text { Peterson (L/g y L/mg, respectivamente) }\end{array}$ \\
\hline & $\begin{array}{l}\mathrm{C}_{\mathrm{e}}=\text { concentración de equilibrio de } \\
\text { adsorbato en solución después de la } \\
\text { adsorción }(\mathrm{mg} / \mathrm{L})\end{array}$ \\
\hline & $\beta=$ exponente de Redlich-Peterson \\
\hline
\end{tabular}

(Foo \& Hameed, 2010) 


\subsubsection{Modelos cinéticos de adsorción}

Las cinéticas de adsorción se emplean para determinar el tiempo necesario para establecer las condiciones de equilibrio para el desarrollo de isotermas de adsorción, éstas describen la velocidad de adsorción del adsorbato sobre el adsorbente (Figueroa et al., 2015).

En el presente estudio, los datos experimentales se ajustan a los modelos de: pseudo-primer orden, pseudo-segundo orden y Elovich.

\subsubsection{Pseudo primer orden}

La expresión matemática correspondiente a la cinética de primer orden reversible se basa en la suposición de que a cada ion metálico se le asigna un sitio de adsorción del material adsorbente, se hace referencia a procesos de fisisorción (Pinzón-Bedoya \& Vera Villamizar, 2009), lo cual, en términos de velocidad de reacción se expresa en la siguiente ecuación como:

La ecuación para este modelo se define en la tabla 10:

Tabla 10. Ecuación para cinética de pseudo primer orden y sus parámetros

\begin{tabular}{|c|c|}
\hline Ecuación & Parámetros \\
\hline$q_{t}=q_{e}\left(1-e^{k_{1} t}\right)$ & $\begin{array}{l}\mathrm{q}_{\mathrm{e}}=\text { capacidad de adsorción en el } \\
\text { equilibrio }[\mathrm{mg} / \mathrm{g}] \\
\mathrm{q}_{\mathrm{t}}=\text { capacidad de adsorción al tiempo } \mathrm{t} \\
{[\mathrm{mg} / \mathrm{g}]} \\
\mathrm{t}=\text { tiempo }(\mathrm{min})\end{array}$ \\
\hline & $\begin{array}{l}\mathrm{k}_{1}=\text { constante de rapidez de adsorción de } \\
\text { pseudo primer orden }[1 / \mathrm{min}]\end{array}$ \\
\hline
\end{tabular}

(Pinzón-Bedoya \& Vera Villamizar, 2009) 


\subsubsection{Pseudo segundo orden}

Este modelo fue desarrollado por Ho y McKay, dándolo a conocer en 1999. En él se supone que el adsorbato se adsorbe en dos sitios activos de la biomasa. En este modelo se consideran procesos de quimisorción en donde la velocidad de reacción de adsorción depende de los sitios energéticamente heterogéneos sobre el adsorbente (Hamadi et al., 2001).

La ecuación para este modelo se define en la tabla 11:

Tabla 11. Ecuación para cinética de pseudo segundo orden y sus parámetros

\begin{tabular}{|c|c|}
\hline Ecuación & Parámetros \\
\hline $\begin{array}{r}q_{t}=\frac{k_{2} q_{e^{2}} t}{1+k_{2} q_{e} t} \\
\text { (Hamadi et al., 2001) }\end{array}$ & $\begin{array}{l}\mathrm{q}_{\mathrm{e}}=\text { capacidad de adsorción en el equilibrio } \\
{[\mathrm{mg} / \mathrm{g}]} \\
\mathrm{q}_{\mathrm{t}}=\text { capacidad de adsorción al tiempo } \mathrm{t}[\mathrm{mg} / \mathrm{g}] \\
\mathrm{t}=\text { tiempo }(\mathrm{min}) \\
\mathrm{k}=\text { constante de rapidez de adsorción de } \\
\text { pseudo segundo orden }[1 / \mathrm{min}]\end{array}$ \\
\hline
\end{tabular}

\subsubsection{Elovich}

Este modelo, de aplicación general en procesos de quimisorción, supone que los sitios activos del adsorbente son heterogéneos y por ello exhiben diferentes energías de activación, basándose en un mecanismo de reacción de segundo orden para un proceso de reacción heterogénea. Este modelo ha mostrado resultados satisfactorios en la identificación del mecanismo controlante en procesos de adsorción de un soluto en fase líquida a partir de un sólido adsorbente (Pinzón-Bedoya \& Vera Villamizar, 2009).

La ecuación para este modelo se define en la tabla 12: 
Tabla 12. Ecuación de Elovich y sus parámetros

\begin{tabular}{|c|c|}
\hline Ecuación & Parámetros \\
\hline$q_{t}=\frac{1}{\beta} \ln (\beta \alpha t)$ & $\begin{array}{l}\mathrm{q}=\text { capacidad de adsorción al tiempo } \mathrm{t}[\mathrm{mg} / \mathrm{g}] \\
\mathrm{t}=\text { tiempo }(\mathrm{min}) \\
\alpha=\text { rapidez de adsorción inicial }[\mathrm{mg} / \mathrm{gmin}] \\
\beta=\text { constante de desorción }[\mathrm{g} / \mathrm{mg}]\end{array}$ \\
\hline
\end{tabular}

(Pinzón-Bedoya \& Vera Villamizar, 2009).

\subsection{Técnicas para cuantificar arsénico}

\subsubsection{Espectrofotometría de absorción atómica}

Dentro de los métodos espectrométricos de análisis para identificar y cuantificar elementos presentes en distintas matrices, se encuentra la espectrometría óptica atómica. Este método convierte elementos presentes en una muestra en átomos o iones elementales en estado gaseoso por medio de un proceso denominado atomización (Litter et al., 2009).

La técnica de espectrofotometría se basa en la ley de Lambert-Beer. Los electrones de los átomos en el atomizador pueden ser promovidos a orbitales más altos por un instante mediante la absorción de una cantidad de energía (luz de una determinada longitud de onda) (Litter et al., 2009).

Los dos métodos más utilizados para lograr la atomización de la muestra incluyen la aplicación de una flama (empleada en la absorción atómica con flama, FAAS) o el uso de energía electrotérmica en un horno de grafito (Litter \&Ingallinella, 2010). La técnica de espectrofotometría de absorción atómica con horno de grafito (GFAAS), a diferencia de la técnica de flama, permite bajar los límites de detección al intervalo de partes por billón (ppb); este proceso ocurre en el interior de un 
cilindro de grafito donde la muestra se introduce a través de un orificio ubicado en la parte central del cilindro (Litter et al., 2009).

\subsubsection{Espectrofotometría de absorción atómica con horno de grafito (GFAAS)}

El principio del método se basa en la absorción de luz por parte de un elemento en estado atómico. La longitud de onda a la cual la luz se absorbe es específica de cada elemento (por ello, es necesario utilizar una lámpara específica para cada elemento). Como resultado de la absorción, se mide la atenuación de la intensidad de la luz, siendo la cantidad de radiación absorbida proporcional a la cantidad de átomos del elemento presente. El método involucra fundamentalmente 2 procesos: la atomización de la muestra y la absorción de radiación proveniente de una fuente por los átomos libres (Mañay, Clavijo, \& Díaz, s.f.).

El tratamiento de la muestra hasta la atomización comprende las siguientes etapas:

1. Secado: la muestra es inyectada dentro del tubo de grafito, posteriormente, el tubo se calienta a una temperatura inferior al punto de ebullición del solvente (usualmente entre 80 a $180^{\circ} \mathrm{C}$ ) con el objetivo de lograr la evaporación del disolvente. (Mañay, Clavijo, \& Díaz, s.f.).

2. Calcinado: con el incremento de temperatura, será posible remover la mayor cantidad de materia orgánica de la muestra, sin pérdida del analito. La temperatura de calcinación varía en el intervalo de 350 a $1600 \stackrel{\circ}{\circ}$. Durante esta etapa, el material sólido se descompone mientras que los materiales refractarios permanecen inalterados (Mañay, Clavijo, \& Díaz, s.f.).

3. Atomización: el horno se calienta rápidamente temperaturas entre los 1800 y $2800{ }^{\circ} \mathrm{C}$ con el objetivo de vaporizar los residuos que quedan en el paso anterior. En este proceso, se destruye la matriz y los átomos quedan libres en el camino óptico. La temperatura de atomización dependerá de la 
volatilidad de cada elemento. En este paso, se mide la absorbancia (Mañay, Clavijo, \& Díaz, s.f.).

4. Usualmente se agrega una cuarta etapa para limpieza del horno, utilizando una temperatura superior a la temperatura de atomización. Cuanto mejor sea la separación de los elementos concomitantes del analito, mejor será la atomización y se reducirán las interferencias en la determinación (Litter et al., 2008).

\subsubsection{Técnica de espectroscopia de emisión atómica}

La espectroscopia de emisión atómica, se basa en la producción y detección de espectros de línea emitidos durante el proceso de excitación de los átomos de una muestra, este proceso es provocado por una fuente de energía externa que transfiere a los átomos al estado de plasma, provocando la emisión de radiación electromagnética (Litter et al., 2009).

Los espectros de líneas son específicos de cada elemento y la adecuada selección de una línea y su aislamiento por medio de un sistema dispersivo permite al analista verificar la presencia de un elemento y determinar su concentración (Litter et al., 2008).

\subsubsection{Espectroscopia de emisión atómica de plasma por microondas (MP-AES)}

En la técnica de espectroscopia de emisión atómica de plasma por microondas, se utiliza plasma de nitrógeno para desolvatar, atomizar y excitar los átomos de la muestra líquida que se han nebulizado en ella. El plasma de nitrógeno es más caliente (hasta $5.000^{\circ} \mathrm{K}$ ) que la llama de aire-acetileno utilizada en absorción atómica con flama. La emisión atómica es bastante fuerte para la mayoría de los elementos, lo que supone una capacidad de detección mejorada y un intervalo dinámico lineal con respecto a la absorción atómica con flama (Litter et al., 2009). 
La intensidad de la luz emitida se mide mediante una detección óptica en las longitudes de onda características de los elementos que se desean analizar.

EI MP-AES trabaja con nitrógeno obtenido del aire utilizando un generador de nitrógeno.(Agilent, 2018)

En esta técnica, la fuente de plasma por microondas excitada magnéticamente proporciona unos límites de detección óptimos en comparación con los espectrómetros de absorción atómica (Agilent, 2018).

\subsection{Estudios de remoción de As por EDI}

La remoción de especies de arsénico en agua por electrodesionización, es una técnica que ha sido escasamente explorada. Los casos que han sido reportados, se describen a continuación:

- Lee y colaboradores (2017): realizaron experimentos de remoción de As en una celda de tres compartimentos. Para ello, utilizaron una solución de arseniato de sodio heptahidratado a una concentración de $10 \mathrm{mg} / \mathrm{L}$. Se utilizó un lecho mixto de resina en proporción 1:1 como capacidad de intercambio total. Se utilizaron potenciales de 0.8 a $5.2 \mathrm{~V}$, con un aumento de $0.2 \mathrm{~V}$ con una retención de tres horas para investigar el nivel de saturación de la celda. En este estudio se compara la eficiencia entre dos celdas; la primera: una celda con la que se han realizado diversas pruebas a diferentes potenciales durante un periodo de 200 horas; $y$, la segunda: una celda recién preparada. Finalmente, se comprueba que la eficiencia de remoción depende del voltaje (alto voltaje, mayor remoción), el tiempo que ha sido utilizada la celda (edad de la celda) y el nivel de saturación.

- Ortega y colaboradores (2017): en este caso se utilizó una celda de cinco compartimientos para pruebas de remoción de As por electrodesionización. El compartimiento central fue delimitado con membranas aniónicas y 
empacado con lecho de resinas aniónicas. Los compartimientos de enjuague fueron delimitados con membranas catiónicas. Se utilizaron diversas concentraciones de As: 2.1 , 5.0, 6.9, 10, 13.5 y $15.0 \mathrm{mg} / \mathrm{L}$ y de potencial de celda: 5, 10, 15 y 20V. Se empleó un ánodo de Ti/Pt y un cátodo de acero inoxidable. La concentración final de estos experimentos fue $<10 \mu \mathrm{g}$-1 en un tiempo de 400 minutos.

- Gutiérrez-López (2018): para las pruebas de remoción de As por EDI, se utilizaron dos resinas aniónicas: Amberlite IRA-900 de Sigma Aldrich y ASM10-HP de Resintech. Se trabajó con una celda de 3 compartimientos. Cada resina aniónica (Amberlite IRA-900) fue empacada junto con una resina catiónica (Amberlite IR-120) de Sigma Aldrich en proporción 1:1. En este estudio, bajo las condiciones experimentales mencionadas, no fue posible remover As por debajo de $0.025 \mathrm{mg} / \mathrm{L}$ (máximo permisible establecido en la NOM-127-SSA1-1994). De acuerdo con los resultados obtenidos, la resina Amberlite IRA-900 es la mejor opción para su uso en electrodesionización debido a su continua regeneración. 


\title{
Capítulo 2
}

\author{
Hipótesis
}

Esperando que los fenómenos fisicoquímicos asociados al arsénico en el acuífero de Matehuala sobrepasan los valores normados, desarrollar una metodología para la remoción de este contaminante. 


\section{Capítulo 3}

\section{Objetivos}

\subsection{Objetivo general}

Determinar la especiación de arsénico en los puntos conocidos como Club de Tiro y Tecnológico Regional utilizando modelación hidrogeoquímica y datos de literatura, así como determinar el carácter hidrogeoquímico del agua contaminada de Matehuala. Finalmente, analizar la eficiencia del proceso de electrodesionización removiendo arsénico en agua sintética para su posible aplicación en campo.

\subsection{Objetivos particulares}

1. Realizar modelación hidrogeoquímica directa con base en datos experimentales de concentración de arsénico en agua, obtenidos "in situ" por Matínez-Villegas y colaboradores, y establecer la química del agua entre los puntos de muestreo (CT y TR): elementos mayoritarios, potencial óxido-reducción, $\mathrm{pH}$, conductividad eléctrica y dureza; con el fin de determinar la especiación del arsénico en el sitio de estudio y tomarla en cuenta para el proceso de electrodesionización.

2. Determinar isoterma y cinética de adsorción para la resina aniónica Amberlite IRA900

3. Construir una celda de electrodesionización de tres compartimentos.

4. Analizar la eficiencia de remoción de arsénico en agua, utilizando una celda de electrodesionización a diferentes condiciones, de concentración de arsénico y lecho de resinas (lecho mixto y lecho aniónico). 


\section{Capítulo 4}

\section{Materiales y métodos}

\subsection{Base de datos utilizada en modelamiento hidrogeoquímico}

La base de datos fisicoquímicos de agua utilizados en el modelamiento hidrogeoquímico provienen del estudio realizado por Martínez-Villegas et al., 2013, en donde se realizó una campaña de muestreo con duración de 12 meses, iniciando en septiembre de 2008 y finalizando en agosto de 2009. En campo se midieron los siguientes parámetros: temperatura, $\mathrm{pH}$, potencial redox (Eh), oxígeno disuelto, conductividad eléctrica y alcalinidad, mientras que en el laboratorio se determinaron cationes y aniones mayoritarios, además del arsénico. En 2013, Martínez-Villegas y colaboradores determinan las fuentes de contaminación y los mecanismos de movilidad del As. Los resultados muestran que la disolución de arseniatos de calcio en residuos de una antigua fundición, son los responsables de la contaminación por As en agua. Además, encontraron que la disponibilidad del ion calcio controla la movilidad del As a través de la precipitación de arseniatos de calcio. En el presente, se utilizaron datos para el modelamiento de dos puntos de muestreo (obtenidos por Martínez-Villegas., et al 2013) que comprenden la variabilidad espacial que caracteriza al sistema; el primero, conocido como el Club de Tiro (CT) y el segundo punto, el Instituto Tecnológico Regional de Matehuala (TR).

Los datos experimentales obtenidos durante la campaña de muestreo de 2013, señalan que, espacialmente, la concentración de arsénico presenta un decrecimiento del punto Campo de Tiro (CT) al punto Instituto Tecnológico Regional de Matehuala (TR). En la figura 9a se muestra un esquema de la zona de 
estudio, donde el punto A corresponde al Club de Tiro y el punto B al Tecnológico Regional de Matehuala, al final del canal se localiza la laguna de Cerrito Blanco. En la figura 9b se muestra la ubicación geográfica de los puntos de muestreo (CT y TR) y la laguna de Cerrito Blanco. El punto CT es el más contaminado, su concentración más alta se registra en el mes de agosto con $158.50 \mathrm{mg} / \mathrm{L}$ de As; esto decrece en el punto TR, donde la concentración máxima, también en el mes de agosto, es de $19.59 \mathrm{mg} / \mathrm{L}$ de As. Es importante mencionar que tanto la concentración de As como la de otros elementos mayoritarios se mantiene prácticamente constante a partir del Tecnológico Regional hasta la laguna donde el agua es utilizada con fines recreativos y de irrigación (Martínez et. al., 2013), por lo que es de esperar que la especiación química del elemento de interés no cambie. 


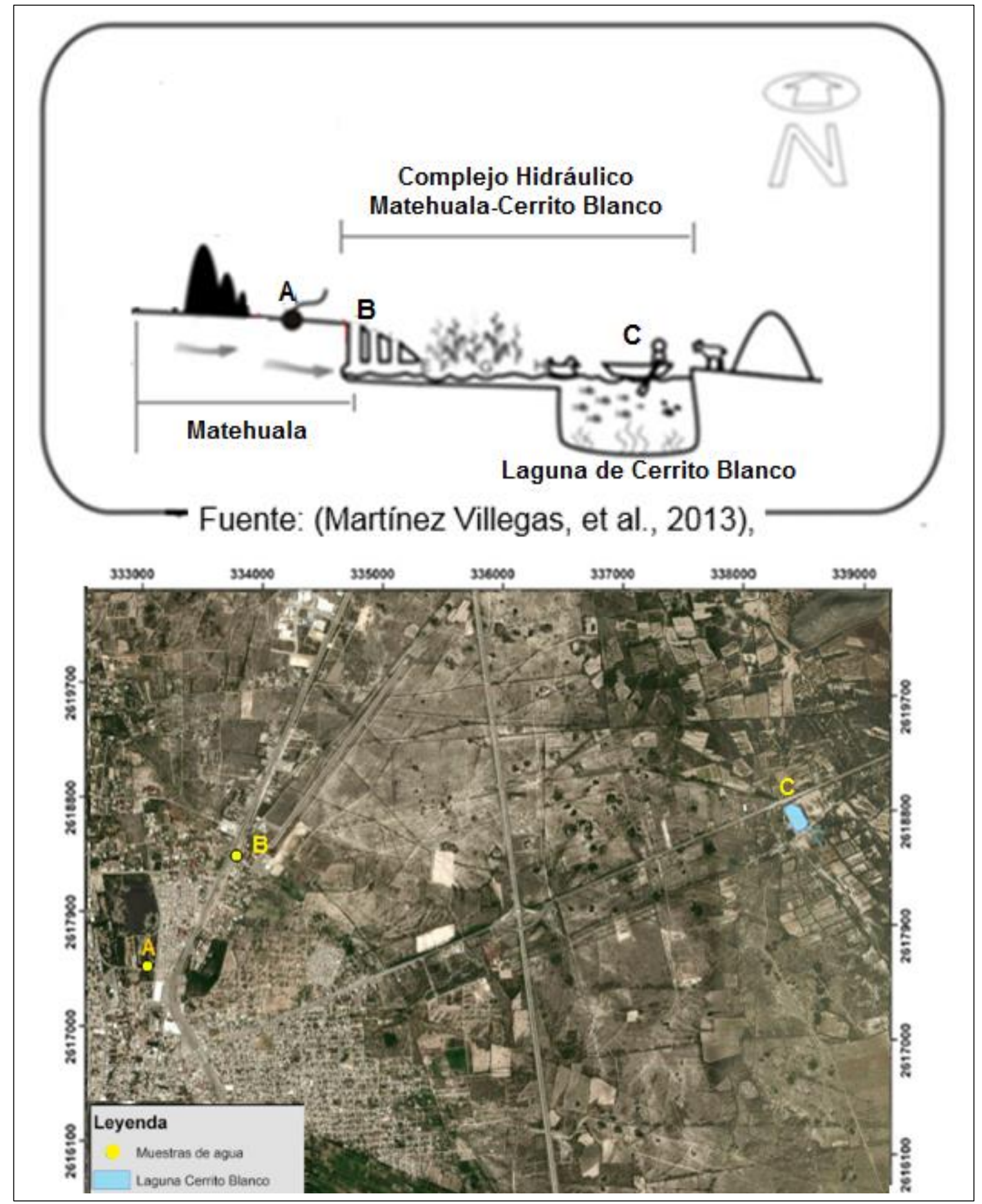

Figura 9. a) Esquema del complejo hidráulico Matehuala-Cerrito Blanco

b) Ubicación geográfica de los puntos de muestreo 


\subsubsection{Modelo Hidrogeoquímico}

Se realizó un modelamiento hidrogeoquímico directo de los puntos de muestreo CT y TR utilizando los resultados de los análisis químicos de campo y de laboratorio; esto mediante el uso del software PHREEQC 3.0. Este software es un código libre desarrollado en el U.S. Geological Survey, disponible en el link: http://water.usgs.gov/nrp/gwsoftware/tdpf/tdpf.html.

Se utilizó la base de datos termodinámica wateq4f, modificada de acuerdo a Martínez-Villegas et al (2013).

Los elementos mayoritarios utilizados en la modelación fueron: oxígeno disuelto, carbonato, fluoruro, cloruro, amonio, nitrato, fosfato, sulfato, calcio, potasio, sodio, magnesio, arsénico, hierro y manganeso; mientras que los parámetros utilizados, fueron los siguientes: $\mathrm{pH}$, potencial eléctrico, temperatura y alcalinidad como $\mathrm{CaCO}_{3}$.

En el Apéndice I se presenta un ejemplo de la modelación de PHREEQC 3.0. 


\subsection{Tratamiento para la remoción de arsénico 4.2.1 Intercambio iónico}

Las resinas de intercambio iónico utilizadas en el proceso de electrodesionización, tienen las siguientes características:

Tabla 13. Características de las resinas de intercambio iónico

\begin{tabular}{|c|c|c|c|c|c|c|}
\hline Resina & Tipo & Matriz & $\begin{array}{c}\text { Grupo } \\
\text { funcional }\end{array}$ & $\begin{array}{c}\text { Ion } \\
\text { móvil }\end{array}$ & $\begin{array}{c}\text { Capacidad } \\
\text { de } \\
\text { intercambio }\end{array}$ & Tamaño \\
\hline $\begin{array}{c}\text { Amberlite } \\
\text { IRA-900 }\end{array}$ & $\begin{array}{c}\text { Aniónica } \\
\text { macroporosa }\end{array}$ & $\begin{array}{c}\text { Estireno } \\
\text { divinilbenceno }\end{array}$ & $\begin{array}{c}\text { Trimetilamina } \\
{\left[\mathrm{N}\left(\mathrm{CH}_{3}\right)_{3}\right]}\end{array}$ & $\mathrm{Cl}^{-}$ & $\geq 1.00 \mathrm{Eq} / \mathrm{L}$ & $\begin{array}{c}0.6-0.8 \\
\mathrm{~mm}\end{array}$ \\
\hline $\begin{array}{c}\text { Amberlite } \\
\text { IRA-120 }\end{array}$ & Catiónica gel & $\begin{array}{c}\text { Estireno } \\
\text { divinilbenceno }\end{array}$ & $\begin{array}{c}\text { Sulfonato } \\
\left(\mathrm{SO}_{3}{ }^{-}\right)\end{array}$ & $\mathrm{Na}^{+}$ & $\geq 2.00 \mathrm{Eq} / \mathrm{L}$ & $\begin{array}{c}0.65-0.82 \\
\mathrm{~mm}\end{array}$ \\
\hline
\end{tabular}

\subsubsection{Activación de resinas de intercambio iónico}

Activación de resina, parte catiónica:

1. Las resinas fueron sumergidas en una solución $0.1 \mathrm{M}$ de hidróxido de sodio durante 1 hora con agitación constante de 400 rpm.

2. Las resinas se filtraron

3. Fueron enjuagadas 2 veces con agua desionizada, en agitación constante durante 30 minutos por cada enjuague.

4. Al finalizar los dos enjuagues con agua desionizada, las resinas fueron filtradas y secadas a $50^{\circ} \mathrm{C}$.

Activación de resina, parte aniónica:

1. Las resinas fueron sumergidas en una solución $0.1 \mathrm{M}$ de ácido clorhídrico durante 1 hora con agitación constante de 400 rpm.

Los pasos 2 a 5, se repiten para la activación de la resina aniónica. 


\subsubsection{Cinéticas de adsorción}

1. Se pesaron $0.1 \mathrm{~g}$ de resina aniónica en viales de $20 \mathrm{~mL}$.

2. A cada vial se les agregaron $10 \mathrm{~mL}$ de una solución de 50 ppm de arseniato de sodio heptahidratado.

3. Cada vial fue mantenido en agitación durante: 1, 5, 10, 15, 30, 60, 90, 120, $180,240,300$ y 360 minutos respectivamente.

4. Pasado el tiempo para cada vial, se filtró la solución de arsénico para separarla de la resina.

5. El arsénico remanente fue cuantificado por espectroscopía de absorción atómica en horno de grafito (GFAAS).

6. Obtenidos los datos experimentales, se realizó el análisis matemático ajustando los datos a modelos cinéticos no lineales: Elovich, difusión intrapartícula, pseudo primer y pseudo segundo orden, con el objetivo de identificar el modelo que mejor describe el proceso de adsorción.

\subsubsection{Isotermas de adsorción}

1. Se pesaron $0.1 \mathrm{~g}$ de resina aniónica en viales de $20 \mathrm{~mL}$.

2. A cada vial se le agregó $10 \mathrm{~mL}$ de solución de arseniato de sodio heptahidratado a distintas concentraciones: $0,5,10,15,20,25,30,35,40$, 45, 50 ppm se manejó a un pH de 7.8 para cada muestra.

3. Cada vial se mantuvo en agitación durante 72 horas.

4. Se filtró la solución

5. El arsénico remanente fue cuantificado por espectroscopía de absorción atómica en horno de grafito (GFAAS).

6. Los datos obtenidos experimentalmente fueron comparados con modelos no lineales de isotermas de adsorción: Freundlich, Langmuir y Redlich Peterson. 


\subsection{Electrodiálisis}

\subsubsection{Activación de membranas}

Se utilizaron membranas de intercambio iónico de grado estándar NEOSEPTA. Para la activación de las membranas (catiónica y aniónica), estas fueron sumergidas en soluciones $0.1 \mathrm{~N}$ de ácido clorhídrico e hidróxido de sodio, respectivamente durante 24 horas. Transcurridas las 24 horas, las membranas fueron enjugadas y preservadas con agua desionizada hasta su uso en el electrodesionizador.

\subsubsection{Síntesis de ánodo dimensionalmente estable (DSA)}

Para el electrodesionizador, se utilizó un ánodo de titanio recubierto con catalizadores: óxidos de rutenio e iridio. Estos catalizadores favorecen la regeneración in situ de las resinas de intercambio iónico.

Para la síntesis del DSA se realizaron los siguientes pasos:

- Decapado físico por la técnica de Sandblasting: consistió en impactar granalla de acero sobre la superficie del ánodo, con el objetivo de remover impurezas e incrementar su área superficial.

- Decapado químico: consistió en sumergir el ánodo en una solución de ácido oxálico al $10 \%$ durante 30 minutos con agitación constante y temperatura controlada de $60^{\circ} \mathrm{C}$. En este paso se eliminaron impurezas presentes en la superficie de la placa de titanio.

- Recubrimiento metálico por el Método de precursor polimérico (método de Pechini). Se recubrió la placa de titanio empleando una solución precursora de Etilenglicol, Ácido cítrico, Rutenio-iridio en proporción molar 16:0.12:0.0222:0.0074. mediante el método de Pechini. 


\subsection{Electrodesionización (EDI)}

\subsubsection{Construcción de celda de electrodesionización}

Para la construcción de la celda de electrodesionización, se utilizaron los siguientes materiales:

- Tubería y conexiones de PVC: para el montaje de las líneas de recirculación, se utilizó tubería de $1 / 4$ " y $1 / 2 "$

- Bombas centrífugas: se utilizaron tres bombas centrífugas (una para cada compartimento) para dar impulso al fluido y permitir la recirculación.

- Rotámetros: se utilizaron tres rotámetros para ajuste de caudal en cada compartimento.

- Placas de acero inoxidable (2 placas de $13 \times 8 \mathrm{~cm}$ ): colocadas a los extremos, su función es brindar soporte al resto de las piezas.

- Placas de polipropileno: consecutivas a las placas de acero inoxidable, se colocaron dos placas rectangulares de polipropileno soportando a los electrodos. Al centro de la celda, se colocaron tres placas más; estas placas centrales son los distribuidores de flujo $\left(24 \mathrm{~cm}^{2}\right)$.

- Electrodos: posteriores a las placas de polipropileno, se colocaron los electrodos; el ánodo, de titanio y el cátodo, de acero inoxidable.

- Membranas: seguidas de los electrodos, se colocaron las membranas Neosepta, aniónica (M.A.) y catiónica (M.C.), previamente activadas.

- Resinas: el lecho de resinas fue empacado en el distribuidor de flujo central. Este espacio está delimitado por las membranas.

- Empaques de silicón: estos empaques fueron colocados entre las placas, los electrodos y las membranas; mejorando la compactación y evitando fugas.

En la figura 10 se muestra la disposición de los componentes de la celda de electrodesionización. 


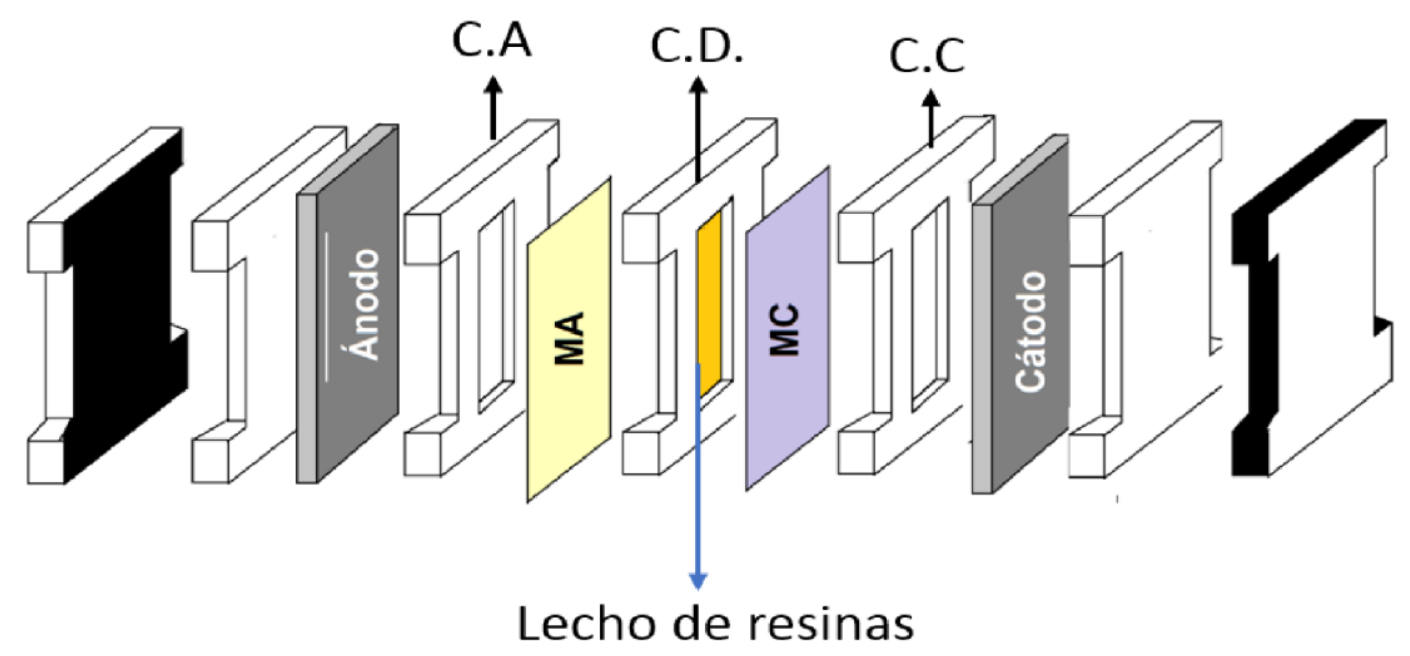

Figura 10. Esquema de la celda de electrodesionización

En los compartimentos anódico (CA) y catódico (CC) se concentran los iones (aniones y cationes, respectivamente) que migran a través de las membranas permeables por aplicación de corriente eléctrica. El distribuidor de flujo central, es el compartimento del diluido (CD) y es aquí donde se empaca el lecho de resinas. El agua contaminada entra por un orificio localizado en la parte inferior de la placa central (CD), asciende y emerge por la parte superior. Las placas correspondientes a los compartimientos anódico y catódico, son alimentadas con una solución de electrolito soporte que ingresa por la parte inferior y se recupera en la parte superior. Se utilizó un electrodo de referencia de calomel (SCE), conectado al compartimiento central mediante un puente salino (solución saturada de $\mathrm{KCl}$ ) cuya función es aislar el contenido de ambas partes manteniendo la conductividad eléctrica entre ellas. En la figura 11 se muestra un esquema de la celda de electrodesionización y sus conexiones. 


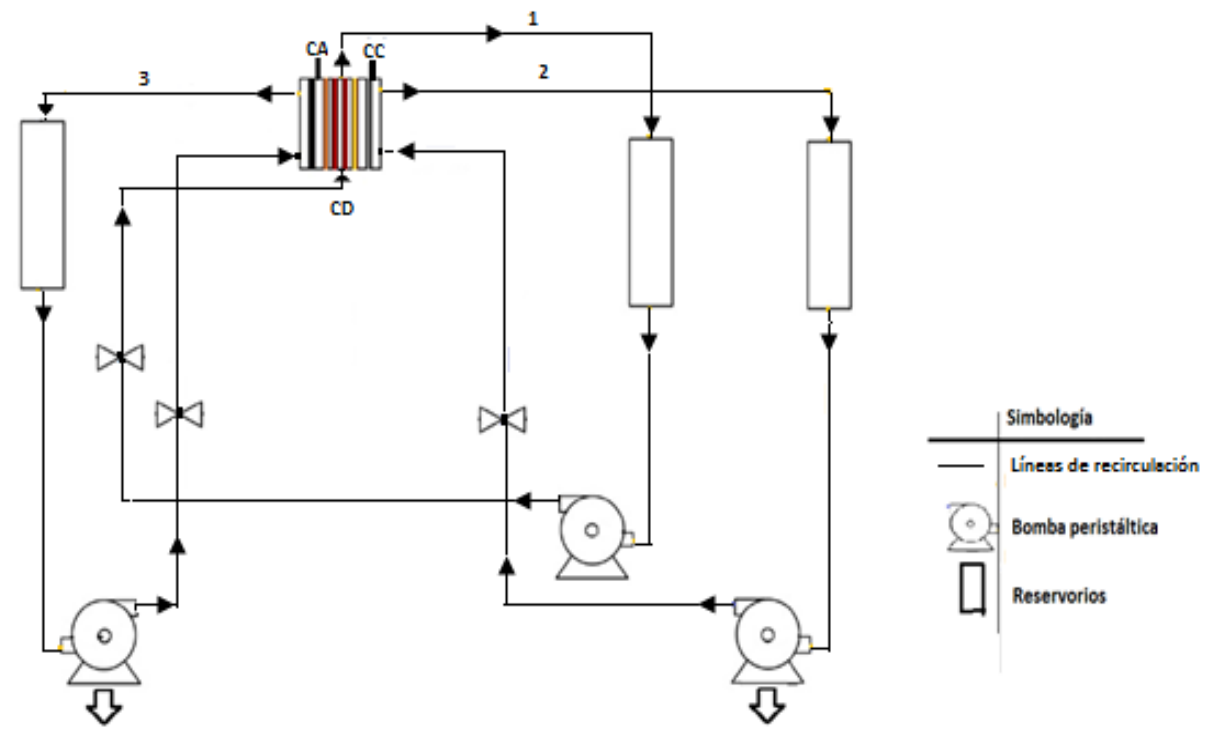

Figura 11. Esquema del sistema de EDI(el número 1 corresponde a las líneas de recirculación del CD, el 2 es para el CC y el 3 para CA)

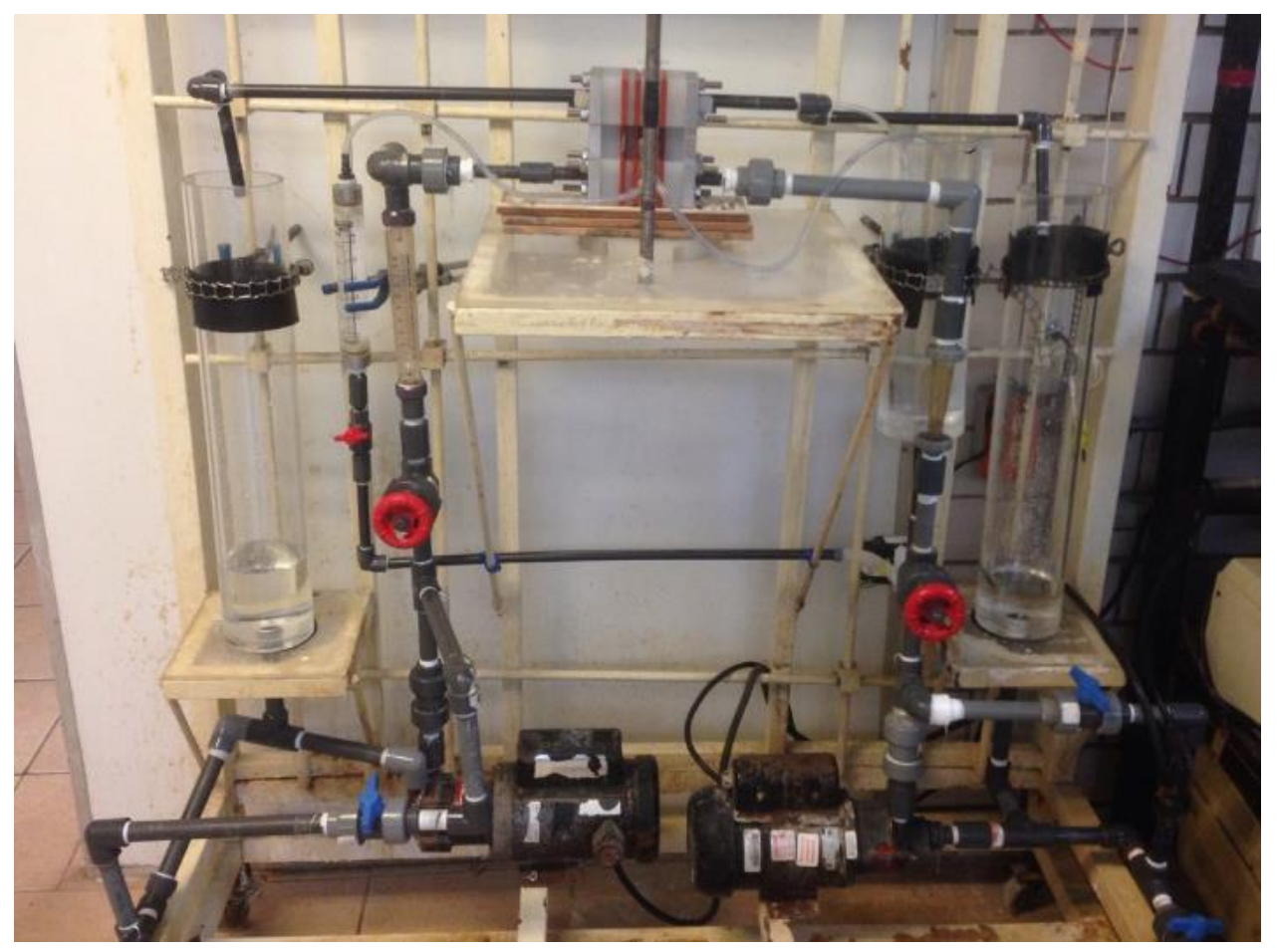

Figura 12. Sistema de EDI 


\subsubsection{Pruebas de remoción de As en celda de electrodesionización}

En 2018, Gutiérrez López, realizó pruebas de remoción de As (V) por la técnica de EDI, la concentración de la solución de arseniato fue de 50 ppm. En dichas pruebas, se demostró que la mayor eficiencia de remoción de arsénico se obtiene al utilizar una densidad de corriente límite (máxima densidad de corriente a la que puede ocurrir la oxidación del agua) de $1.82 \mathrm{~mA} / \mathrm{cm}^{2}$, para ello, se realizaron pruebas utilizando un valor $10 \%$ por debajo de esta corriente límite $\left(1.63 \mathrm{~mA} / \mathrm{cm}^{2}\right)$ y $10 \%$ por encima de este valor $\left(2.0 \mathrm{~mA} / \mathrm{cm}^{2}\right)$. Considerando estos resultados, en el presente trabajó, se utilizó dicha densidad de corriente límite $\left(1.82 \mathrm{~mA} / \mathrm{cm}^{2}\right)$ para la realización de los experimentos.

Se realizaron pruebas utilizando lecho aniónico y lecho mixto. Para un lecho mixto, se empacaron $10 \mathrm{~g}$ de resina catiónica (Amberlite IRA-120) y $20 \mathrm{~g}$ de resina aniónica (Amberlite IRA-900) en proporción 1:1 de capacidad máxima de adsorción en $\mathrm{mEq} / \mathrm{mL}$. Mientras que, para lecho aniónico, se empacaron $30 \mathrm{~g}$ de resina aniónica. Para ambos casos, se utilizaron resinas previamente activadas. En el compartimento central se recirculó la solución de $\mathrm{Na}_{2} \mathrm{HAsO}_{4} \cdot 7 \mathrm{H}_{2} \mathrm{O}$ (se trabajó con concentraciones de 50 y $15 \mathrm{mg} / \mathrm{L}$ de $\mathrm{Na}_{2} \mathrm{HAsO}_{4} \cdot 7 \mathrm{H}_{2} \mathrm{O}$ ) ajustando el caudal a 10 $\mathrm{mL} / \mathrm{min}$; en los compartimentos anódico y catódico se recirculó una solución de $\mathrm{Na}_{2} \mathrm{SO}_{4} 0.1 \mathrm{M}$ a un caudal de $150 \mathrm{~mL} / \mathrm{min}$. Para el ajuste del caudal se utilizaron rotámetros. En cada prueba de EDI y para cada compartimento, se determinó el $\mathrm{pH}$, conductividad y potencial óxido reducción. El arsénico se cuantificó mediante MP-AES para los compartimentos anódico y diluido. 


\subsection{Cuantificación de arsénico}

Las concentraciones de As utilizadas en el modelamiento hidrogeoquímico provienen de Martínez-Villegas (2013) en el que fueron obtenidas mediante ICPOES, en el laboratorio LANBAMA de IPICyT. En el presente, la cuantificación de As se realizó con dos técnicas. La primera: absorción atómica con horno de grafito; esta técnica se utilizó en la realización de la cinética e isoterma de adsorción; mientras que la segunda técnica: espectrometría de emisión atómica de plasma por microondas, se utilizó para cuantificar arsénico remanente en las pruebas de remoción por EDI.

Los experimentos para cinética e isoterma fueron realizados por lote, siguiendo el procedimiento descrito en los numerales 4.2 .3 y 4.2 .4 , respectivamente.

Para la técnica de horno de grafito, se utilizó una longitud de onda de: $\lambda=193.7 \mathrm{~nm}$, que es la longitud a la que la luz es absorbida para As. Para la cuantificación de arsénico remanente en cinética e isoterma de adsorción por la técnica de horno de grafito, se siguieron los siguientes pasos:

- Curva de calibración: la cuantificación de As inicia con la realización de una curva de calibración para cada lote de muestras. Para aprobar una curva de calibración, ésta debe presentar un $\mathrm{R}^{2}>0.995$.

- Estándares: Para cada lote de muestras se introdujeron tres estándares de concentración conocida: 1, 5, 10, 30, $50 \mathrm{mg} / \mathrm{L}$ de As.

- Modificador de matriz: se utilizó un modificador de matriz de $\mathrm{Pd}\left(\mathrm{NO}_{3}\right.$ )2/ $\mathrm{HNO}_{3}$; modificador comercial de Perkin Elmer para As cuya función es evitar la volatilización del analito durante la etapa de calcinación.

- Blanco: se utilizó una solución de $\mathrm{HNO}_{3}$ al $0.2 \%$, cuya función es calibrar una concentración cero dentro de la curva de calibración. 
Para la cuantificación de arsénico remanente de las pruebas de electrodesionización (EDI) por la técnica de espectrometría de emisión atómica de plasma por microondas, se siguieron los siguientes pasos:

- Curva de calibración: se construyó una curva de calibración para cada lote de muestras. Al igual que en la técnica anterior, en la curva de calibración se debe obtener un coeficiente de correlación $\mathrm{R}^{2}>0.995$.

- Estándares: Para construcción de la curva de calibración, se prepararon tres estándares de concentración conocida.

- Blanco: se utilizó agua desionizada como blanco en la curva de calibración.

- Muestras: para una correcta lectura, se necesitaron, por lo menos $10 \mathrm{~mL}$ de muestra colectados en cada prueba de EDI. 


\section{Capítulo 5}

\section{Resultados}

\subsection{Parámetros fisicoquímicos}

En las tablas 14 y 15 se enlistan los parámetros fisicoquímicos medidos en campo y laboratorio, que corresponden a lo realizado en 2008-2009 por Martínez-Villegas y colaboradores.

Se registraron temperaturas variables que dependen el mes de muestreo. Los valores de temperatura de las muestras, oscilan entre 20 y $28.6^{\circ} \mathrm{C}$; los valores más altos se registran en los meses de abril a junio. Los valores de $\mathrm{pH}$ para los puntos CT y TR, se encuentran entre 6.3 y 7.1. Del Razo (2004), menciona que estos valores se atribuyen a sistemas calcáreos. Los valores de conductividad eléctrica observados son característicos de procesos de disolución y precipitación de calcita y/o yeso (Armienta et al., 2008). Se reportan alcalinidades entre $120 \mathrm{mg}$ de $\mathrm{CaCO} / \mathrm{L}$ y $300 \mathrm{mg}$ de $\mathrm{CaCO} / \mathrm{L}$. La alcalinidad tiene una relación directa con el $\mathrm{pH}$; los iones provenientes de la disolución de rocas con alto contenido de carbonatos que dan alcalinidad al agua y consumen los ácidos. Generalmente se inhibe el transporte químico de metales (Razo et al., 2004). Los valores correspondientes al potencial óxido-reducción miden la tendencia de un sistema a oxidar o reducir una especie química (Albarrán-Zavala, 2008), de acuerdo a los datos presentados en la tabla 14 , estos valores se encuentran en un intervalo de 380 a $-201 \mathrm{mV}$.

Para los iones mayoritarios $\left(\mathrm{Ca}^{2+}, \mathrm{Mg}^{2+}, \mathrm{Na}^{2+}, \mathrm{SO}_{4}^{2-}, \mathrm{Cl}^{-}, \mathrm{NO}_{3}^{-}\right)$de cada muestra, se verificó la condición de electroneutralidad, de acuerdo con la siguiente ecuación (los cálculos se muestran en el apéndice II): 


$$
\text { Error }(\%)=\frac{\sum \text { aniones }-\sum \text { cationes }}{\sum \text { aniones }+\sum \text { cationes }} * 100
$$

En aguas poco salinas $(<1000 \mathrm{mg} / \mathrm{L})$ se admiten errores $<10 \%$ y $<1$ o $2 \%$ en aguas con más de $1000 \mathrm{mg} / \mathrm{L}$. Si el error es mayor, puede deberse a errores analíticos o a la presencia excepcional de alguna sustancia no analizada (Lloyd \&Heathcote, 1985; Tostado, 2010). La mayoría de los valores de las muestras cumplen con la condición de electroneutralidad, ya que presentan porcentajes de error $<10 \%$ (Apéndice II).

En todas las muestras analizadas, el ion sulfato rebasa el límite de $400 \mathrm{mg} / \mathrm{L}$ que establece la NOM-127-SSA1-1994. El origen de los sulfatos está asociado principalmente con la disolución yeso $\left(\mathrm{CaSO}_{4} 2 \mathrm{H}_{2} \mathrm{O}\right)$ y anhidrita $\left(\mathrm{CaSO}_{4}\right)$ (Lillo J. , 2007). El catión calcio, presente en las muestras analizadas, al ser muy soluble, puede precipitar como carbonato o sulfato, explicando así su presencia en calcita, yeso y anhidrita. Por otra parte, el ion magnesio $\left(\mathrm{Mg}^{2+}\right)$ procede de la disolución de rocas con alto contenido de carbonatos (Fagundo \& González, 2005) (Tabla 15).

En la tabla 15 se muestran las concentraciones de As en mg/L para los puntos de muestreo CT-TR. En el primer punto, correspondiente al Club de Tiro (CT), la concentración de arsénico para los meses de septiembre de 2008 a enero de 2009, es, en promedio $96.06 \mathrm{mg} / \mathrm{L}$ de As; esta concentración decrece en los meses de febrero a mayo de 2009, llegando a $44.44 \mathrm{mg} / \mathrm{L}$ de As en promedio y vuelve a incrementarse en los meses de junio, julio y agosto de 2009 (tabla 15). En el segundo punto (TR), la concentración decrece; los meses de mayor concentración en el TR, coinciden con los de CT. Para los meses de septiembre a enero, se tiene en promedio $12.89 \mathrm{mg} / \mathrm{L}$ de As; de febrero a mayo, la concentración disminuye a $5.73 \mathrm{mg} / \mathrm{L}$ de As, en promedio; para volver a incrementar de mayo a agosto donde se tiene un promedio de $15.93 \mathrm{mg} / \mathrm{L}$. 
En 2013, Martínez-Villegas y colaboradores establecen que la contaminación por arsénico en agua en el punto de origen (Club de Tiro) se debe a la disolución de arseniatos de una antigua fundición inactiva en Matehuala. Dichos residuos son el resultado de procesos metalúrgicos que operaron en la comunidad de Matehuala hasta la década de 1960 (Martínez Villegas, et al., 2013). En la tabla 15, es posible observar una diferencia de hasta $90 \%$ en la concentración de As entre el Club de Tiro y el Tecnológico Regional. 
Tabla 14. Parámetros fisicoquímicos medidos en campo por Martínez Villegas., et al 2013, correspondientes al área de interés.

\begin{tabular}{|c|c|c|c|c|c|c|c|}
\hline $\begin{array}{c}\text { Mes de } \\
\text { muestreo }\end{array}$ & $\begin{array}{l}\text { Punto de } \\
\text { muestreo }\end{array}$ & $\begin{array}{c}\mathrm{T}_{\mathrm{M}} \\
\left({ }^{\circ} \mathbf{C}\right)\end{array}$ & $\mathrm{pH}$ & $\begin{array}{c}\mathrm{O}_{2} \\
(\mathrm{mg} / \mathrm{L})\end{array}$ & Eh $(m V)$ & $\begin{array}{c}\text { CE } \\
(\mu S / c m)\end{array}$ & $\begin{array}{l}\text { Alcalinidad } \\
\left(\mathrm{mgCaCO}_{3} / \mathrm{L}\right)\end{array}$ \\
\hline \multirow[t]{2}{*}{ Septiembre } & CT & 23 & 6.3 & 1.57 & 86 & 3240 & 300 \\
\hline & TR & 24 & 6.4 & 4.61 & 34.6 & 2720 & 225 \\
\hline \multirow[t]{2}{*}{ Octubre } & CT & 21 & 7 & 3.1 & 190 & 3130 & 200 \\
\hline & TR & 21 & 7.1 & 3.66 & 14.5 & 2660 & 160 \\
\hline \multirow[t]{2}{*}{ Noviembre } & CT & 21 & 6.6 & 3.04 & 163 & 3110 & 160 \\
\hline & TR & 22 & 7 & 3.87 & 116 & 2690 & 120 \\
\hline \multirow[t]{2}{*}{ Diciembre } & CT & 21 & 7 & 3.19 & 267 & 2710 & 280 \\
\hline & TR & 21 & 6.9 & 3.26 & 160 & 2770 & 180 \\
\hline \multirow[t]{2}{*}{ Enero } & $\mathrm{CT}$ & 20.9 & 6.7 & 4.08 & 380.3 & 3270 & 280 \\
\hline & TR & 21.9 & 6.7 & 2.39 & 196.5 & 2870 & 200 \\
\hline \multirow[t]{2}{*}{ Febrero } & CT & 21.8 & 6.7 & 2.49 & 138.5 & 3190 & 300 \\
\hline & TR & 23.5 & 6.7 & 3.22 & 92 & 2830 & 200 \\
\hline \multirow[t]{2}{*}{ Marzo } & CT & 22.5 & 6.6 & 1.51 & -9.4 & 3109 & 260 \\
\hline & TR & 23.1 & 6.7 & 1.91 & -27.2 & 2725 & 200 \\
\hline \multirow[t]{2}{*}{ Abril } & CT & 23.6 & 6.5 & 1.54 & 57.7 & 3108 & 280 \\
\hline & TR & 25.8 & 6.5 & 1.96 & -113.5 & 2555 & 200 \\
\hline \multirow[t]{2}{*}{ Mayo } & CT & 24.0 & 7.1 & 2.21 & -50.2 & 3083 & 280 \\
\hline & TR & 22.4 & 6.6 & 2.28 & -22.1 & 2713 & 160 \\
\hline \multirow[t]{2}{*}{ Junio } & CT & 22.9 & 6.8 & 1.05 & -3.20 & 3169 & 220 \\
\hline & TR & 28.6 & 7.1 & 0 & -313 & 2620 & 160 \\
\hline \multirow[t]{2}{*}{ Julio } & CT & - & 7.1 & 1.64 & -201 & 3202 & - \\
\hline & TR & 26.7 & 6.7 & 2.45 & 3.2 & 2750 & 160 \\
\hline \multirow[t]{2}{*}{ Agosto } & CT & 21 & 7.5 & 2.54 & -47 & 3300 & 460 \\
\hline & TR & 22 & 7 & 3.16 & 143 & 2940 & 260 \\
\hline
\end{tabular}


Tabla 15. Parámetros medidos en laboratorio, utilizados en el modelo hidrogeoquímico

\begin{tabular}{|c|c|c|c|c|c|c|c|c|c|c|c|c|}
\hline \multirow{2}{*}{$\begin{array}{l}\text { Mes de } \\
\text { muestreo }\end{array}$} & \multirow{2}{*}{$\begin{array}{l}\text { Punto } \\
\text { de } \\
\text { muestre } \\
\text { o }\end{array}$} & \multicolumn{7}{|c|}{ Cationes (mg/L) } & \multicolumn{3}{|c|}{ Aniones (mg/L) } & \multirow[b]{2}{*}{$\mathrm{SO}_{4}{ }^{2-}$} \\
\hline & & $\begin{array}{l}\text { As } \\
\text { Total }\end{array}$ & $\mathbf{C a}$ & $\mathrm{Fe}$ & $\mathrm{Mg}^{2+}$ & $\mathrm{Na}$ & $\mathrm{K}^{+}$ & $\mathrm{NH}_{4}$ & $\mathbf{F}^{-}$ & $\mathrm{Cl}^{-}$ & $\mathrm{NO}_{3}^{-}$ & \\
\hline \multirow{2}{*}{$\begin{array}{l}\text { Septiembr } \\
\mathrm{e}\end{array}$} & CT & 77.7 & 447 & 0.04 & 45 & 165 & 12.6 & 0.09 & 0.65 & 23 & 6 & 1120 \\
\hline & TR & 11.5 & 441 & 0.06 & 33 & 74.4 & 12.2 & 0.31 & 0.74 & 16 & 8 & 920 \\
\hline \multirow[t]{2}{*}{ Octubre } & CT & 83.9 & 445 & 0.03 & 43 & 165 & 11.7 & 0.39 & 0.77 & 50.4 & 6 & 1200 \\
\hline & TR & 10.7 & 430 & 0.04 & 33 & 70.2 & 12.9 & 0.87 & 0.63 & 47 & 20 & 1200 \\
\hline \multirow{2}{*}{$\begin{array}{l}\text { Noviembr } \\
\text { e }\end{array}$} & CT & 96.7 & 448 & 0.07 & 48.4 & 153 & 11.2 & 0.35 & 1.05 & 40.8 & 10 & 1280 \\
\hline & TR & 13.5 & 648 & 0.05 & 34.8 & 67.5 & 10.6 & 0.47 & 1.16 & 30.2 & 10 & 1180 \\
\hline \multirow[t]{2}{*}{ Diciembre } & CT & 96.8 & 384 & 0.07 & 47.6 & 154 & 11.2 & 0.56 & 0.96 & 35 & 0.56 & 1300 \\
\hline & TR & 13.9 & 402 & 0.05 & 34.8 & 70.2 & 10 & 0.65 & 0.87 & 26 & 13 & 2000 \\
\hline \multirow[t]{2}{*}{ Enero } & CT & 100 & 366 & 0.07 & 47.6 & 150 & 10.6 & 0.45 & 1.14 & 36.5 & 2 & 1240 \\
\hline & TR & 14.6 & 370 & 0.06 & 34.2 & 69.3 & 10.4 & 1.4 & 0.87 & 28.5 & 5 & 800 \\
\hline \multirow[t]{2}{*}{ Febrero } & CT & 36.3 & 401 & 0.08 & 40 & 150 & 11.5 & 0.52 & 1.3 & 60 & 10 & 1360 \\
\hline & TR & 5.03 & 396 & 0.08 & 35.9 & 68.7 & 10.4 & 0.64 & 1.38 & 48 & 17 & 1280 \\
\hline \multirow[t]{2}{*}{ Marzo } & CT & 39.2 & 401 & 0.07 & 40 & 140 & 12.2 & 0.39 & 0.82 & 41 & 15 & 1880 \\
\hline & TR & 5.51 & 398 & 0.07 & 31.4 & 70 & 10.6 & 0.43 & 0.87 & 36 & 10 & 1480 \\
\hline \multirow[t]{2}{*}{ Abril } & CT & 46.1 & 401 & 0.07 & 42 & 150 & 12 & 0.51 & 0.72 & 45 & 13 & 1420 \\
\hline & TR & 5.71 & 393 & 0.06 & 36.1 & 71.2 & 9.6 & 0.62 & 0.81 & 48 & 14 & 1360 \\
\hline \multirow[t]{2}{*}{ Mayo } & CT & 56 & 366 & 0.19 & 39 & 120 & 19.3 & 4.52 & 0.18 & 33 & 11 & 1140 \\
\hline & TR & 6.7 & 365 & 0.01 & 33.2 & 67.1 & 9.7 & 1.01 & 0.18 & 46 & 14 & 1180 \\
\hline \multirow[t]{2}{*}{ Junio } & CT & $\begin{array}{c}153 . \\
9\end{array}$ & 596 & 0.28 & 60.3 & 161 & 15.1 & 2.52 & 0.63 & 22 & 4 & 1220 \\
\hline & TR & 9.98 & 666 & 2.23 & 40.7 & 101 & 18.4 & 9.36 & 0.47 & 6 & 3 & 1200 \\
\hline \multirow[t]{2}{*}{ Julio } & CT & $\begin{array}{c}152 . \\
7\end{array}$ & 578 & 0.12 & 60.4 & 151 & 17.5 & 2.30 & 0.58 & 14 & 9 & 1260 \\
\hline & TR & 18.2 & 596 & 0.15 & 37.8 & 74.1 & 10.8 & 0.48 & 0.55 & 24 & 11 & 1340 \\
\hline \multirow[t]{2}{*}{ Agosto } & CT & $\begin{array}{c}158 . \\
5\end{array}$ & 572 & 0.36 & 60.3 & 132 & 21.5 & 9.36 & 0.31 & 22 & 13 & 1880 \\
\hline & TR & 19.5 & 570 & 0.22 & 38.6 & 69.3 & 9.6 & 12.2 & 0.22 & 34 & 8 & 2040 \\
\hline
\end{tabular}




\subsection{Clasificación hidrogeoquímica del agua en el sitio de interés}

Para determinar el carácter hidrogeoquímico del agua en la zona de estudio, los resultados analíticos obtenidos por Martínez-Villegas y colaboradores, fueron graficados en un diagrama de Piper.

De acuerdo al diagrama de Piper representado en la figura 13, el agua analizada es de tipo sulfatada cálcica $\left(\mathrm{Ca}^{2+} \mathrm{SO}_{4}^{-}\right)$, asociada a materiales de naturaleza calcárea debido a la interacción del fluido con el medio geológico; claramente relacionado con la abundancia de rocas yesíferas y carbonatadas en la zona de estudio. Tanto las rocas yesíferas como las carbonatadas tienen un alto impacto en la hidrogeoquímica del agua debido a su fácil disolución (Benavente, 2015).

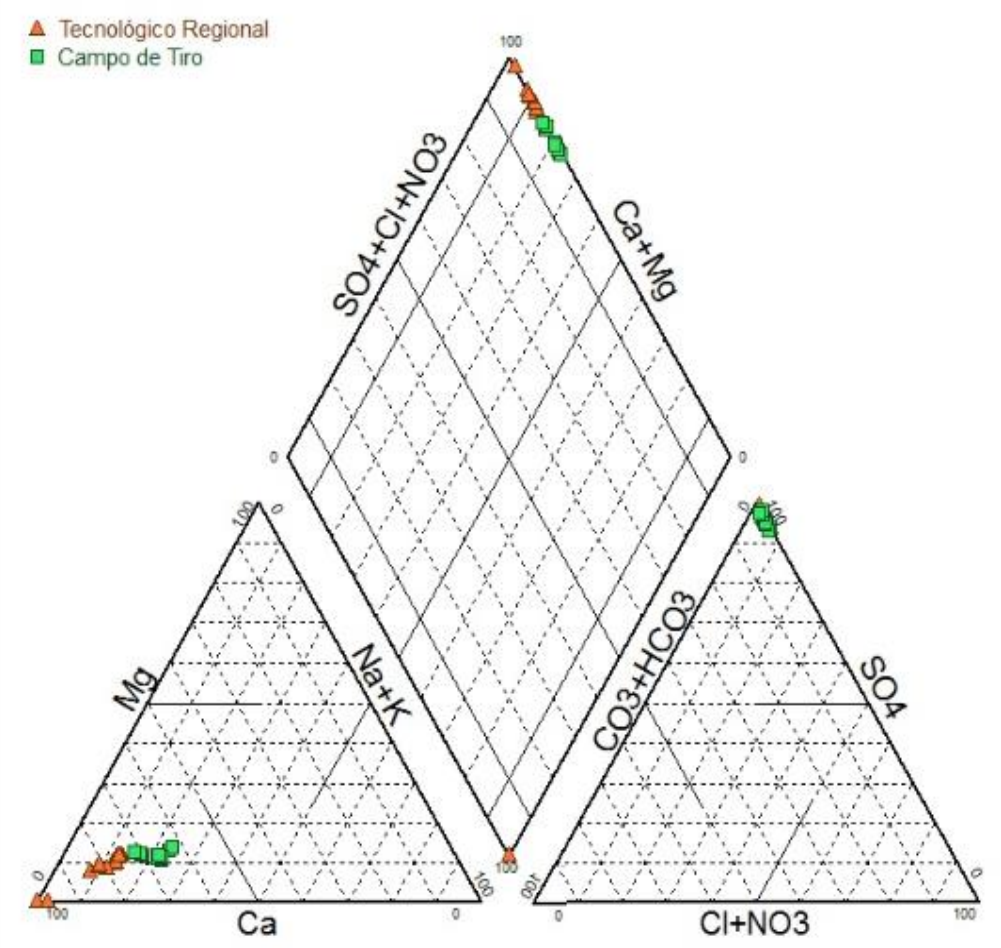

Figura 13. Diagrama de Piper para la zona de estudio (puntos de muestreo CT y TR) 


\subsection{Modelación hidrogeoquímica directa}

En este apartado, se emplea la modelación hidrogeoquímica directa para el conjunto de datos obtenidos por Martínez-Villegas et al., (2013), con el objetivo de establecer la especiación química del arsénico en el agua y analizar los índices de saturación para conocer las posibles fases presentes en el sistema y así, determinar el estado de equilibrio del sistema dado por los puntos de muestreo: Club de Tiro (CT) y Tecnológico Regional de Matehuala (TR). Los modelos se hicieron siguiendo la dirección del flujo (O-E) considerando como solución inicial el punto CT.

\subsubsection{Especiación química de arsénico}

En cuanto a la especiación de arsénico, debido a las condiciones oxidantes del medio, predomina la forma pentavalente. En mayor concentración y debido a un $\mathrm{pH}$ casi neutro (tabla 13), se tiene $\mathrm{HAsO}_{4}{ }^{2-}$, esto en comparación con el $\mathrm{H}_{2} \mathrm{AsO}_{4}-$ que está presente en menores concentraciones (figura 14); el punto CT, presenta concentraciones en el intervalo de 0.000897 a $1.57 \mathrm{E}-09 \mathrm{~mol} / \mathrm{L}$, teniendo la mayor concentración $(0.000897 \mathrm{~mol} / \mathrm{L})$ en el mes de agosto, donde se tiene registrado un valor de $\mathrm{pH}$ de 6.3 por lo que su presencia se atribuye a que el valor de $\mathrm{pH}$ es menor de 6.9 (esta especie se encuentra a valores de $\mathrm{pH}<6.9$ ). La segunda especie más abundante, es el $\mathrm{CaAsO}_{4}^{-}$(figura 14), presenta su mayor concentración (0.0002258 $\mathrm{mol} / \mathrm{L}$ ) en el punto Club de Tiro en el mes de julio. La presencia de esta sal de arseniato se justifica debido a la alta concentración de $\mathrm{Ca}^{2+}$ (tabla 14), que, en el

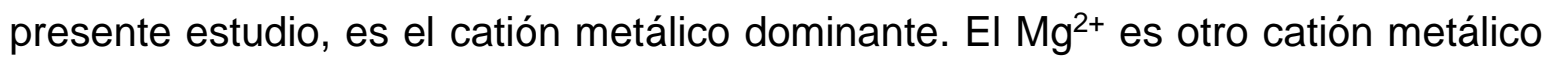
cuya presencia también es significativa; aunque en menor concentración, se tiene la presencia de $\mathrm{MgAsO}_{4}^{-}$(figura 14). Los procesos de precipitación con $\mathrm{Ca}^{2+} \mathrm{y} \mathrm{Mg}^{2+}$ que dan lugar a la formación de sales altamente solubles de arseniato (arseniato de 
calcio y magnesio, respectivamente), explican la movilidad de As en la zona de estudio, siendo la precipitación con $\mathrm{Ca}^{2+}$ el proceso dominante

Las concentraciones molares para las especies de arsénico trivalente no son significativas, el $\mathrm{H}_{3} \mathrm{AsO}_{3}$ es la especie de mayor presencia (figura 15), con una concentración de $0.0019 \mathrm{~mol} / \mathrm{L}$ en el punto de muestro conocido como Club de Tiro (CT), en el mes de junio; en este mes, también se registra la mínima concentración de oxígeno disuelto (tabla 14). Un nivel bajo de oxígeno disuelto indica contaminación por materia orgánica, por lo que, la presencia de esta especie de arsénico trivalente podría deberse a la actividad microbiana; estos microorganismos son capaces de reducir el arsénico pentavalente (Macur et al., 2004). En el punto de muestreo "Tecnológico Regional", las concentraciones molares del $\mathrm{H}_{3} \mathrm{AsO}_{3}$ (especie con mayor concentración) están entre $1.1 \mathrm{E}-12$ y $2.4 \mathrm{E}-35 \mathrm{~mol} / \mathrm{L}$, por lo que no se consideran significativas. 


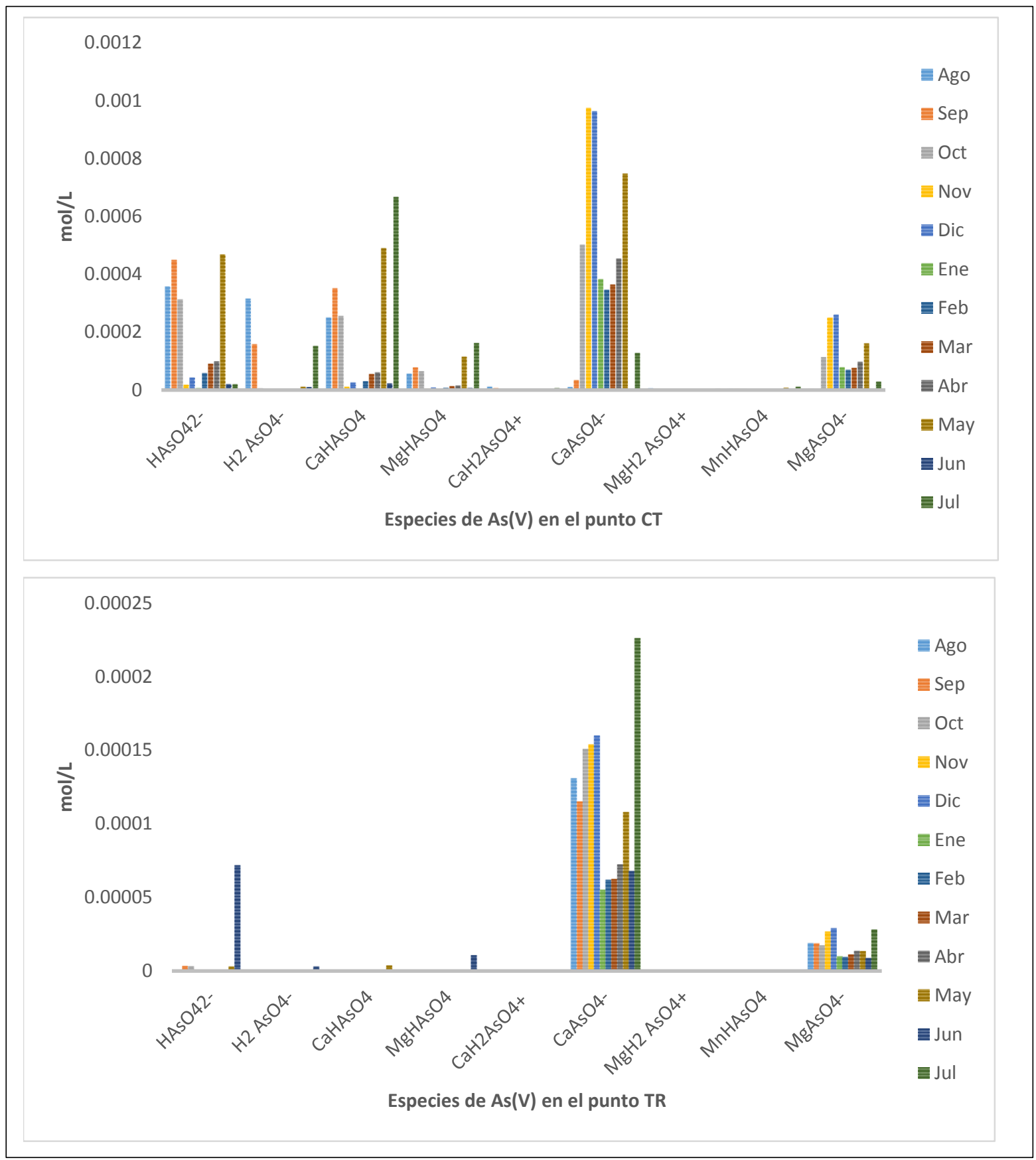

Figura 14. Distribución de especies de arsénico pentavalente en los puntos de muestreo CT y TR (las concentraciones están dadas en $\mathrm{mol} / \mathrm{L}$ y fueron obtenidas mediante modelación directa en PHREEQC) 


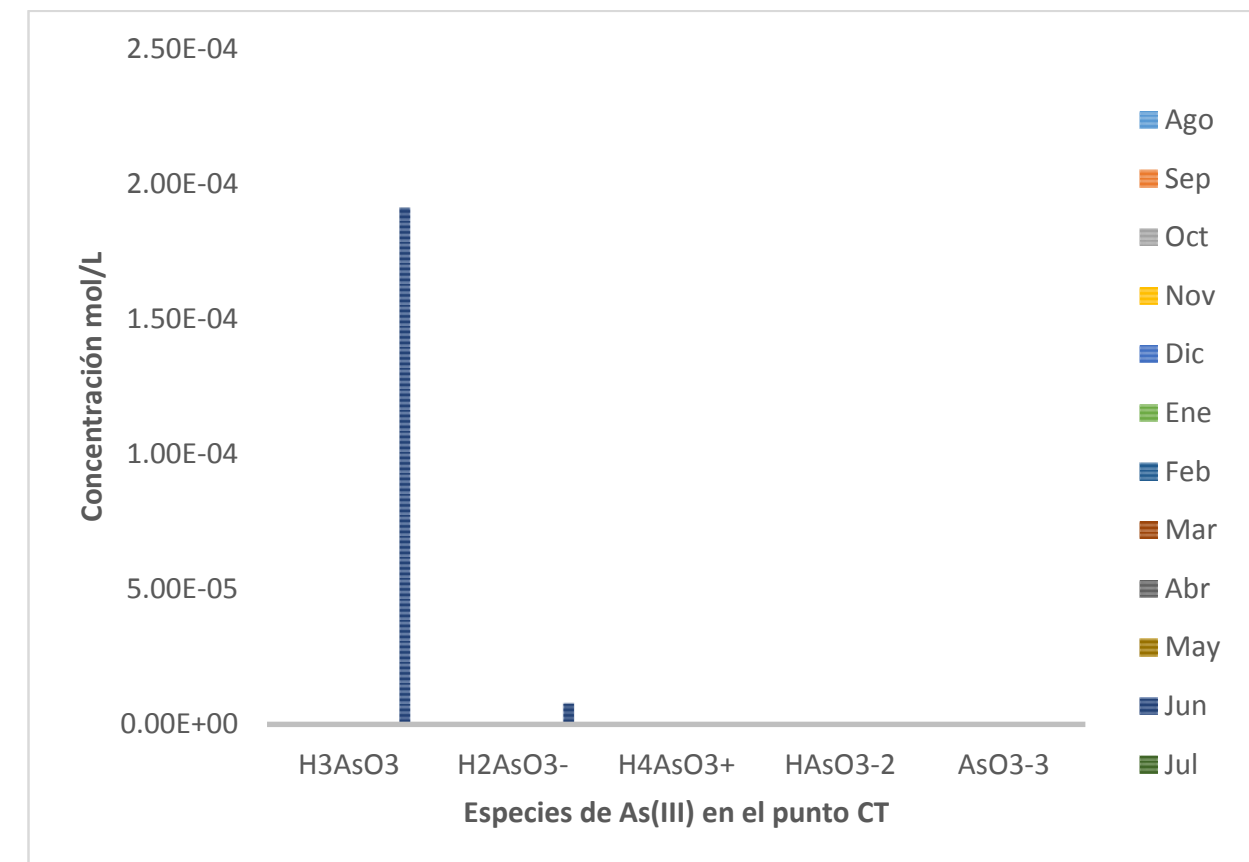

\section{Figura 15. Distribución de especies de arsénico trivalente en el punto de muestreo CT (las concentraciones están dadas en $\mathrm{mol} / \mathrm{L}$ y fueron obtenidas mediante modelación directa en PHREEQ}

En la tabla 16 se muestra el porcentaje de abundancia de las especies de arsénico con mayor presencia en la zona de estudio. Se indica en el mes y punto en el que se localizó cada especie. El porcentaje se obtuvo considerando la concentración molal de As total como el $100 \%$; se obtuvieron porcentajes relativos de abundancia para las principales especies en cada mes y punto de muestreo. Las especies de arsénico pentavalente predominan sobre las especies de arsénico trivalente. La abundancia de $\mathrm{As}(\mathrm{V})$, se debe a las condiciones óxicas del medio. La especie de As $(V)$ que mostró la mayor abundancia a lo largo del tiempo es el $\mathrm{HAsO}_{4}{ }^{2-}$ con un porcentaje relativo de $88.83 \%$, respecto a la concentración de arsénico total en $\mathrm{mol} / \mathrm{L}$, obtenida con modelación directa en PHREEQC; este porcentaje corresponde a una concentración de $0.0002258 \mathrm{~mol} / \mathrm{L}$, obtenida en el mes de julio para el punto de muestro Club de Tiro. $\mathrm{El}_{3} \mathrm{AsO}_{3}$ presenta un porcentaje de $92.91 \%$, atribuido a una concentración de $0.0019 \mathrm{~mol} / \mathrm{L}$, en el mes de junio. Como se mencionó 
anteriormente, este valor se atribuye a las condiciones anóxicas presentes al momento de tomar la muestra.

Tabla 16. Porcentajes relativos de las especies de arsénico más significativas

\begin{tabular}{|c|c|c|c|c|}
\hline $\begin{array}{c}\text { Año de } \\
\text { muestreo }\end{array}$ & $\begin{array}{c}\text { Mes de } \\
\text { muestreo }\end{array}$ & Especie & $\begin{array}{c}\text { Porcentaje } \\
\text { relativo }\end{array}$ & $\begin{array}{c}\text { Punto de } \\
\text { muestreo }\end{array}$ \\
\hline \multirow{3}{*}{2008} & Septiembre & $\mathrm{HAsO}_{4}^{-2}$ & 88.83 & $\mathrm{CT}$ \\
\cline { 2 - 5 } & Noviembre & $\mathrm{CaAsO}_{4}^{-}$ & 88.69 & $\mathrm{TR}$ \\
\cline { 2 - 5 } & Diciembre & $\mathrm{MgAsO}_{4}^{-}$ & 54.59 & $\mathrm{CT}$ \\
\hline \multirow{4}{*}{2009} & Junio & $\mathrm{H}_{3} \mathrm{AsO}_{3}$ & 92.91 & $\mathrm{CT}$ \\
\cline { 2 - 5 } & \multirow{2}{*}{ Julio } & $\mathrm{CaHAsO}_{4}$ & 27.84 & $\mathrm{CT}$ \\
\cline { 3 - 5 } & $\mathrm{MgHAsO}_{4}$ & 16.10 & $\mathrm{CT}$ \\
\cline { 2 - 5 } & Agosto & $\mathrm{H}_{2} \mathrm{AsO}_{4}^{-}$ & 29.35 & $\mathrm{CT}$ \\
\hline
\end{tabular}

\subsection{2 Índices de saturación}

Para conocer las fases presentes en el sistema, es necesario conocer los índices de saturación (SI) dentro de la zona de estudio. En la tabla 17 se presentan los índices de saturación de las fases más importantes presentes en la línea de flujo ubicada entre los puntos de muestreo Club de Tiro (CT) y Tecnológico Regional (TR). Como se mencionó en el numeral 1.2.4, un valor negativo indica que la muestra está subsaturada con respecto al mineral analizado, mientras que un valor positivo indica sobresaturación del mineral. Los valores en torno a cero indican que el mineral está en equilibrio con los fluidos.

Se ha comprobado la presencia de calcita y yeso en el ambiente geológico, en el 2017, Hernández-Bárcenas realizó una caracterización mineralógica de muestras de sustrato de suelo en Matehuala, para identificar las fases de arsénico en las que se encuentra presente el contaminante. Los resultados del estudio evidencian que 
las muestras de sustrato se encuentran constituidas mayoritariamente por calcita y yeso (Hernández-Bárcenas, 2017).

Al analizar los valores expuestos en la Tabla 17 se establece que la mayor parte de las fases minerales incluidas presentan SI negativos; esto indica que, si el agua interactúa con dichas fases, ésta tendrá la capacidad de disolverlas (anhidrita, arsenolita, fluorita, guerinita, yeso, haidingerita). Por otra parte, los carbonatos (calcita, aragonita, dolomita) presentan SI positivos, lo que indica la posible precipitación de estas fases si y sólo si la cinética es lo suficientemente rápida. La disolución de yeso aporta $\mathrm{Ca}^{2+}$ y $\mathrm{SO}_{4}{ }^{2-}$ a la fase acuosa; el $\mathrm{Ca}^{2+}$ liberado lleva a la precipitación de calcita. Este fenómeno se refiere a la precipitación del ion común (Langmuir et al., 1977; Back \& Hanshaw, 1970). Se presenta el efecto del ion común, que permite la disolución de yeso y precipitación de calcita, ambas fases minerales contienen calcio, siendo el yeso más soluble que la calcita, la disolución del yeso aporta cantidades importantes de $\mathrm{Ca}^{2+}$ favoreciendo la precipitación de calcita. El yeso controla la solubilidad del $\mathrm{Ca}^{2+}$ donde la concentración de $\mathrm{SO}_{4}{ }^{2-}$ es relativamente alta (Back \& Hanshaw, 1970).

La presencia de $\mathrm{Ca}$ y $\mathrm{Mg}$ en forma de carbonatos (hidromagnesita, huntita y magnesita) favorece la precipitación de dolomita, mientras que la disolución de hidromagnesita favorece la liberación de $\mathrm{Mg}^{2+}$ (Al-Awadi, et al., 2009).

Se observa que en los meses de noviembre y diciembre de 2008; y, enero, junio, julio y agosto de 2009, que es cuando se tienen las concentraciones más altas de As (Tabla 15), la disolución de yeso es menor (Tabla 17) mientras que, a menor concentración de As, se observa que hay mayor disolución de yeso. Esto sugiere que, en ambientes calcáreos, las concentraciones de arsénico en el agua parecen estar inversamente correlacionadas con la disolución de yeso. 
Por otra parte, de acuerdo con los resultados obtenidos en el modelamiento hidrogeoquímico (tabla 17), se observa que hay disolución de los arseniatos de calcio: guerinita $\left([\mathrm{Ca} 5 \mathrm{H} 2(\mathrm{AsO} 4) 4 \cdot 9 \mathrm{H} 2 \mathrm{O}]\right.$, arsenolita $\left(\mathrm{As}_{2} \mathrm{O}_{3}\right)$ y haidingerita $\left[\mathrm{CaHAsO}_{4} \cdot \mathrm{H}_{2} \mathrm{O}\right.$ ], esto se relaciona con la precipitación de calcita y explica la movilidad del arsénico a través de la disolución de sus fases. Por lo tanto, a mayor concentración de calcita, mayor será la dilución de las fases arsenicales. En los resultados, calcita precipita en todos los meses modelados; sin embargo, no se observa una relación directa con la disminución en la concentración de As del punto CT al punto TR (tabla 15), a pesar de la capacidad de la calcita para adsorber e incorporar As en su estructura (Armienta et al., 2004) y la capacidad de otorgar al medio un $\mathrm{pH}$ neutro, favoreciendo la precipitación de hidróxidos de Fe que retienen al As (Armienta M. , et al., 2012). En un ambiente geológico como el del área de estudio (suelos ricos en carbonatos de calcio, yeso y valores de $\mathrm{pH}$ cerca de la neutralidad), minerales como calcita y yeso pueden controlar y atenuar la concentración de As en el agua, de acuerdo con Bhumbla y Keffer (1994), el As (V) podría estar asociado a la calcita, ya que su adsorción se incrementa a pH entre 6 y 10 , en el estudio de Sø y colaboradores (2008), también se afirma que el arseniato si puede adsorberse sobre la superficie de calcita, sin embargo, debido a la alta solubilidad de los arseniatos de calcio, este mecanismo no es suficiente para mantener la concentración de As en niveles aceptables (de acuerdo a lo establecido en la NOM-001-SEMARNAT-1996, $0.2 \mathrm{mg} / \mathrm{L}$ en agua para riego agrícola), pero si podría influenciar el decrecimiento de la concentración de arsénico entre los puntos de muestreo CT y TR.

Se observa precipitación de hematita (hidróxido de hierro). La precipitación de las fases de oxihidroxidos de hierro, colabora en el decrecimiento de la concentración de arsénico del punto CT al punto TR; indicando atenuación por fisisorción. De acuerdo con Armienta et al., (2012), la calcita posee un efecto sobre la movilidad de los metales en el suelo, además de otorgarle al medio un $\mathrm{pH}$ neutro, 
favoreciendo la precipitación de hidróxidos de hierro que retienen As y otros metales.

La disolución de yeso explica el exceso de calcio y la movilidad del arsénico a través de la disolución de sus fases. 
Tabla 17. Índices de saturación de las principales fases minerales presentes en el área de estudio (campaña 2008-2009)

\begin{tabular}{|c|c|c|c|c|c|c|c|c|c|c|c|c|}
\hline \multirow[t]{2}{*}{ Mineral } & \multicolumn{12}{|c|}{ Índices de Saturación (SI) } \\
\hline & Sep & Oct & Nov & Dic & Ene & Feb & Mar & Abr & May & Jun & Jul & Ago \\
\hline Anhidrita $\left(\mathrm{CaSO}_{4}\right)$ & -0.5 & -0.47 & -0.46 & -0.37 & -0.64 & -0.48 & -0.43 & -0.46 & -0.59 & -0.32 & -0.40 & -0.28 \\
\hline Aragonita $\left(\mathrm{CaCO}_{3}\right)$ & -0.8 & 1.60 & 0.86 & 1.76 & 1.81 & 1.78 & 1.78 & 1.78 & 1.30 & 1.9 & -0.25 & 0.81 \\
\hline Arsenolita $\left(\mathrm{As}_{2} \mathrm{O}_{3}\right)$ & -15.4 & $\begin{array}{l}- \\
45.84\end{array}$ & $\begin{array}{l}- \\
16.86\end{array}$ & $\begin{array}{l}-\overline{6} \\
65.46\end{array}$ & $\begin{array}{l} \\
68.58\end{array}$ & $\begin{array}{l} \\
61.68\end{array}$ & $-54-6$ & $\begin{array}{l}- \\
47.04\end{array}$ & $\begin{array}{l} \\
32.53\end{array}$ & -23.6 & 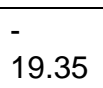 & -28.92 \\
\hline Calcita $\left(\mathrm{CaCO}_{3}\right)$ & -0.6 & 1.75 & 1.01 & 1.91 & 1.95 & 1.92 & 1.93 & 1.93 & 1.45 & 2.05 & -0.10 & 0.95 \\
\hline $\begin{array}{c}\text { Dolomita } \\
{\left[\mathrm{CaMg}\left(\mathrm{CO}_{3}\right)_{2}\right]}\end{array}$ & -1.99 & 2.67 & 1.33 & 3.01 & 3.14 & 3.09 & 3.03 & 3.13 & 2.22 & 3.24 & -0.90 & 1.20 \\
\hline $\begin{array}{c}\text { Huntita } \\
{\left[\left(\mathrm{CaMg}_{3}\left(\mathrm{CO}_{3}\right)_{4}\right]\right.}\end{array}$ & -9.03 & 0.15 & -2.39 & 0.86 & 1.15 & 1.08 & 0.89 & 1.18 & -0.58 & 1.31 & -6.83 & -2.66 \\
\hline $\begin{array}{c}\text { Hidromagnesita } \\
{\left[\mathrm{Mg}_{5}\left(\mathrm{CO}_{3}\right) 4(\mathrm{OH})_{2} \cdot 4 \mathrm{H}_{2}\right.} \\
\text { O] }\end{array}$ & $\begin{array}{l}- \\
21.87\end{array}$ & -5.81 & $\begin{array}{l} \\
10.73\end{array}$ & -3.10 & -2.55 & -2.76 & -2.90 & -2.72 & -7.83 & -4.56 & $\overline{17.46}$ & -11.17 \\
\hline Magnesita $\left(\mathrm{MgCO}_{3}\right)$ & -1.92 & 0.35 & -0.25 & 0.54 & 0.61 & 0.59 & 0.53 & 0.62 & 0.19 & 0.61 & -1.37 & -0.32 \\
\hline Fluorita $\left(\mathrm{CaF}_{2}\right)$ & -1 & -1 & -0.56 & -0.85 & -0.73 & -0.40 & -0.81 & -0.91 & -2.25 & -1.71 & -1.02 & -1.60 \\
\hline
\end{tabular}




\begin{tabular}{|c|c|c|c|c|c|c|c|c|c|c|c|c|}
\hline $\begin{array}{c}\text { Guerinita } \\
{\left[\mathrm{Ca}_{5} \mathrm{H}_{2}(\text { AsO })_{4} \cdot 9 \mathrm{H}_{2} \mathrm{O}\right]}\end{array}$ & -8.74 & -8.83 & -3.52 & -10.54 & -10.39 & -12.13 & -12.19 & -11.78 & -5 & -8.50 & -3.94 & -2.63 \\
\hline $\begin{array}{c}\text { Haidingerita } \\
{\left[\mathrm{CaHAsO} \cdot \mathrm{H}_{2} \mathrm{O}\right]}\end{array}$ & -1.69 & -3.50 & -1.51 & -4.41 & -4.42 & -4.81 & -4.87 & -4.68 & -2.13 & -3.42 & -1.03 & -1.25 \\
\hline $\mathrm{Yeso}\left(\mathrm{CaSO}_{4}: 2 \mathrm{H}_{2} \mathrm{O}\right)$ & -0.29 & -0.24 & -0.22 & -0.14 & -0.41 & -0.25 & -0.21 & -0.25 & -0.36 & -0.12 & -0.17 & -0.05 \\
\hline Halita $(\mathrm{NaCl})$ & -7.08 & -7.15 & -6.88 & -7.43 & -7.36 & -7.16 & -7.28 & -7.15 & -7.08 & -7.92 & -7.36 & -7.23 \\
\hline Hematita $\left(\mathrm{Fe}_{2} \mathrm{O}_{3}\right)$ & 9.15 & 15.21 & 15.44 & 13.41 & 13.37 & 13.75 & 13.41 & 13.63 & 17.52 & 18.41 & 14.27 & 18.57 \\
\hline
\end{tabular}


En el área de estudio, predominan condiciones oxidantes, en un medio con valores de $\mathrm{pH}$ cercanos a la neutralidad y valores ligeramente alcalinos que favorecen la presencia de especies de arsénico pentavalente que, como se ha mencionado, es más fácil de remover debido a sus propiedades eléctricas (se encuentran cargadas negativamente a diferencia de las especies de As(III) que son eléctricamente neutro). Para la remoción de arseniatos en agua, en el presente estudio, se emplea la electrodesionización (EDI) por las ventajas que presenta sobre las tecnologías convencionales.

En las secciones siguientes, se muestran los resultados de las pruebas de remoción de As en agua sintética preparada con $\mathrm{NaH}_{2} \mathrm{AsO}_{4} \cdot \mathrm{H}_{2} \mathrm{O}$ por la técnica de EDI; iniciando con los resultados de cinéticas e isotermas de adsorción para la resina aniónica Amberlite IRA-900. 


\subsection{Resultados de remoción de arsénico en agua sintética por la técnica de electrodesionización (EDI)}

\subsubsection{Isoterma de adsorción de Amberlite IRA-900}

En la figura 16 se muestran los datos experimentales y el ajuste a tres modelos no lineales de isotermas, esto para la resina Amberlite IRA-900.

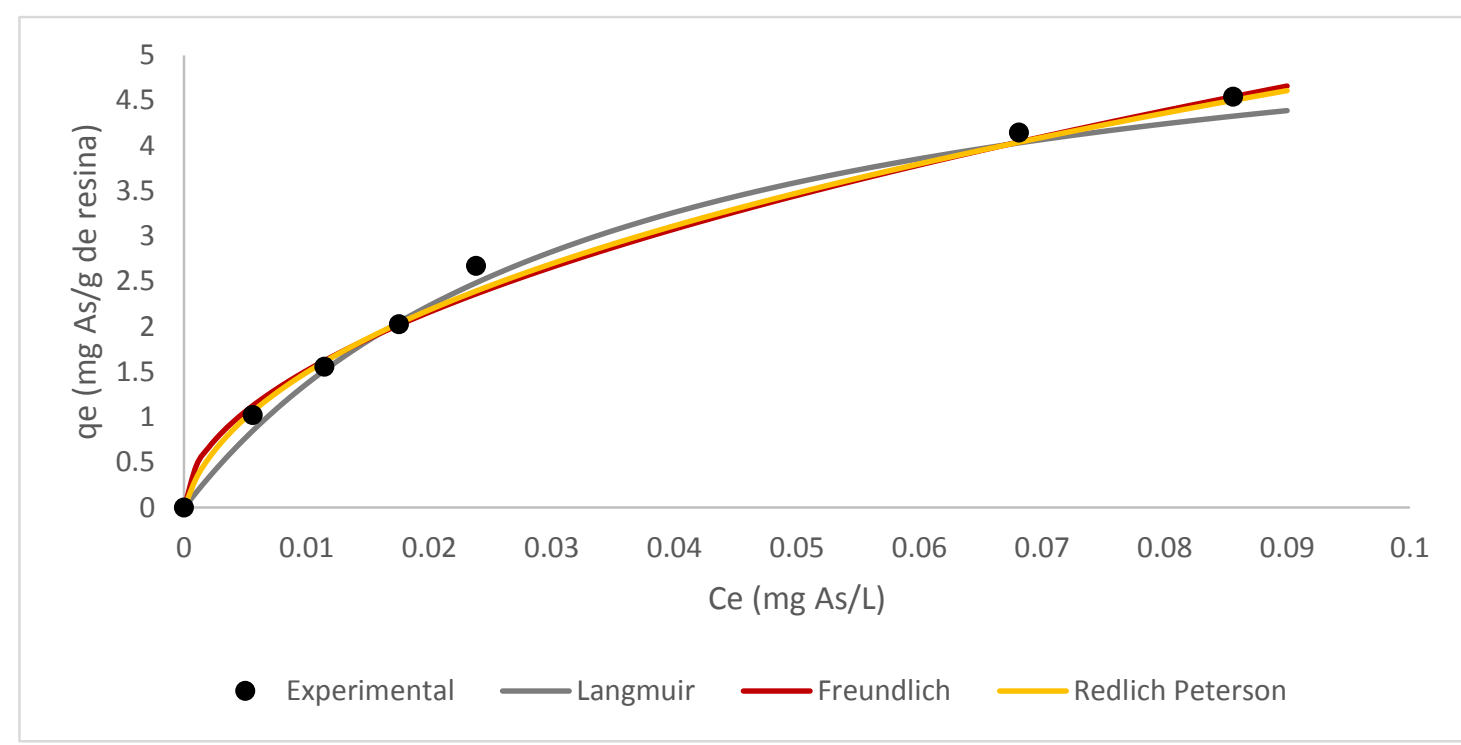

Figura 16. Datos experimentales y ajuste a modelos no lineales de isotermas de adsorción

El análisis de error indica que el modelo de Redlich Peterson es el que mejor representa el equilibrio del proceso de adsorción. Sin embargo, en el modelo de Freundlich se tiene un coeficiente de correlación ligeramente mayor en comparación con el obtenido en el modelo de Redlich-Peterson (tabla 18). Dada la similitud entre los coeficientes de correlación para los modelos de Freundlich y Redlich Peterson, se considera el parámetro " $g$ " del modelo de Redlich Peterson para determinar la influencia de cada uno de estos modelos en el proceso de adsorción. Para valores de "g" cercanos a 1, se indica que el proceso de adsorción 
se ajusta al modelo de Langmuir, mientras que, para valores menores a uno, se tiene que el proceso de adsorción se ajusta al modelo de Freundlich. En este caso, $\mathrm{g}<1$, por lo tanto, se tiene un proceso de adsorción de tipo Freundlich; ésto propone que el proceso de adsorción ocurre en multicapa sobre una superficie heterogénea por un proceso de quimisorción.

En el modelo de Freundlich, el coeficiente " $n$ " está relacionado con la intensidad de adsorción, para valores mayores a la unidad, se indica que los sitios activos son energéticamente equivalentes y la intensidad de adsorción es alta, relacionada a procesos de quimisorción (Rivas et al., 2014).

Tabla 18. Valores de coeficientes y constantes para cada modelo de isoterma

\begin{tabular}{|c|c|c|c|c|}
\hline \multicolumn{5}{|c|}{ Langmuir } \\
\hline Constante & Valor & $x^{2}$ & $\mathbf{R}^{2}$ & SSE \\
\hline Qo $\left(\mathrm{mg} \mathrm{g}^{-1}\right)$ & 7.01043 & \multirow[t]{2}{*}{0.0471} & \multirow[t]{2}{*}{0.9804} & \multirow[t]{2}{*}{0.315} \\
\hline $\mathrm{b}\left(\mathrm{dm}^{3} \mathrm{mg}^{-1}\right)$ & 28.1059 & & & \\
\hline \multicolumn{5}{|c|}{ Freundlich } \\
\hline Constante & Valor & $x^{2}$ & $\mathbf{R}^{2}$ & SSE \\
\hline $\mathrm{kf}\left(\mathrm{mg} \mathrm{g}^{-1}\right)$ & 17.3752 & \multirow[t]{2}{*}{0.0263} & \multirow[t]{2}{*}{0.9889} & \multirow[t]{2}{*}{0.153} \\
\hline $\mathrm{n}$ & 2.0231 & & & \\
\hline \multicolumn{5}{|c|}{ Redlich Peterson } \\
\hline Constante & Valor & $x^{2}$ & $\mathbf{R}^{2}$ & SSE \\
\hline $\mathrm{aR}\left(\mathrm{mg}^{-1}\right)$ & 40.127 & \multirow[t]{3}{*}{0.02987} & \multirow[t]{3}{*}{0.9850} & \multirow[t]{3}{*}{0.142} \\
\hline $\mathrm{kR}\left(\mathrm{Lg}^{-1}\right)$ & 579.267 & & & \\
\hline g & 0.65105 & & & \\
\hline
\end{tabular}




\subsubsection{Cinética de adsorción de Amberlite IRA-900}

Para la identificación de la dinámica de adsorción de iones arseniato sobre la resina aniónica Amberlite IRA-900, se analizó la evolución de la concentración de Arsénico en solución con respecto al tiempo a un pH de 7.8.

Los resultados se ajustaron a tres diferentes modelos cinéticos de adsorción en su forma no lineal: pseudo-primer orden, pseudo-segundo orden, y Elovich (Figura 17), referidos al porcentaje de adsorción con respecto al tiempo. En la gráfica (Figura 17), en los datos experimentales la cantidad de arsénico adsorbida sigue una tendencia exponencial. Al inicio del proceso, la velocidad de adsorción es elevada y disminuye paulatinamente hasta alcanzar el equilibrio. Después de 50 minutos, se llega al equilibrio, es decir, la concentración de arsénico en la solución se adsorbe lentamente sobre la superficie porosa de las resinas.

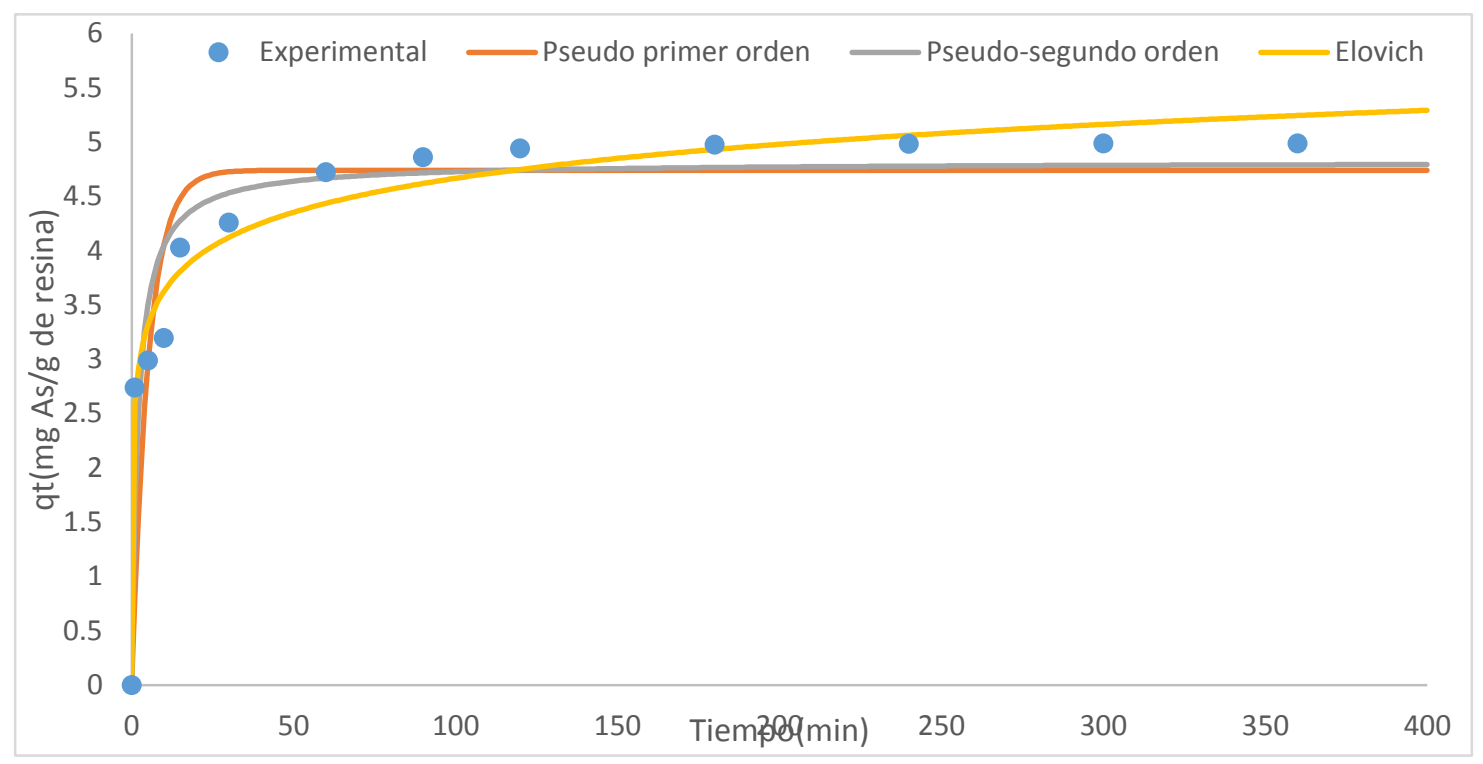

Figura 17. Datos experimentales y su ajuste a modelos no lineales de cinética de adsorción 
Los valores de los parámetros característicos obtenidos para los tres modelos lineales antes mencionados, junto con los coeficientes de correlación obtenidos, se resumen en la Tabla 19.

\section{Tabla 19. Valores de coeficientes y constantes para cada modelo no lineal de cinética}

\begin{tabular}{|c|c|c|c|c|}
\hline \multicolumn{5}{|c|}{ Pseudo-primer orden } \\
\hline Constante & Valor & $x^{2}$ & $R^{2}$ & SSE \\
\hline Qe $\left(\mathrm{mg} \mathrm{g}^{-1}\right)$ & 5.261 & \multirow[t]{2}{*}{0.51} & \multirow[t]{2}{*}{0.88} & \multirow[t]{2}{*}{4.79} \\
\hline $\mathrm{k}_{1}\left(\min ^{-1}\right)$ & 0.210 & & & \\
\hline \multicolumn{5}{|c|}{ Pseudo-segundo orden } \\
\hline Constante & Valor & $x^{2}$ & $\mathrm{R}^{2}$ & SSE \\
\hline Qe $\left(\mathrm{mg} \mathrm{g}^{-1}\right)$ & 5.341 & \multirow[t]{2}{*}{0.471} & \multirow[t]{2}{*}{0.924} & \multirow[t]{2}{*}{1.973} \\
\hline $\mathrm{K}_{2}\left(\min ^{-1}\right)$ & 0.17 & & & \\
\hline \multicolumn{5}{|c|}{ Elovich } \\
\hline Constante & Valor & $x^{2}$ & $\mathrm{R}^{2}$ & SSE \\
\hline$\alpha\left(\mathrm{g} \mathrm{mg}^{-1} \mathrm{~min}^{-2}\right)$ & 156.4 & \multirow[t]{2}{*}{0.04} & \multirow[t]{2}{*}{0.98} & \multirow[t]{2}{*}{0.57} \\
\hline$\beta\left(\min ^{-1}\right)$ & 3.3412 & & & \\
\hline
\end{tabular}

De acuerdo con los resultados mostrados (Tabla 19), el modelo de Elovich es el que describe mejor el comportamiento de las cinéticas para la resina amberlite IRA900. Este modelo describe la cinética de la quimisorción de fases sobre superficies sólidas no homogéneas, basados en mecanismos de reacción de segundo orden. De acuerdo con esto, se tiene que el proceso de adsorción está controlado por reacciones químicas. Esto coincide con el resultado de la isoterma en donde, el modelo que mejor representa el equilibrio del proceso de adsorción (RedlichPeterson) hace referencia a procesos de quimisorción. 
En el modelo de Elovich, el parámetro a está relacionado con la velocidad de quimisorción y el parámetro $\beta$ con la superficie cubierta. En tiempos menores a 15 minutos, se tiene una rápida adsorción de arsénico debido a que la superficie de las resinas está libre, al disminuir la superficie de adsorción $(\beta)$ disponible para los adsorbatos se tiene una adsorción más lenta, provocando una disminución en la velocidad de adsorción (Pinzón-Bedoya et al., 2009).

\subsubsection{Pruebas de electrodesionización}

\subsubsection{1 $\mathrm{pH}$}

La celda de EDI, es un circuito eléctrico cerrado en el que se tienen los conductores metálicos y los conductores formados por la solución electrolítica. La corriente consiste en un flujo de electrones en la parte metálica del circuito y un flujo de iones en la parte donde se concentra el fluido. Al tiempo cero, el $\mathrm{pH}$ en los tres compartimentos es de 7.8. En la figura 18, se muestra el comportamiento del pH en los tres compartimentos: anódico, catódico y compartimento del diluido. $\mathrm{La}$ concentración de la solución de $\mathrm{NaH}_{2} \mathrm{AsO}_{4} \cdot \mathrm{H}_{2} \mathrm{O}$ fue de $15 \mathrm{mg} / \mathrm{L}$.

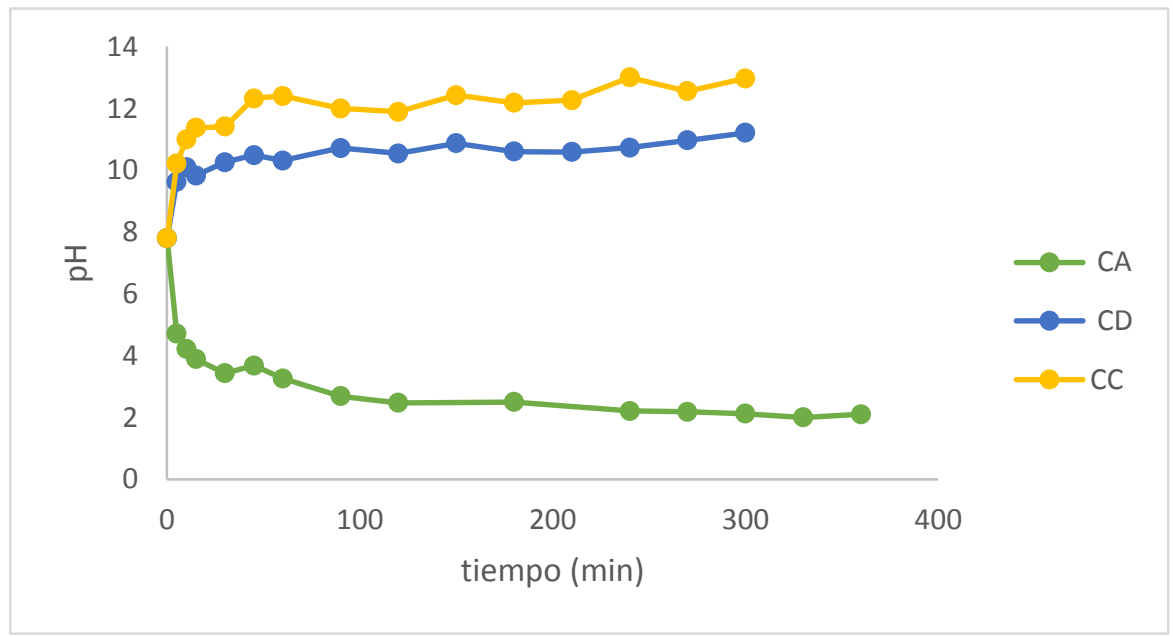

Figura 18. comportamiento del $\mathrm{pH}$ en los tres compartimentos: Compartimento Anódico (CA), Compartimento del Diluido (CD) y compartimento Catódico (CC) (lecho mixto) 
Una vez iniciado el proceso de electrodesionización, el pH en el compartimento del diluido (CD) tiende a incrementar su valor, basificándose (Figura 18). Con la aplicación de corriente eléctrica, los iones de arseniato se disocian intercambiándose por los iones $\mathrm{Cl}^{-}$presentes en el lecho de resina y migrando a través de las membranas semipermeables hacia su contra electrodo. La corriente aplicada también produce la disociación del agua, dando origen a la formación de iones $\mathrm{H}^{+}$y $\mathrm{OH}^{-}$, que favorecen la regeneración de las resinas impidiendo la acumulación de iones.

En el compartimento anódico (CA), en torno al ánodo, ocurre la reacción de oxidación por la aplicación de corriente eléctrica. Aquí el agua es oxidada a través de la siguiente reacción:

$$
2 \mathrm{H}_{2} \mathrm{O} \leftrightarrow \mathrm{O}_{2}+4 \mathrm{H}^{+}+4 \mathrm{e}^{-}(5.1)
$$

favoreciendo la producción de protones y provocando una importante disminución en el pH. Por esta razón, el pH en este compartimento tiende a acidificarse (Figura 18).

En el compartimento catódico $(\mathrm{CC})$ ocurre la reacción de reducción del agua:

$$
2 \mathrm{H}_{2} \mathrm{O}+2 \mathrm{e}^{-} \leftrightarrow \mathrm{H}_{2}+{ }_{2} \mathrm{OH}^{-} \quad \text { (5.2) }
$$

favoreciendo la producción de iones $\mathrm{OH}^{-}$, incrementado el $\mathrm{pH}$ y basificando el medio (Figura 18).

Al cambiar el lecho, a aniónico, el pH sigue el mismo comportamiento que en las pruebas con lecho mixto (Figura 19). En el compartimento aniónico (CA), el pH desciende hasta un valor de 5 unidades en los primeros 5 minutos; al finalizar la prueba, en 280 minutos, se tiene un valor de 2.1, en este compartimento. En el compartimento catiónico (CC), las condiciones del medio se vuelven básicas, alcanzando un valor de 12.9 al final de la prueba. Finalmente, en el CD, al igual que en el CC, las condiciones del medio se basifican. 


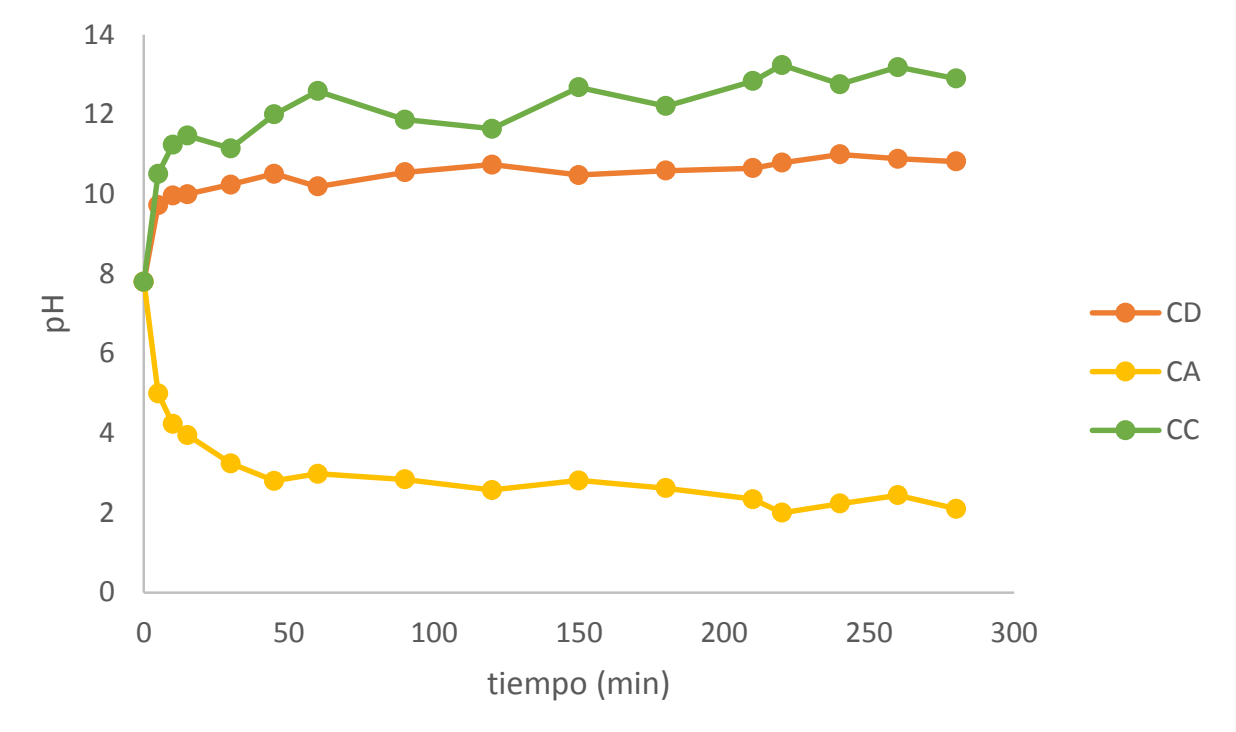

Figura 19. Comportamiento del pH en los tres compartimentos:

Compartimento Anódico (CA), Compartimento del Diluido (CD) y compartimento Catódico (CC) (lecho aniónico)

\subsubsection{Conductividad}

Dentro de la celda, la corriente eléctrica fluye del ánodo hacia el cátodo debido a la diferencia de potencial eléctrico entre los electrodos. En los compartimentos, anódico y catódico, existe conductividad al tiempo cero $(9.89 \mathrm{mS} / \mathrm{cm})$ debido a los iones $\mathrm{Na}^{+}$y $\mathrm{SO}_{4}^{-}$presentes en la solución de $\mathrm{Na}_{2} \mathrm{SO}_{4}(0.1 \mathrm{M})$ disociada (5.3), utilizada como electrolito soporte.

$$
\mathrm{Na}_{2} \mathrm{SO}_{4} \leftrightarrow 2 \mathrm{Na}^{+}+\mathrm{SO}_{4}{ }^{2-}
$$

Con la aplicación de corriente eléctrica, la conductividad en ambos compartimentos se incrementa por un aumento en la concentración iónica, causada por la migración de los iones arseniato (provenientes del CD) y por las reacciones de oxidación (formación de protones) y reducción (generación de iones $\mathrm{OH}^{-}$) que ocurren en el ánodo y cátodo, respectivamente. Un incremento en la concentración de iones, es lo que provoca el aumento de la conductividad (Figura 20 y 21). 
Al tiempo cero, la conductividad en el compartimento del diluido (CD) es de 0.36 $\mathrm{mS} / \mathrm{cm}$; esto debido a la presencia de los iones de la sal de arseniato. Con la aplicación de corriente eléctrica, los iones disociados, migran hacia los compartimentos adyacentes ( $\mathrm{CA}$ y $\mathrm{CC}$ ), provocando una disminución en la conductividad (Figura 21). Al cambiar el lecho a aniónico, la conductividad eléctrica aumenta en los compartimentos donde se encuentra el electrolito soporte (CA Y $\mathrm{CC}$ ), debido a las reacciones de oxidación y reducción del agua (Figura 20).

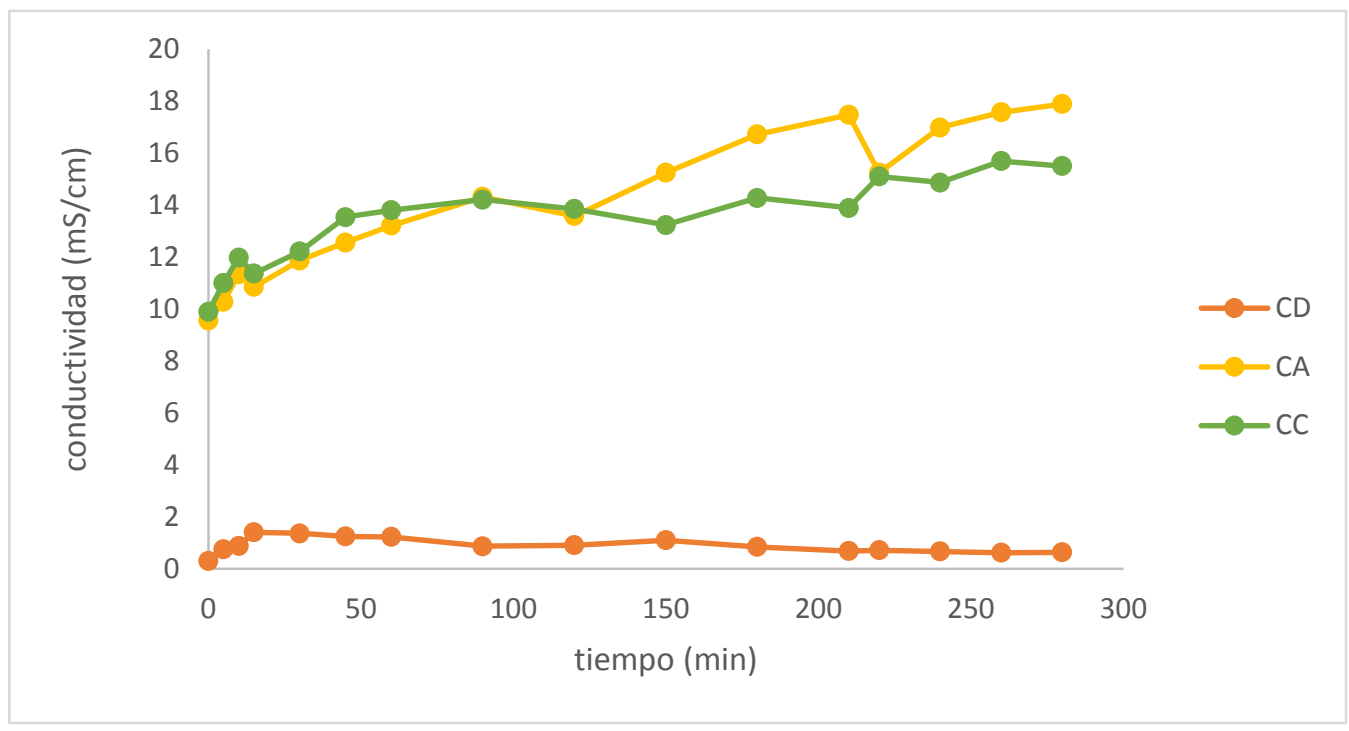

Figura 20. Conductividad eléctrica para los tres compartimentos: Compartimento Anódico (CA), Compartimento del Diluido (CD) y compartimento Catódico (CC) (lecho aniónico) 


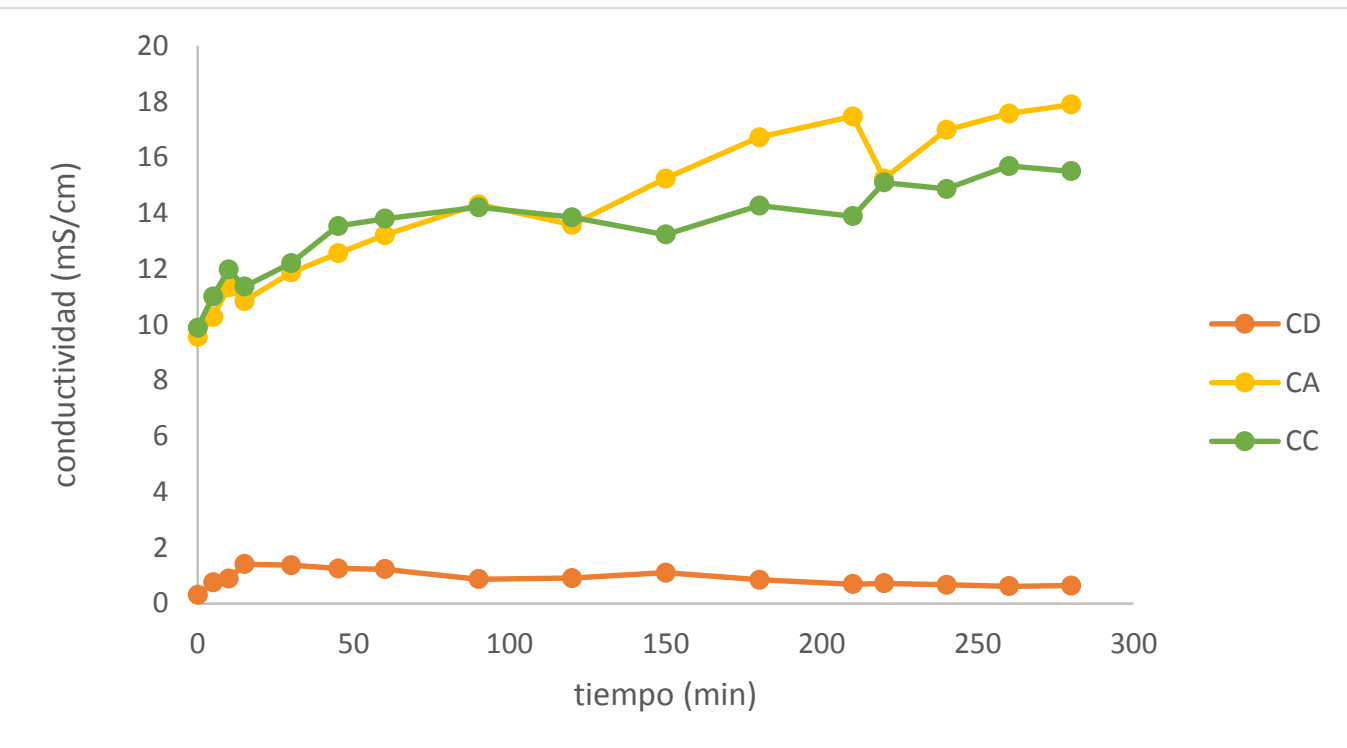

Figura 21. Conductividad eléctrica para los tres compartimentos: Compartimento Anódico (CA), Compartimento del Diluido (CD) y compartimento Catódico (CC) (lecho mixto)

\subsubsection{Potencial redox}

El potencial redox (Eh), mide la actividad de los electrones, a diferencia del $\mathrm{pH}$, que mide la actividad de los protones. En el compartimento del diluido (CD), el potencial redox disminuye hacia valores negativos debido a las condiciones reductoras del medio (Figuras 22 y 23); los iones $\mathrm{OH}^{-}$producidos por la hidrólisis del agua (causada por la diferencia de potencial), basifican el medio, generando así las condiciones reductoras.

En el compartimento anódico, al tiempo cero, se tiene $38.6 \mathrm{mV}$, durante los primeros cinco minutos de aplicar corriente eléctrica, este valor aumenta hasta 148 $\mathrm{mV}$. A partir del tiempo de100 minutos, las fluctuaciones disminuyen (Figura 23). Las condiciones oxidantes en el compartimento anódico, explican los valores positivos de Eh medidos en este compartimento. Por el contrario, en el compartimiento catódico, se tienen condiciones reductoras, al igual que en el 
compartimento del diluido, por lo que los valores de Eh disminuyen (Figuras 22 y 23).

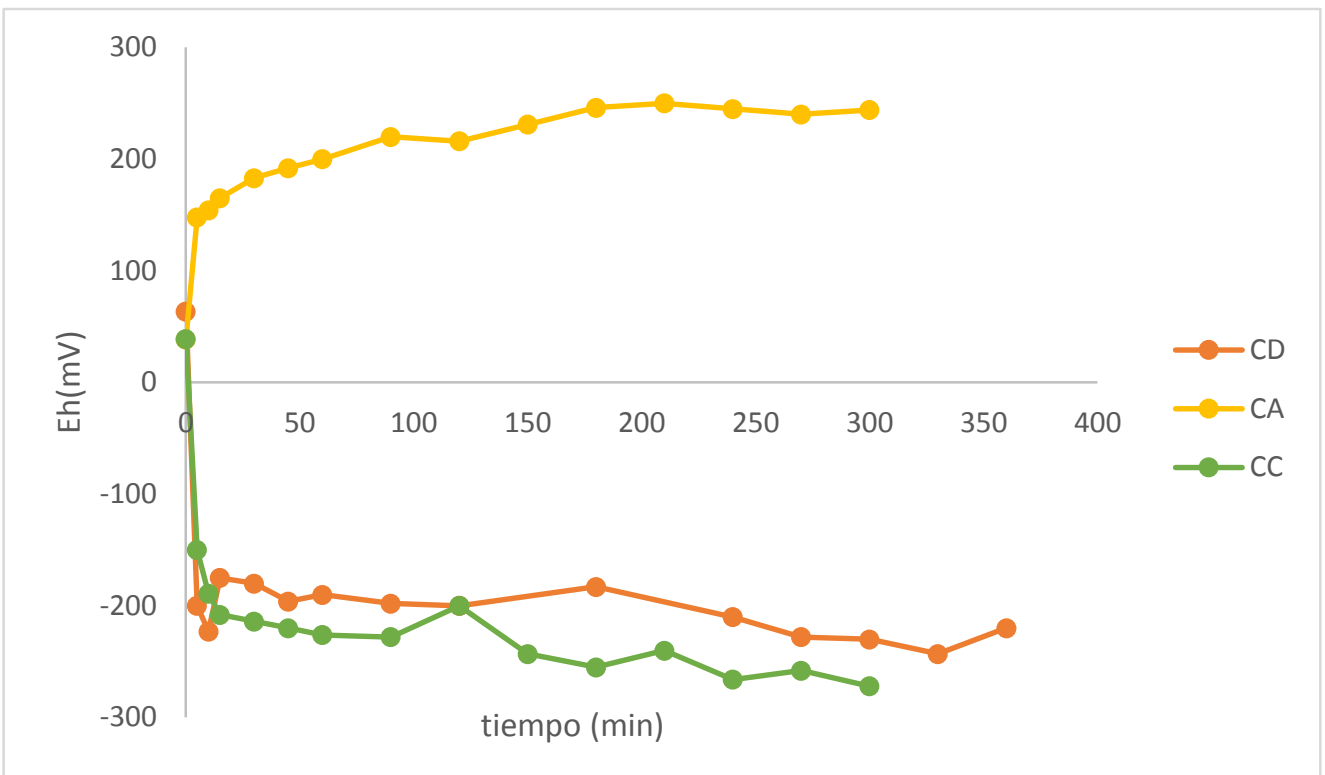

Figura 22. Potencial redox, para los tres compartimentos: Compartimento Anódico (CA), Compartimento del Diluido (CD) y compartimento Catódico (CC) (lecho mixto)

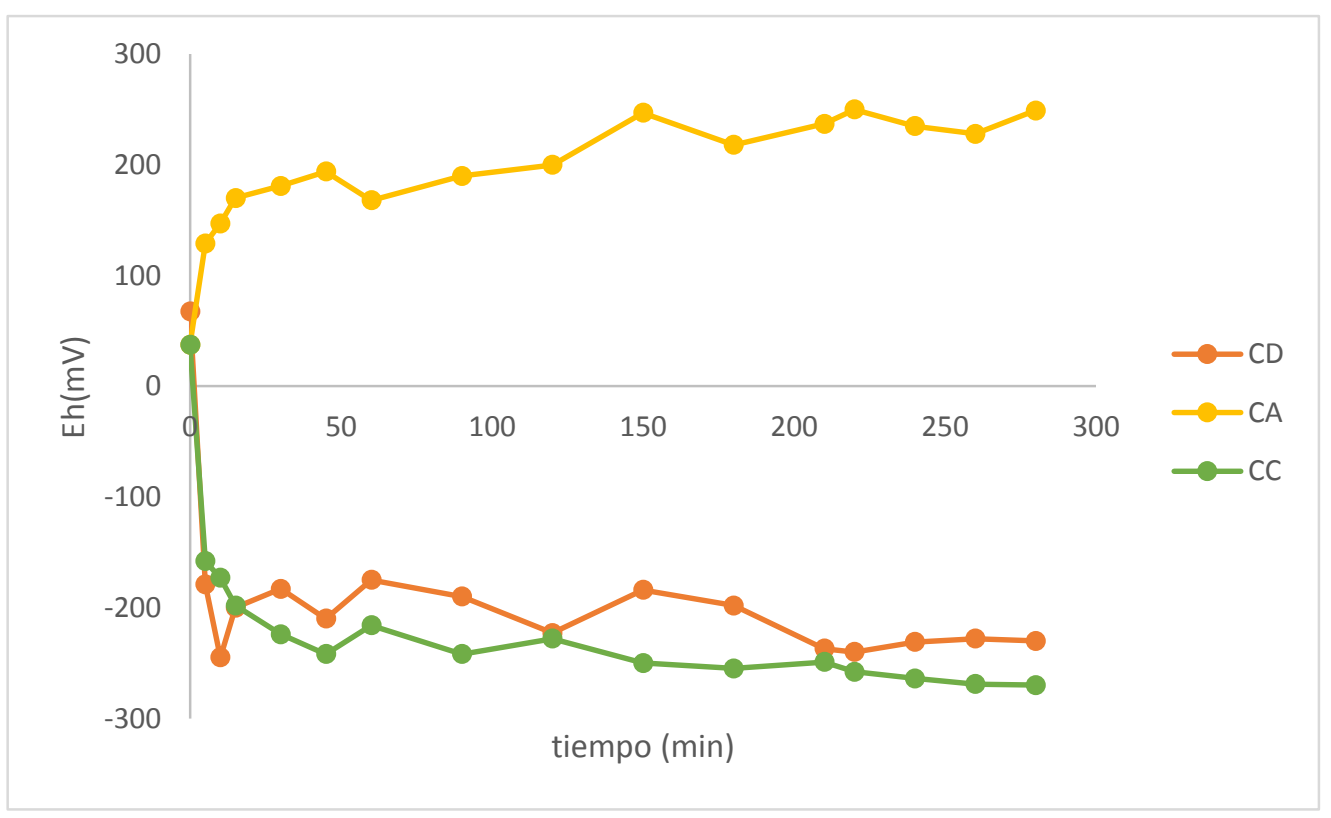

Figura 23. Potencial redox, para los tres compartimentos: Compartimento Anódico (CA), Compartimento del Diluido (CD) y compartimento Catódico (CC) (lecho aniónico) 


\subsubsection{Pruebas de remoción de arsénico}

En el proceso de electrodesionización, la regeneración "in situ" del lecho de resinas es de suma importancia para la viabilidad del proceso. Las resinas de intercambio iónico adsorben los iones arseniato que posteriormente son desorbidos, moviéndose a través de la membrana aniónica y migrando hacia el ánodo. En el 2009 , Alvarado y colaboradores mencionan que la electro-regeneración de la resina se lleva a cabo en lugares donde hay material catiónico en contacto con material aniónico y viceversa, por lo que, al utilizar lecho aniónico, la regeneración de la resina se realizará entre la membrana catiónica y la resina aniónica. Por el contrario, si el lecho es mixto, la cantidad de sitios de electro regeneración será mayor.

En la tabla 20 se muestran los resultados de las pruebas de remoción de arsénico a $15 \mathrm{mg} / \mathrm{L}$ y $50 \mathrm{mg} / \mathrm{L}$ en el compartimento del diluido (CD). Para cada prueba se muestra el porcentaje de remoción y, en las figuras 24,25 y 26 se muestra la remoción de As en el CD en función del tiempo, así como la acumulación de iones arseniato en el CA. Para la cuantificación de arsénico, se calculó el límite de detección (cantidad mínima de analito cuya señal puede ser detectada) y de cuantificación (cantidad mínima de analito que puede cuantificarse con exactitud) del método. El cálculo de límite de detección (L.D.) se hizo con la siguiente fórmula:

$$
Y_{l d}=b+3 s y c
$$

En donde: $b=$ señal del blanco (ordenada al origen) y Syc= desviación estándar del blanco. Se obtiene un resultado en unidades de absorbancia $\left(\mathrm{L} \mathrm{mol}^{-1} \mathrm{~cm}^{-1}\right)$ por lo que, para convertirlo en concentración $(\mathrm{mg} / \mathrm{L})$ se utilizó la ecuación de la recta, obtenida al realizar análisis de regresión lineal entre la concentración de estándares de concentración conocida y su lectura de absorbancia (Corley, 2003). Por otro lado, el límite de cuantificación (L.C.) se obtuvo con:

$$
Y_{l d}=b+10_{\text {syc }}
$$

Para convertir el resultado en concentración ( $\mathrm{mg} / \mathrm{L})$, se siguió el procedimiento descrito para límite de detección (Corley, 2003). 
Tabla 20. Límites de detección y cuantificación para arsénico

\begin{tabular}{|l|c|c|c|}
\hline Elemento & $\begin{array}{c}\text { Límite de } \\
\text { detección (L.D.) } \\
(\mathbf{p p m})\end{array}$ & $\begin{array}{c}\text { Límite de } \\
\text { cuantificación (L.C.) } \\
(\mathbf{p p m})\end{array}$ & Observaciones \\
\hline Arsénico & 0.01 & 0.04 & $\begin{array}{c}\text { Las soluciones fueron } \\
\text { preparadas con NaH2AsO4.H2O } \\
\text { y agua desionizada }\end{array}$ \\
\hline
\end{tabular}

Tabla 21. Concentración de arsénico en el compartimento del diluido

\begin{tabular}{|c|c|c|c|}
\hline $\begin{array}{c}\text { Concentración } \\
\text { de la solución } \\
\text { (ppm) }\end{array}$ & $\begin{array}{c}\mathbf{1 5} \mathbf{~ p p m} \\
\text { Lecho mixto }\end{array}$ & $\begin{array}{c}\mathbf{1 5} \mathbf{~ p p m} \\
\text { Lecho } \\
\text { aniónico }\end{array}$ & $\begin{array}{c}\mathbf{5 0} \mathbf{~ p p m} \\
\text { Lecho } \\
\text { aniónico }\end{array}$ \\
\hline $\begin{array}{c}\text { Concentración } \\
\text { inicial (mg/L) }\end{array}$ & 15 & 15 & 50 \\
\hline $\begin{array}{c}\text { Concentración } \\
\text { final (mg/L) }\end{array}$ & <L.D. & <L.D. & 0.016 \\
\hline$\%$ de remoción & 100 & 100 & 99.98 \\
\hline $\begin{array}{c}\text { Tiempo de } \\
\text { remoción (min) }\end{array}$ & 300 & 280 & 690 \\
\hline
\end{tabular}

En la tabla 21, se reportan resultados por debajo del límite de detección (0.01ppm) para las muestras con concentración inicial de 15 ppm.

En la figura 24 se muestran los resultados de remoción en lecho mixto a $15 \mathrm{mg} / \mathrm{L}$ de $\mathrm{Na}_{2} \mathrm{HAsO}_{4} \cdot 7 \mathrm{H}_{2} \mathrm{O}$. Con lecho mixto, se utilizaron las resinas Amberlite IRA-900 (resina aniónica) y Amberlite IRA-120 (resina catiónica) en proporción 1:1 tal como se describe en el numeral 4.4.2. El tiempo para eliminar por completo los iones arseniato es de 300 minutos. En el compartimento anódico (CA), la concentración de As al tiempo cero es de $0.02 \mathrm{mg} / \mathrm{L}$, al finalizar la prueba en el electrodesionizador, la concentración en este compartimento es de $15.05 \mathrm{mg} / \mathrm{L}$ de As, debido a que los iones de la sal de arseniato, presentes en el compartimento 
del diluido (CD), han migrado hacia el ánodo por la aplicación de corriente eléctrica. De acuerdo con estos resultados, la regeneración "in situ" de la resina, es completa, los iones arseniato se recuperan por completo en el compartimento anódico, esto significa que la migración de los iones de la sal de arsénico en la superficie de la membrana es constante e indica que las resinas se regeneran. El excedente en el balance de masas entre la entrada (CD) y salida (CA) se debe a la acumulación de As en pruebas anteriores.

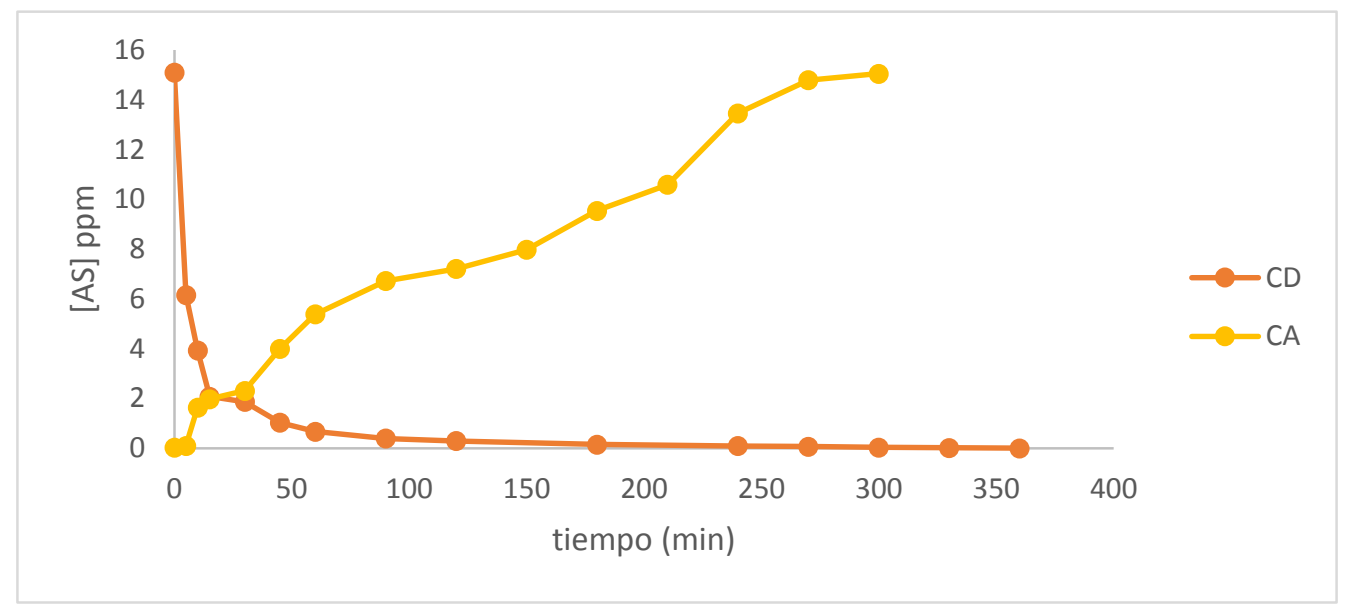

Figura 24. Remoción de Arsénico en lecho mixto a 15 ppm de As(V) 
En las figuras 25 y 26 se muestran los resultados de remoción de As en agua utilizando lecho de resinas aniónico y dos concentraciones distintas: 15 y 50 ppm de As (V).

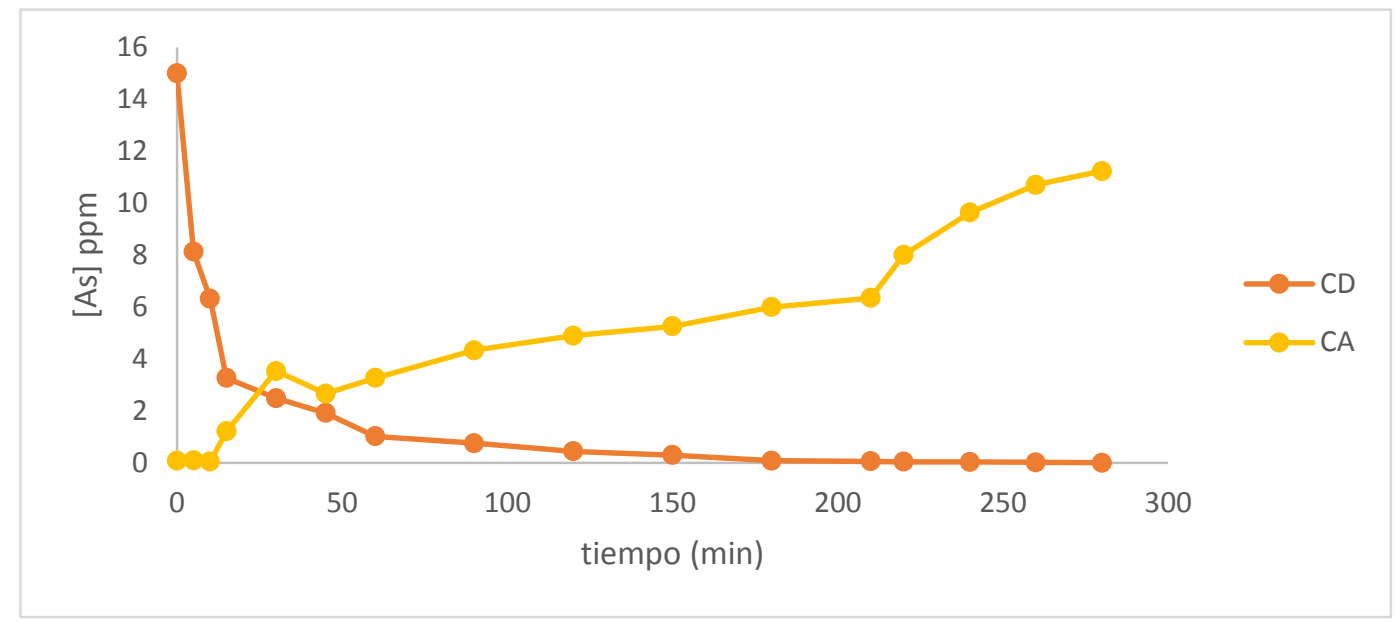

Figura 25. Remoción de Arsénico en lecho aniónico a 15 ppm de As(V)

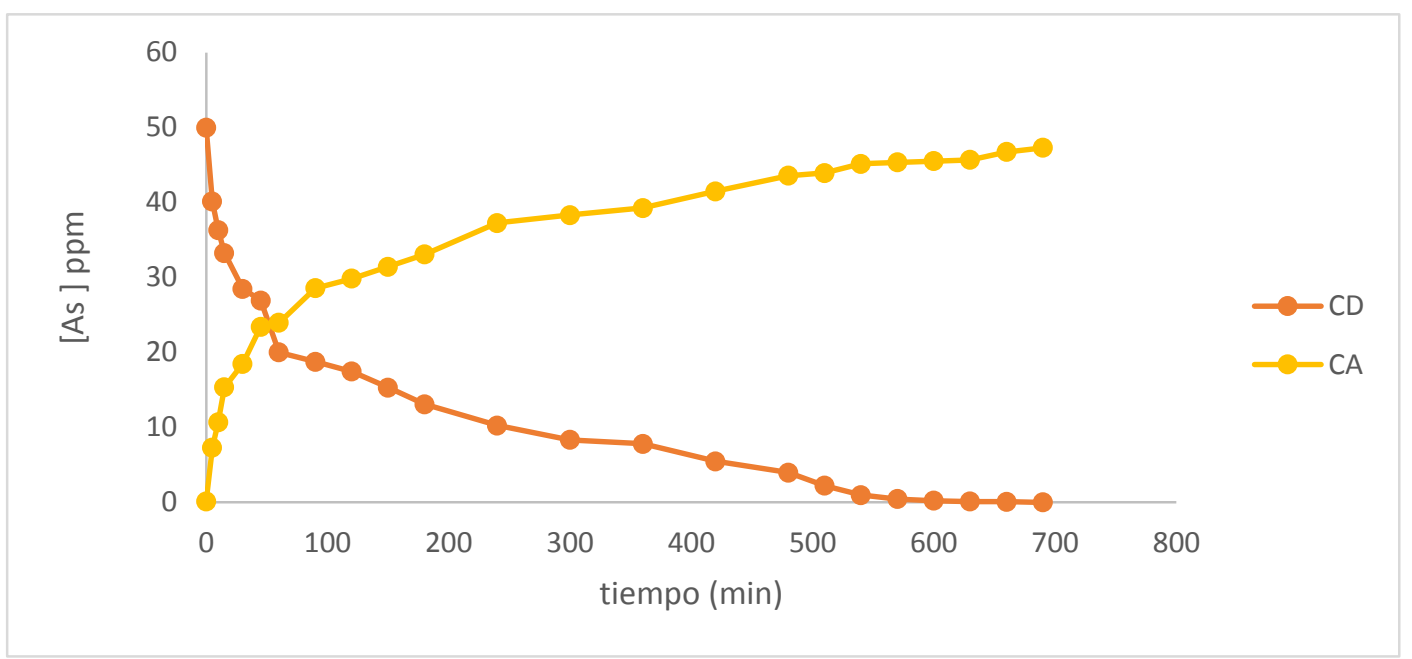

Figura 26. Remoción de As en lecho aniónico a 50 ppm de As(V)

En las pruebas de remoción con lecho aniónico (resina aniónica Amberlite IRA900), en el compartimento del diluido se inicia con una concentración de $15 \mathrm{mg} / \mathrm{L}$, mientras que, en el compartimento anódico, al tiempo cero se tiene una 
concentración de $0.07 \mathrm{mg} / \mathrm{L}$ de As. Al finalizar la prueba en 280 minutos, en el CD se llega a valores por debajo del límite de detección $(0.01 \mathrm{mg} / \mathrm{L})$ mientras en el CA se tiene una concentración de $11.24 \mathrm{mg} / \mathrm{L}$. No se están recuperando por completo los iones arseniato en el compartimento anódico, esto significa que la resina se está regenerando lentamente. Este comportamiento se debe a la disminución de sitios de regeneración; como menciona Alvarado y colaboradores (2009).

A una concentración de 15 ppm, se logra remover el arsénico del compartimento del diluido a valores inferiores a $0.01 \mathrm{mg} / \mathrm{L}$ de arsénico (Límite de detección). Estos resultados se obtienen tanto en las pruebas con lecho de resinas aniónico como en lecho de resinas mixto. La diferencia entre las pruebas con lecho aniónico y lecho mixto es el tiempo de remoción, ya que utilizando lecho aniónico, este tiempo se reduce considerablemente; sin embargo, la regeneración de la resina no es completa; se observa que la recuperación de los iones arseniato en el compartimento anódico no es total (Figura 25). Esto quiere decir que algunos iones no se están desorbiendo de la resina aniónica y que la electro-regeneración es más lenta.

En las pruebas de remoción con lecho aniónico, a una concentración de 50 ppm; en el compartimento del diluido se inicia con $50 \mathrm{mg} / \mathrm{L}$ de As al tiempo cero. En el compartimento anódico se inicia con $0.1 \mathrm{mg} / \mathrm{L}$ de As. Transcurridos 690 minutos; en el CD no se han eliminado por completo los iones arseniato, aun así, se ha obtenido una concentración que está dentro de los límites máximos permisibles establecidos en la NOM-127-SSA1-1994 (Tabla 4). Al finalizar la prueba, en el CA se tiene una concentración de $47.31 \mathrm{mg} / \mathrm{L}$ de As. Se repite el comportamiento observado en las pruebas con $15 \mathrm{mg} / \mathrm{L}$ de As; la regeneración del lecho de resina aniónica es más lenta que la regeneración en lecho mixto. En los primeros 150 minutos, se observa una mayor velocidad de remoción (Figura 25), esta velocidad disminuye a partir de los 200 minutos, alentando el proceso de remoción. 


\section{Capítulo 6}

\section{Conclusiones}

Como resultado de esta investigación, se concluye que en la zona muestreada correspondiente a los puntos Club de Tiro (CT) y Tecnológico Regional (TR), en la comunidad de Matehuala, la composición química del agua está determinada principalmente por la composición química de las rocas. De acuerdo al diagrama de Piper, se tiene un agua de tipo sulfatada cálcica. En cuanto a los resultados de las modelaciones de la zona delimitada por los puntos CT y TR, se derivan las siguientes conclusiones:

- De la especiación de arsénico derivada de modelación directa, se tiene que el arsénico está predominantemente como $\mathrm{As}(\mathrm{V})$. La especie que presentó el mayor porcentaje relativo fue $88.5 \%$. de $\mathrm{CaAsO}_{4}$.

- De acuerdo con los datos de modelación hidrogeoquímica, se sugiere que la adsorción de arseniatos sobre la superficie de calcita podría favorecer la disminución de concentración de arsénico entre los puntos de muestreo Club de Tiro y Tecnológico Regional, aunque este mecanismo no es suficiente para controlar la movilidad de arsénico debido a la alta solubilidad de sus fases.

Se propone la electrodesionización (EDI) como tratamiento terciario eficiente para el agua contaminada con As proveniente de Matehuala, las concentraciones estudiadas en el proceso de remoción (15 y $50 \mathrm{mg} / \mathrm{L}$ de As) se encontraron en el intervalo de concentraciones muestreadas en la zona de estudio. Debido a las eficiencias en remoción mostradas en las pruebas experimentales realizadas para el presente estudio, se demuestra que el proceso es capaz de remover As en aguas sintéticas altamente contaminadas.

Es importante recordar que el agua utilizada en las pruebas de EDI, es agua sintética, preparada con $\mathrm{Na}_{2} \mathrm{HAsO}_{4} \cdot 7 \mathrm{H}_{2} \mathrm{O}$ y agua desionizada; si se agregaran los 
iones mayoritarios presentes en el agua analizada de Matehuala, existiría mayor competencia por los sitios activos de las resinas de intercambio iónico, disminuyendo el tiempo de remoción de As.

En cuanto a los resultados obtenidos en las pruebas de EDI, se derivan las siguientes conclusiones:

- El análisis de error en los resultados de isotermas de adsorción indica que el modelo no lineal que mejor describe el equilibrio del proceso de adsorción es Redlich-Peterson, indicando procesos de quimisorción. Este resultado coincide con el obtenido en la cinética de adsorción, en donde, de acuerdo a los resultados, el modelo de Elovich es el que mejor describe el comportamiento de la cinética de adsorción. Este modelo también hace referencia a procesos de quimisorción sobre superficies heterogéneas. Esto explica la mayor adsorción de As en tiempos cortos debido a la disponibilidad de sitios activos en la superficie de la resina.

- Las pruebas de EDI sobre lecho de resinas aniónico mostraron mayor eficiencia en cuanto a tiempo de remoción, en comparación con las pruebas sobre lecho de resinas mixto. Sin embargo, en las pruebas con lecho aniónico, la regeneración "in situ" de las resinas es más lento en comparación con las pruebas en lecho mixto.

- En comparación con los resultados obtenidos en 2018 por Gutiérrez-López, en donde, a una concentración de 50 ppm de $\mathrm{Na}_{2} \mathrm{HAsO}_{4} \cdot 7 \mathrm{H}_{2} \mathrm{O}$, en un tiempo de 720 minutos, se obtuvo una concentración final de $0.75 \mathrm{ppm}$; los resultados presentados muestran mayor eficiencia en remoción. Las condiciones experimentales utilizadas en el presente estudio, fueron las mismas que se utilizaron en 2018. La diferencia entre los experimentos fue el tipo de membrana utilizada. 


\section{Recomendaciones}

Para el tratamiento de los residuos generados en las pruebas de electrodesionización (soluciones sintéticas de $\mathrm{Na}_{2} \mathrm{HAsO}_{4} \cdot 7 \mathrm{H}_{2} \mathrm{O}$ ) podría considerarse el uso de materiales de óxidos de hierro como sorbentes, por su bajo costo. Investigaciones realizadas por Petkova (1998) identifican la hematita como un sorbente alternativo para la remoción de arsénico, siempre y cuando se mantenga un pH en el intervalo de 6.5 a 7.0 para evitar la solubilización del hierro (componente principal de la hematita).

En el proceso de electrodesionización se utilizaron soluciones sintéticas de arsénico; sin embargo, para probar la eficiencia del proceso de electrodesionización, se recomienda añadir iones tales como sulfatos y cloruros (presentes en el agua del complejo hidráulico Matehuala-Cerrito Blanco) a la solución sintética de arsénico (Compartimento Diluido), con el fin de que el agua tratada se asemeje al agua real. Es probable que el tiempo de remoción sea mayor debido a la selectividad de las resinas. 


\section{Bibliografía}

Abernathy , C., Calderon , R., \& Chappell, W. (2012). Arsenic: Exposure and Health effects. Springer Science \& Business Media.

Adamson, A., \& Gast, A. (1997). Physical Chemistry of Surfaces, sixth ed.,. New York: Wileylnterscience.

Agilent. (2018). MP-AES Systems. Obtenido de https://www.agilent.com/en/products/mp-aes/mpaes-systems/4200-mp-aes

Al-Awadi, M., Clark, W., Moore, W., Herron, M., Zhang, T., Zhao , W., \& Sadooni, F. (2009). La dolomía: Aspectos de un mineral desconcertante. Oiffield Review, 32-47.

Albarrán-Zavala, E. (2008). El potencial redox y la espontaneidad de lasreacciones electroquímicas. Latin-American Journal of Physics Education.

Alvarado , L. (2009). Estudio del mecanismo de electrodesionización aplicado a la remoción de cromo hexavalente. Universidad Autónoma de San Luis Potosí, San Luis Potosí: Tesis Doctoral.

Alvarado, L., Ramírez, A., \& Rodríguez-Torres, I. (2009). Cr (VI) removal by continuous electrodeionization: Study of its basic technologies. Desalination, 423-428.

André, L., Franceschi, M., Pouchan, P., \& Atteia, O. (2005). Using geochemical data and modelling to enhance the understanding of groundwater flow in a regional deep aquifer, Aquitaine Basin, south-west of France. Journal of Hydrology, 40-62.

Appelo, C., \& Postma, D. (1993). Geochemistry, Groundwater and Pollution. Rotterdam, Netherlands: Balkema.

Armienta , M., Villaseñor , G., Rodríguez, R., Ongley, L., \& Mango , H. (2001). The role of arsenicbering rocks in groundwater pollution at Zimapán Valley, Mexico. Environmental Geology, 571-581.

Armienta , M., Villaseñor, G., Cruz, O., Ceniceros, N., Aguayo, A., \& Morton , O. (2012). Geochemical processes and mobilization of toxic metals and metalloids in an As-rich base metal waste pile in Zimapán, Central Mexico. Applied geochemistry . 
Armienta, M., Vilaclara, G., De la Cruz-Reyna, S., Ramos , S., Ceniceros, N., Cruz, O., \& ArcegaCabrera, F. (2008). Water chemistry of lakes related to active and inactive Mexican volcanoes. Journal of Volcanology and Geothermal Research, 249-258.

Back, W., \& Hanshaw, B. (1970). Comparison of chemical hydrogeology of the carbonate peninsulas of Florida and Yucatan. Journal of Hydrology, 330-368.

Benavente, O. (2015). Origen y naturaleza de los fluidos de los sistemas volcánicos e hidrotermales activos de los Andes de Chile Central. Universidad de Chile: Tesis de Doctorado.

Birkle, P., \& Merkel, B. (2000). Environmental impact by spill of geothermal fluids at the geothermal field Los Azufres, Michoacán. Water, air and soil pollution, 371-410.

Castro de Esparza, M. L. (2006). Natural arsenic in groundwaters of Latin America. Obtenido de http://www.bvsde.paho.org/bvsacd/cd51/remocion-agua.pdf

Castro, L., Kramar, U., \& Puchelt, H. (1997). 200 years of mining activities at La Paz/San Luis Potosí México. Consequences for enviroment and geochemical exploration. Geochem explor, 8191.

Castro-Larragoitia, J., Kramar, U., \& Puchelt, H. (1970). 200 years of mining activities at La Paz, San Luis Potosí, MéxicoConsequences for enviromental and geochemical exploration. Geochem Explor.

Chadha, D. (1999). A proposed new diagram for geochemical classification of natural waters and interpretation of chemical data. Hydrogeology journal.

Chávez, L., Alarcón, F., \& Parga, J. (1999). Minning Exploration Potential of VMS and Carbonatehosted Polymetallic Deposits in Central Mexico. British Columbia and Yukon Chamber of Mines, 1-13.

Choi, Y., Kang, M., \& Moon, S. (2002). A new preparation method for cation exchange membrane using monomer sorption into reinforcing materials. Desalination, 287-291.

Choong, T., Chuah, T., Robiah, Y., Koay, F., \& Azni, I. (2007). Arsenic toxicity, health hazards and removal techniques from water: an overview. Desalination, 1-3, 139-166.

Corley, J. (2003). Best practices in stablishing detection and quantification limits for pesticide residues in foods. Handbook of residue analytical methods for agrochemicals.

Cortés, F., Guillén, R., Navarro, P., \& Smedley, P. (2010). Una revisión de la presencia de arsénico en el agua subterránea en México. Tlaloc AMH, 1-11. 
Del Razo, L., Arellano, M., \& Cebrián, M. (1990). The oxidation states of arsenic in well-water from a chronic arsenicism area of northern Mexico. Environ Pollut, 143-153.

Department of healt and human services. (2007). Toxicological profile for arsenic U.S. Obtenido de https://www.atsdr.cdc.gov/toxprofiles/tp2.pdf

Dermentzis, K. (2010). Removal of nickel from electroplating rinse waters using electrostatic shielding electrodialysis/electrodeionization. Journal of hazardous materials, 647-652.

Doménech, X., Jardim, W. F., \& Litter, M. (2001). Procesos avanzados de oxidación para la eliminación de contaminantes. Eliminación de contaminantes por fotocatálisis heterogénea, 3-26.

Fagundo, J., \& González, P. (2005). Hidrogeoquímica. La Habana, Cuba: Centro Nacional de Medicina Natural y Tradicional (CENAMENT).

Figueroa, D., Moreno, A., \& Hormanza, A. (2015). Equilibrio, termodinámica y modelos cinéticos en la adsorción de Rojo 40 sobre tuza de maíz . Revista Ingenierías Universidad de Medellín, 105-120.

Figueroa, D., Moreno, A., \& Hormaza, A. (2015). Equilibrio, termodinámica y modelos cinéticos en la adsorción de Rojo 40 sobre tuza de maíz. Revista Ingenierías Universidad de Medellín, 105-120.

Foo, K., \& Hameed, B. (2010). Insights into the modeling of adsorption isotherm systems. Chemical engineering journal, 2-10.

Freundlich, H. (1907). Over the adsorption in solution. J. Phys. Chem , 385-470.

Gidahatari. (22 de 01 de 2018). Diagrama de piper . Obtenido de http://gidahatari.com/ih-es/ahorapuedes-hacer-diagramas-de-piper-online-con-hatarichem

Gómez-Hernández , A., Rodríguez, R., Del Río, A., Ruíz-Huerta, E., Armienta, M., Dávila-Harris, P., \& Martínez-Villegas, N. (2020). Alluvial and gypsum karst geological transition favors spreading arsenic contamination in Matehuala, México. Science of the Total Environment.

González Partida , E., Hinojosa , T., \& Verma , M. (2001). Interacción agua geotérmica-manantiales en el campo geotérmico de los Huméros, Puebla, México. Ingeniería hidráulica en México, 185-194. 
Gutiérrez López, A. (2018). Evaluación de dos resinas aniónicas en el proceso de electrodesionización para la remoción de arsénico en aguas sintéticas. Universidad Autónoma Metropolitana, Ciudad de México: Tesis de maestria.

Hamadi, N., Chen, X., Farid, M., \& Lu, M. (2001). Adsorption kinetics for the removal of chromium (VI) from aqueous solution by adsorbents derived from used tyres and sawdust. Chemical Engineering Journal, 95-105.

Hlavay, J., Prohaska, T., Weisz, M., \& Stingeder, G. (2004). Determination of trace elements bound to soil and sediment fractions (IUPAC Technical Report). Pure and Applied chemistry, 415422.

INEGI. (2002). Síntesis geográfica del estado de San Luis Potosí. 112 p.

INEGI. (2009). Prontuario de información geográfica municipal de Matehuala. Obtenido de http://www3.inegi.org.mx/contenidos/app/mexicocifras/datos_geograficos/24/24020.pdf

Kaltreider , R., Davis, M., Lariviere, J., \& Hamilton , J. (2001). Arsenic alters the function of glucorticoid receptor as a transcription factor. Environ Healt Perspect , 245-251.

Katsoyiannis, I., \& Zouboulis, A. (2004). Application of biological processes for the removal of arsenic from groundwaters. Wate Research, 38, 17-26.

Langmuir , I. (1916). The constitution and fundamental properties of solids and liquids. Part I. Solids. Journal of the American chemical society, 2221-2295.

Langmuir, C., Bender, J., Bence, A., Hanson, G., \& Taylor, S. (1977). Petrogenesis of basalts from the FAMOUS area: Mid-Atlantic Ridge. Earth and Planetary Science Letters, 133-156.

Leal , M., \& Gelover, S. (2003). Evaluación de la calidad del agua subterránea de fuentes de abastecimiento en acuíferos prioritarios de la región Cuencas centrales del Norte. Obtenido de http://www.imta.mx/instituto/historial-proyectoswrp/tc/2002/CA4-Evaluación.pdf.

Lillo, J. (2007). Técnicas Hidrogeoquímicas. Tesis de maestría. Madrid: Universidad Rey.

Lillo, J. (2008). Peligros geoquímicos: arsénico de origen natural en las aguas. Obtenido de Grumpos de Estudio de Minería y Medio Ambiente (GEMM: http://www.aulados.net/GEMM/GEMM.html

Litter, M., Pérez Carrera, A., Morgada, M., Ramos , O., Quintanilla, J., \& Fernández, A. (2008). <distribución de arsénico en las regiones ibérica e iberoamericana. Obtenido de http://paginas.fe.up.pt/ cigar/html/documents/Monografia1_000.pdf 
Litter, M., \& Ingallinella, A. (2010). Tecnologías económicas para el abatimiento de arsénico en agua. Argentina: Iberoarsen.

Litter, M., Armienta, M., \& Farías, S. (2009). IBEROARSEN. Metodologías analíticas para la determinación y especiación de arsénico en aguas y suelos. . Argentina: CYTED.

Lloyd, J. W., \& Heathcote, J. A. (1985). Natural inorganic hydrochemistry in relation to ground water.

Macur, R., Jackson , C., Botero, L., McDermontt, T., \& Inskeep, W. (2004). Bacterial populations associated with the oxidation and reduction of arsenic in an unsaturated soil. Environ.Sci.Technol.

Mañay, N., Clavijo, G., \& Díaz, L. (s.f.). Capítulo 5. Absorción atómica con horno de grafito. Obtenido de http://riquim.fq.edu.uy/archive/files/02ba23e6cc083af03bfc55ac63a98a0c.pdf

Martínez Villegas, N., Briones Gallardo, R., Ramos Leal, J., Avalos Borja, M., Castañón Sandoval, A., Razo Flores, E., \& Villalobos, M. (2013). Arsenic mobility controlled by solid calcium arsenates: a case study in México showcasing a potentially widespread environmental problem. Environ Pollut, 114-123.

Matehuala.

Obtenido

de http://www.campopotosino.gob.mx/monografias2014/Matehuala.12.pdf

Milán , S. (2015). Principios de Hidrogeoquímica. México: Aqua Ediciones.

Momplaisir, G., Rosal, C., \& Heithmar, E. (2001). Arsenic speciation methods for studying the enviromental fate of organoarsenic animal-feed additives.

Morató, J., Subirana, A., Gris, A., Carneiro, A., \& Pastor, R. (2006). Tecnologías sostenibles para la potabilización y el tratamiento de aguas residuales. Lasallista de Investigación, 26-27.

Nagarale, R., Gohil, G., \& Shahi, V. (2006). Recent developments on ion-exchamge membranes and electro-membrane processes. Advances in colloid and interface science, 97-130.

Nava Ruíz, C., \& Méndez Armenta, M. (2011). Efectos neurotóxicos de metales pesados (cadmio, plomo, arsénico y talio). Arch Neurocien.

Nava, R., \& Méndez, A. (2011). Efectos neurotóxicos de metales pesados. Obtenido de http://www.medigraphic.com/pdfs/arcneu/ane-2011/ane113f.pdf

Nevárez, R. (2009). Optimiación del proceso de renegenración de resinas de intercambio iónico para ser utilizadas en el desmineralizador de agua de refinería estatal esmeraldas. Ecuador: Tesis de Licenciatura. 
Nriagu, J. (1994). Arsenic in the environment (Part II, Human health and ecosystem effects). Advances in environmental science and technology.

OMS. (2008). Arsenic in drinking water. Obtenido de Documento de referencia para la elaboración de las guías de la OMS para la calidad del agua potable : www.who.org

OMS. (2008). Arsenic in drinking water. Documento de referencia para la elaboración de Guías de la OMS para la calidad del agua potable. Obtenido de www.who.org

Parkhurst, D., \& Appelo, C. (2013). Description of input and examples for PHREEQC version 3-A computer program for speciation, batch-reaction, one-dimensional transport, and inverse geochemical calculations: U.S. Geological Survey Techniques and Methods, book 6, chap. A43, 497 p. Obtenido de https://pubs.usgs.gov/tm/06/a43/

Parkhust, D., \& Apello, C. (1999). User guide to PHREEQC a computer program for speciation, batch reaction, one dimensional transport, and inverse geochemical calculations. U.S. Geological Survey Water Resources Investigations Report.

Pérez-Moreno, F., Prieto-García, F., Rojas-Hernández, A., Marmolejo-Santillán, Y., SalinasRodríguez, E., \& Patiño-Cardona, F. (2006). Estudio de eliminación de arsénico con resinas de intercambio iónico en agua potable de Zimapán, Estado de Hidalgo, México. Revista de Metalurgia, 391-395.

Petkova Simeonova, V. (1999). Estudio piloto para remoción del arsénico, Estado de Hidalgo, México. Ingeniería Hidráulica en México. Vol. XIV, 65-77.

Petkova Simeonova, V. (1999). Remoción de arsénico por sorción en minerales. Obtenido de http://www.bvsde.paho.org/bvsaidis/tratagua/peru/mexapa046.pdf

Pineda Olmedo, R. (2011). Metodología de evaluación de riesgo ecológico. Obtenido de file://C:/Users/User/Downloads/multi-2011-05-06.pdf

Pinzón-Bedoya, M., \& Vera Villamizar, I. (2009). Kinetic modeling biosorption of Cr (III) using orange shell. Dyna, 95-106.

Plummer, L., Prestemon, E., \& Parkhurst, D. (1991). An interactive code (NETPAHT) for modeling NET Geochemical reactions alonh a flow PATH, Version 2.0. U.S. Geol. Survey WaterResources Invest.

Ravencroft, P., Brammer, H., \& Richards, K. (2009). AArsenic pollution: a global synthesis . Singapur: Jhon Wiley \&Sons. 
Razo, I., Carrizales, L., Castro J., Díaz-Barriga, F., \& Monrroy, M. (2004). Arsenic and heavy metal pollution of soil, water and sediments in a semi-arid climate mining area in México. Water, Air, and Soil Pollution.

Razo, I., Carrizales, L., Castro J., Díaz-Barriga, F., \& Monrroy, M. (2004). Arsenic and heavy metal pollution of soil, water and sediments in a semi-arid climate mining area in México. Water, Air, and Soil Pollution.

Registry, A. f. (2007). Toxicological Profile for Arsenic. Atlanta, GA: US Department of Healt and Human Services, Public Health Service. Obtenido de https://www.atsdr.cdc.gov/toxprofiles/tp2.pdf

Registry, A. f. (2007). Toxicological Profile for Arsenic. Atlanta, GA: US Department of Health and Human Services, Public Health Service. Obtenido de https://www.atsdr.cdc.gov/toxprofiles/tp2.pdf

Rivas, C., Núñez, O., Longoria, F., \& González, L. (2014). Langmuir and Freundlich isotherms as model for the adsorption of nucleic acid components on WO3. Saber, 43-49.

Robertson , F. (1989). Arsenic in groundwater under oxidizing conditions, southwest United States. Environ Geochem Health, 171-185.

Sabbatini, P., Rossi, F., Them, G., Marajofsky, A., \& de Cortalezzi, M. F. (2009). Iron oxide adsorbers for arsenic removal: a low cost treatment for rural areas and mobile applications. Desalination, 184-192.

Sabbatini, P., Yrazu, F., Rossi, F., Them, G., Marajofsky, A., \& de Cortalezzi, M. F. (2010). Fabrication and characterization of iron oxide ceramic membranes for arsenic removal. Water research, 5702-5712.

SEMARNAT. (1996). NOM-O01-SEMARNAT-1996. Límites máximos permisibles de contaminantes en las descargas de aguas residuales en aguas y bienes nacionales. Obtenido de https://www.profepa.gob.mx/innovaportal/file/3290/1/nom-001-semarnat-1996.pdf

Smedley, A., \& Kinniburgh, D. (2002). A review of the source, behavior and distribution of arsenic in natural waters. Applied Geochemistry, 517-568.

S $\varnothing$, H., Postma, D., Jakobsen, R., \& Larsen , F. (2008). Sorption and desorption of arsenate and arsenite on calcite. Geochimica et Cosmochimica. 
SSA. (1994). 127-SSA1-1994. Salud ambiental, agua para uso y consumo humano-límites permisibles de calidad y tratamientos a que debe someterse el agua para su potabilización. Obtenido de http://www.salud.gob.mx/unidades/cdi/nom/127ssa14.html

SSA. (2002). NOM-201-SSA1-2002 Productos y servicios. Agua y hielo para consumo humano, e. y. (s.f.). Obtenido de http://www.salud.gob.mx/unidades/cdi/nom/201ssa12.html

Tostado, M. M. (2010). Desarrollo hidrogeoquímico de la cuenca San Miguel, Baja California. Ensenada, Baja California: Tesis de Maestria. CICESE .

Tóth, J. (2000). Las aguas subterráneas como agente geológico: causas, procesos y manifestaciones . Boletín Geológico y Minero.

US, D. (2007). Department of Health and Human Services. Agency for Toxic Substances and Disease Registry: Toxicological Profile for Arsenic. Atlanta, GA. Retrieved from https://www.atsdr.cdc.gov/toxprofiles/tp2.pdf

Vijayaraghavan, K., Padmesh , T., Palanivelu, K., \& Velan, M. (2006). Biosorption of nickel (II) ions onto Sargassum wightii: application of two.parameter and three-parameter isotherm models. Journal of hazardous materials, 304-308.

WHO. (2001). International Programme on chemical safety. Enviromental Health Criteria. Geneva: Arsenic ans arsenic compounds.

Wolfe Simon, F., Switzer, J., Kulp, T., Gordon, G., Hoeft, S., Pett Ridge, J., . . Oremland, R. (2011). A bacterium that can grow by using arsenic instead of phosphorus. Science, 1163-1167. 


\section{Apéndices}

\section{Apéndice I. Datos de entrada y salida en PHREEQC 3.0}

Ejemplo de archivos de entrada para modelaciones directas en PHREEQC

$\begin{array}{lll}\text { SOLUTION } 1 & \text { CT } & 19 / 09 / 2008 \\ \text { temp } & 23 & \\ \text { pH } & 6.3 \\ \text { pe } & 4.783637593 \\ \text { unita } & \text { mg/L } \\ \text { density } & 1.03 \\ \text { O(0) } & 0.57 \\ \text { C }(-4) & 55.89 \\ \text { F } & 0.65 \\ \text { Cl } & 23 \\ \text { P } & 256 \\ \text { S(6) } & 1120 \\ \text { Ca } & 447 \\ \text { Na } & 165 \\ \text { Mg } & 45 \\ \text { Si } & 48 \\ \text { As } & 77.74 \\ \text { Fe } & 0.03893 \\ \text { Alkalinity } 300\end{array}$

$\begin{array}{ll}\text { SOLUTION } 2 & \text { L-22 } \\ \text { temp } & 24 \\ \text { pH } & 6.4 \\ \text { pe } & 3.914807302 \\ \text { units } & \mathrm{mg} / \mathrm{L} \\ \text { density } & 1.03 \\ \mathrm{O}(0) & 4.61 \\ \mathrm{C}(-4) & 39.78 \\ \mathrm{~F} & 0.74 \\ \mathrm{Cl} & 16 \\ \mathrm{P} & 11.84 \\ \mathrm{~S}(6) & 920 \\ \mathrm{Ca} & 441 \\ \mathrm{Na} & 74.4 \\ \mathrm{Mg} & 33 \\ \mathrm{Si} & 60 \\ \text { As } & 11.58 \\ \text { Fe } & 0.06198 \\ & \\ \text { Alkalinity } 225 \text { as } & \mathrm{CaCO3}\end{array}$




\section{Datos desalida obtenidos con modelación directa en PHREEQC. Se muestra la especiación de As y un fragmento de los índices de saturación como SI.}

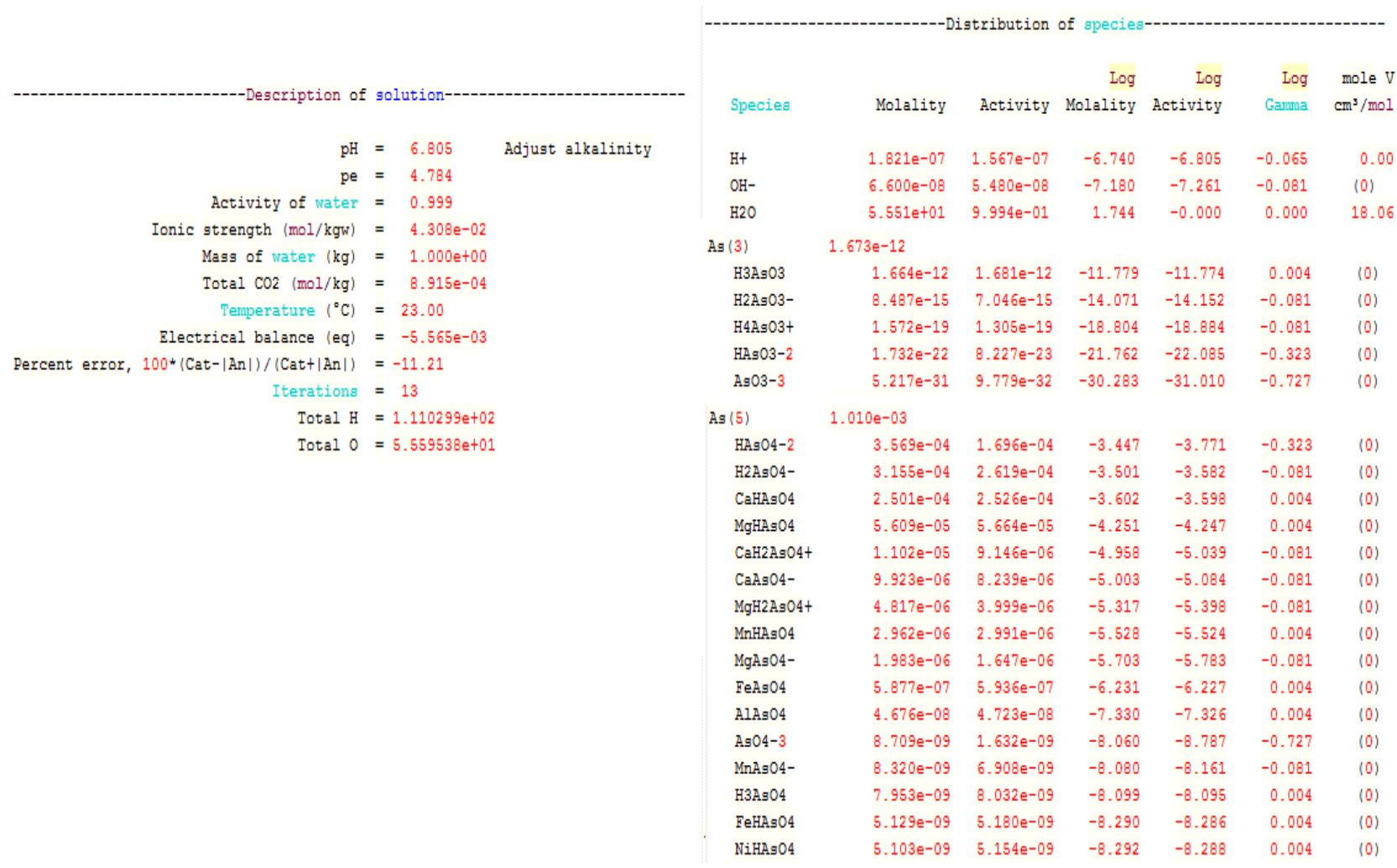

\begin{tabular}{|c|c|c|c|c|}
\hline Phase & SI $\star *$ & $\log$ IAP & $\log \mathrm{K}$ & 1 atm) \\
\hline (UO2) $3($ PO4) $2: 4 \mathrm{w}$ & -41.00 & -78.60 & -37.61 & $(\mathrm{UO2}) 3(\mathrm{PO} 4) 2: 4 \mathrm{H} 2 \mathrm{O}$ \\
\hline Adularia & -0.48 & -21.21 & -20.73 & KAISi308 \\
\hline $\mathrm{Al}(\mathrm{OH}) 3(\mathrm{a})$ & -3.16 & 7.78 & 10.93 & $\mathrm{Al}(\mathrm{OH}) 3$ \\
\hline $\mathrm{A} 1 \mathrm{As} \mathrm{O} 4: 2 \mathrm{H} 2 \mathrm{O}$ & -5.59 & -21.43 & -15.84 & $\mathrm{~A} 1 \mathrm{As} \mathrm{O} 4: 2 \mathrm{H} 2 \mathrm{O}$ \\
\hline Albite & -1.72 & -19.85 & -18.13 & NaAlSi308 \\
\hline Alumk & -15.83 & -21.03 & -5.21 & $\mathrm{KAl}(\mathrm{SO} 4) 2: 12 \mathrm{H} 2 \mathrm{O}$ \\
\hline Alunite & -4.33 & -5.48 & -1.15 & $\mathrm{KAl} 3(\mathrm{SO} 4) 2(\mathrm{OH}) 6$ \\
\hline Analcime & -3.96 & -16.75 & -12.79 & NaAlSi206:H2O \\
\hline Anglesite & -3.61 & -11.41 & -7.80 & $\mathrm{PbSO} 4$ \\
\hline Anhydrite & -0.56 & -4.91 & -4.35 & $\mathrm{CaSO} 4$ \\
\hline Annite & -2.99 & -88.94 & -85.95 & KFe3AlSi3010(OH) 2 \\
\hline Anorthite & -5.54 & -25.31 & -19.77 & CaAl2Si208 \\
\hline Antlerite & -8.53 & -0.24 & 8.29 & $\mathrm{Cu} 3(\mathrm{OH}) 4 \mathrm{SO} 4$ \\
\hline Aragonite & -0.99 & -9.32 & -8.32 & $\mathrm{CaCO} 3$ \\
\hline Arsenolite & -22.13 & -23.55 & -1.42 & $A=203$ \\
\hline Artinite & -9.61 & 0.14 & 9.74 & $\mathrm{MgCO}: \mathrm{Mg}(\mathrm{OH}) 2: 3 \mathrm{H} 2 \mathrm{O}$ \\
\hline$A s 205$ & -24.45 & -16.19 & 8.27 & As205 \\
\hline As_native & -33.87 & -46.54 & -12.67 & As \\
\hline Atacamite & -7.01 & 0.42 & 7.43 & $\mathrm{Cu} 2(\mathrm{OH}) 3 \mathrm{Cl}$ \\
\hline Autunite & -16.75 & -60.60 & -43.86 & $\mathrm{Ca}(\mathrm{UO} 2) 2(\mathrm{PO} 4) 2$ \\
\hline Azurite & -8.26 & -4.36 & 3.90 & $\mathrm{Cu} 3(\mathrm{OH}) 2(\mathrm{CO} 3)_{2}$ \\
\hline $\mathrm{B}-\mathrm{UO} 2(\mathrm{OH}) 2$ & -12.52 & -6.91 & 5.61 & $\mathrm{UO2}(\mathrm{OH}) 2$ \\
\hline $\operatorname{Ba} 3(\mathrm{AsO} 4) 2$ & -16.40 & -41.00 & -24.60 & $\mathrm{Ba} 3(\mathrm{AsO} 4) 2$ \\
\hline $\mathrm{BaF2}$ & -11.21 & -16.97 & -5.76 & $\mathrm{BaF2}$ \\
\hline $\mathrm{BaHAsO} 4 \mathrm{:H} 2 \mathrm{O}$ & -5.98 & -11.58 & -5.60 & $\mathrm{BaHAsO} 4: \mathrm{H} 2 \mathrm{O}$ \\
\hline Barite & -0.20 & -10.20 & -10.00 & $\mathrm{BaSO} 4$ \\
\hline Basaluminite & -7.60 & 15.10 & 22.70 & $\mathrm{Al} 4(\mathrm{OH}) 10 \mathrm{SO} 4$ \\
\hline $\mathrm{BaSeO3}$ & -9.13 & -15.52 & -6.39 & $\mathrm{BaSeO} 3$ \\
\hline Bassetite & -21.75 & -66.14 & -44.39 & $\mathrm{Fe}(\mathrm{UO2}) 2(\mathrm{PO} 4) 2$ \\
\hline
\end{tabular}


Apéndice II. Balance iónico

\begin{tabular}{|c|c|c|c|c|}
\hline $\begin{array}{l}\text { Punto de } \\
\text { muestreo }\end{array}$ & $\begin{array}{c}\text { Mes de } \\
\text { muestreo }\end{array}$ & $\Sigma$ ANIONES & $\underset{\text { CATIONES }}{\boldsymbol{\Sigma}}$ & \%ERROR \\
\hline \multirow{12}{*}{ Club de Tiro } & Septiembre & 26.9990 & 33.8183 & -11.2 \\
\hline & Octubre & 33.2180 & 33.3892 & -0.26 \\
\hline & Noviembre & 33.2771 & 31.3675 & 2.95 \\
\hline & Diciembre & 30.0612 & 34.2477 & -6.51 \\
\hline & Enero & 28.9736 & 33.1347 & -6.70 \\
\hline & Febrero & 30.1181 & 37.4798 & -10.89 \\
\hline & Marzo & 29.7011 & 47.4258 & -22.98 \\
\hline & Abril & 30.2954 & 38.6500 & -12.12 \\
\hline & Mayo & 27.1840 & 32.0665 & -8.24 \\
\hline & Junio & 42.0886 & 30.7967 & 15.49 \\
\hline & Julio & 40.8251 & 28.6573 & 17.51 \\
\hline & Agosto & 39.7933 & 55.3613 & -16.36 \\
\hline \multirow{12}{*}{$\begin{array}{c}\text { Tecnológico } \\
\text { Regional }\end{array}$} & Septiembre & 28.2680 & 24.6476 & 6.84 \\
\hline & Octubre & 27.5543 & 30.5029 & -5.08 \\
\hline & Noviembre & 38.4043 & 28.1806 & 15.35 \\
\hline & Diciembre & 26.2310 & 46.4187 & -27.79 \\
\hline & Enero & 24.5559 & 21.8588 & 5.81 \\
\hline & Febrero & 25.9670 & 32.6583 & -11.41 \\
\hline & Marzo & 25.7584 & 36.1901 & -16.84 \\
\hline & Abril & 25.9221 & 34.2487 & -13.84 \\
\hline & Mayo & 24.1106 & 29.5159 & -10.08 \\
\hline & Junio & 41.0411 & 25.2174 & 23.88 \\
\hline & Julio & 36.3484 & 33.7956 & 3.64 \\
\hline & Agosto & 34.8773 & 50.1239 & $\begin{array}{l}.04 \\
-17.94\end{array}$ \\
\hline
\end{tabular}

electroneutralidad, a pesar de ello, los datos obtenidos en ese mes de muestreo no se descartan debido a que no se cuentan con más dato 
Modelamiento hidrogeoquímico y propuesta de posible

remediación de arsénico en

agua en la zona de

Matehuala, San Luis Potosi.

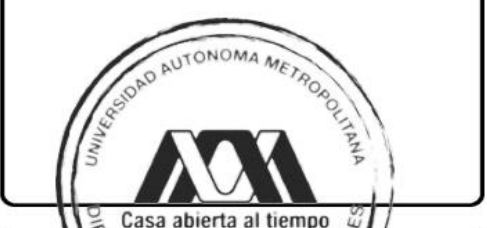

F Casa abierta al tiempo \&
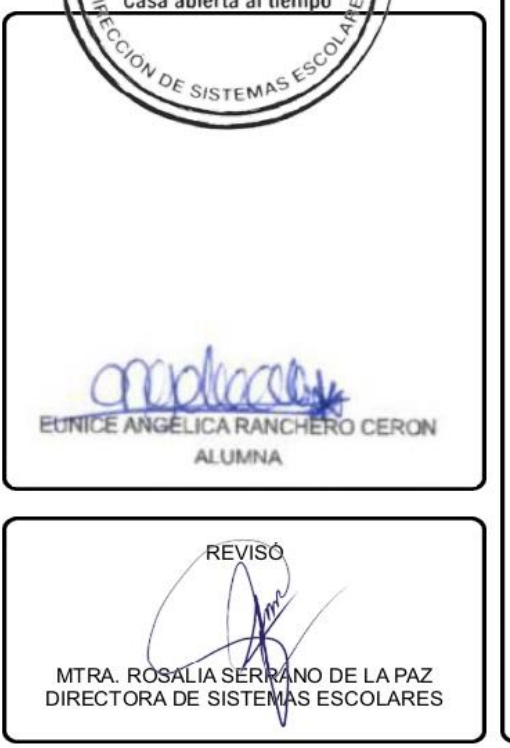

DIRECTOR DE LA DIVISIÓN DE CBI

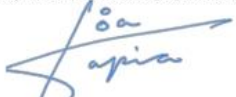

DR. JESUSALBERTO OCHOA TAPIA

VOCAL

DR. ISRAEL RAZO SOTO

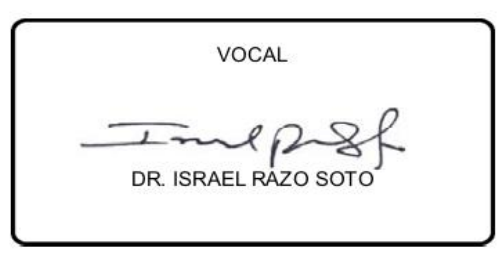

Con base en la Legislación de la Universidad Autónoma Metropolitana, en la Ciudad de México se presentaron a las 18:00 horas del día 30 del mes de septiembre del año 2020 POR VIA REMOTA ELECTRÓNICA, los suscritos miembros del jurado designado por la Comisión del Posgrado:

DRA. MONICA ALICIA MERAZ RODRIGUEZ

DR. ISRAEL RAZO SOTO

DRA. NADIA VALENTINA MARTINEZ VILLEGAS

Bajo la Presidencia de la primera y con carácter de Secretaria la última, se reunieron para proceder al Examen de Grado cuya denominación aparece al margen, para la obtención del grado de:

MAESTRA EN CIENCIAS (ENERGIA Y MEDIO AMBIENTE)

DE: EUNICE ANGELICA RANCHERO CERON

$y$ de acuerdo con el artículo 78 fracción II del Reglamento de Estudios Superiores de la Universidad Autónoma Metropolitana, los miembros del jurado resolvieron:

\section{APROBAR}

Acto continuo, la presidenta del jurado comunicó a la interesada el resultado de la evaluación y, en caso aprobatorio, le fue tomada la protesta.

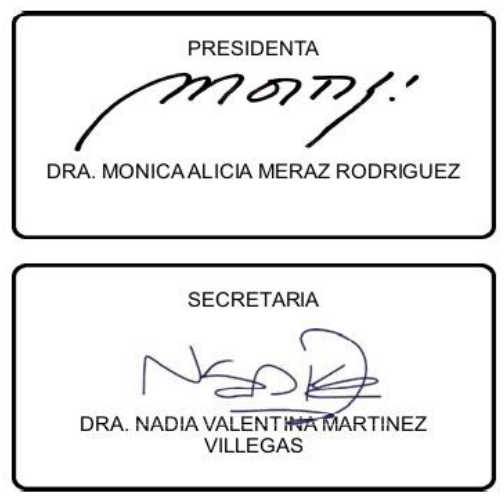

El presente documento cuenta con la firma -autógrafa, escaneada o digital, según corresponda- del funcionario universitario competente, que certifica que las firmas que aparecen en esta acta - Temporal, digital o dictamen- son auténticas y las mismas que usan los c.c. profesores mencionados en ella 
